\title{
WestVirginiaUniversity
}

THE RESEARCH REPOSITORY @ WVU

Graduate Theses, Dissertations, and Problem Reports

1998

\section{Experimental and modeling studies on a catalytic packed bed membrane reactor}

\author{
Ashutosh G. Deshpande \\ West Virginia University
}

Follow this and additional works at: https://researchrepository.wvu.edu/etd

\section{Recommended Citation}

Deshpande, Ashutosh G., "Experimental and modeling studies on a catalytic packed bed membrane reactor" (1998). Graduate Theses, Dissertations, and Problem Reports. 912.

https://researchrepository.wvu.edu/etd/912

This Thesis is protected by copyright and/or related rights. It has been brought to you by the The Research Repository @ WVU with permission from the rights-holder(s). You are free to use this Thesis in any way that is permitted by the copyright and related rights legislation that applies to your use. For other uses you must obtain permission from the rights-holder(s) directly, unless additional rights are indicated by a Creative Commons license in the record and/ or on the work itself. This Thesis has been accepted for inclusion in WVU Graduate Theses, Dissertations, and Problem Reports collection by an authorized administrator of The Research Repository @ WVU. For more information, please contact researchrepository@mail.wvu.edu. 
Experimental and Modeling Studies on

A Catalytic Packed Bed Membrane Reactor

By

Ashutosh G Deshpande

\author{
A Thesis \\ Submitted to \\ West Virginia University \\ in partial fulfillment of the requirements \\ for the degree of \\ Master of Science
}

In

Chemical Engineering

Advisor: Dr. E.Kugler

Committee Members: Dr.D.Dadyburjor, Dr.R.Y.K.Yang

June 1998

Morgantown, West Virginia

Keywords: Membrane, Reactor, Catalytic, Separation, Packed 


\begin{abstract}
In the present work, the effects of operating conditions in a catalytic packed bed membrane reactor were investigated with the reactant gases $\mathrm{H}_{2}$ and $\mathrm{CO}$ flowing through the membrane tube, and an inert gas $\mathrm{N}_{2}$ flowing on the outside. The reaction under study was methanol synthesis with BASF catalyst, and a $\gamma$-Alumina membrane with a nominal pore size of $40 \AA$ was used.

Preliminary experiments were carried out in the membrane reactor without any catalyst inside membrane to characterize it in terms of its flux, permeance, and selectivity of $\mathrm{H}_{2}$ over CO.

Experiments were carried out in the packed bed membrane reactor to study the effects of these conditions on the conversion. A mathematical model was developed for the reactor.

Experiments with similar operating conditions were then carried out in the packed bed tubular reactor. Finally, results of comparison of the two reactors were discussed with recommendations for further studies.
\end{abstract}




\section{TABLE OF CONTENTS}

Title Page $\quad$ i

$\begin{array}{ll}\text { Abstract } & \text { ii }\end{array}$

Table of Contents $\quad$ iii

List of Figures $\quad$ vii

List of Tables $\quad$ viii

$\begin{array}{lll}\text { Chapter } 1 & \text { Introduction } & 1\end{array}$

$\begin{array}{lll}\text { Chapter } 2 \text { Literature Review } & 6\end{array}$

$\begin{array}{lll}2.1 & \text { Membranes } & 6\end{array}$

2.1.1 Nonporous Metallic Membranes 7

2.1.2 Nonporous Oxide Membranes 8

2.1.3 Porous Ceramic Membranes 9

$\begin{array}{ll}2.1 .4 & \text { Porous Glass Membranes } \\ \end{array}$

$\begin{array}{lll}\text { 2.1.5 Zeolite Membranes } & 10\end{array}$

2.2 Terms Used in Membrane Separation 11

2.3 Properties of an Ideal Membrane 12

2.4 Mechanisms of Separation 13

2.4.1 Separation in Nonporous Membranes 13

2.4.2 Separation in Porous Membranes 14

2.4.2.1 Knudsen Diffusion 15

$\begin{array}{lll}\text { 2.4.2.2 Surface Diffusion } & 16\end{array}$

$\begin{array}{ll}\text { 2.4.2.3 Capillary Condensation } & 17\end{array}$

2.4.2.4 Molecular Sieve Separation 18 
2.5 Operating Characteristics of Membrane Reactors 18

2.5.1 Contact of Reactants 19

2.5.1.1 Reactants on One Side $\quad 19$

2.5.1.2 Reactants on Both Sides 19

2.5.2 Type of Flow 22

2.5.3 Simultaneous Reactions 23

2.5.4 Pressure Drop across the Membrane 23

2.6 Characteristics of Membrane Separation 24

$\begin{array}{lll}2.7 & \text { Engineering Issues } & 25\end{array}$

$\begin{array}{lll}\text { Chapter } 3 & \text { Experimental Design } & 29\end{array}$

3.1 Equipment Setup 29

3.2 Experimental Procedure 33

3.2.1 Membrane Characterization Experiments 34

3.2.2 Experiments on Packed-Bed Reactors 34

3.2.2.1 Packed-Bed Membrane Reactor 36

3.2.2.2 Packed-Bed Tubular Reactor 38

$\begin{array}{lll}\text { Chapter } 4 \quad \text { Data Analysis and Results } & 40\end{array}$

4.1 Analysis of Experiments for Membrane Characterization 40

4.2 Analysis of Data from Packed Bed Reactors 44

4.2.1 Rate-Expression for Methanol Synthesis 46

4.2.2 Packed-Bed Membrane Reactor Data $\quad 50$

4.2.2.1 Model for Packed-Bed Membrane Reactor $\quad 61$

4.2.2.2 Catalyst Aging 63 
Chapter 5 Results and Discussions

5.1 Membrane Characterization $\quad 69$

5.2 Packed Bed Membrane Reactor $\quad 70$

5.2.1 Effect of the Reaction Temperature $\quad 70$

5.2.2 Effect of Flow Rate in the Shell Side $\quad 70$

5.2.3 Effect of Residence Time of Reactants inside the Tube 71

5.2.4 Effect of Introducing Reactants in the Shell Side Stream 71

5.2.5 Effect of Replacing Nitrogen with Reactants on the Shell Side 72

5.3 Model for Packed Bed Membrane Reactor 72

5.3.1 Model With Experimental Values of Permeances 73

5.3.2 Model With Optimized Values of Permeances 73

5.3.2.1 Optimization Routine 73

5.3.2.1.1 Model With Infinite Permeance of CO 77

5.3.3 Model Assuming Free Mixing through Membrane 80

5.4 Comparison with Packed Bed Tubular Reactor 82

Chapter $6 \quad$ Conclusions and Recommendations 84

$\begin{array}{lll}6.1 & \text { Conclusions } & 84\end{array}$

6.2 Recommendations 85

$\begin{array}{lll}\text { Chapter } 7 & \text { Symbols And Notation } & 87\end{array}$

$\begin{array}{lll}\text { Chapter } 8 & \text { Bibliography } & 92\end{array}$

Appendix A Experimental Data for Packed Bed Membrane Reactor 95

Appendix B Program for developing a Model for Packed Bed Membrane Reactor 103

$\begin{array}{ll}\text { Acknowledgements } & 114\end{array}$ 
Approval of Examining Committee 


\section{LIST OF FIGURES}

Figure $1 \quad$ Schematic of a Packed Bed Membrane Reactor 3

$\begin{array}{lll}\text { Figure } 2 & \text { Experimental Setup } & 30\end{array}$

$\begin{array}{lll}\text { Figure } 3 & \text { Membrane Module } & 31\end{array}$

Figure $4 \quad$ Rate Expression fit for Packed Bed Tubular Reactor from Power-Law Model 49

Figure 5 Rate Expression fit for Packed Bed Tubular Reactor from 8-Parameter Model 51

Figure $6 \quad$ Overall Fit for Catalyst Aging Flow Condition MR1 52

Figure $7 \quad$ Overall Fit for Catalyst Aging Flow Condition MR2 53

Figure $8 \quad$ Overall Fit for Catalyst Aging Flow Condition MR3 54

Figure $9 \quad$ Overall Fit for Catalyst Aging Flow Condition MR4 55

Figure $10 \quad$ Overall Fit for Catalyst Aging Flow Condition MR5 56

Figure 11 Overall Fit for Catalyst Aging Flow Condition MR6 57

Figure 12 Overall Fit for Catalyst Aging Flow Condition MR7 58

Figure 13 Overall Fit for Catalyst Aging Flow Condition MR8 59

Figure 14 Overall Fit for Catalyst Aging Flow Condition MR9 60

Figure 15 Comparison between Experimental conversions and conversions predicted by using Table 5 for Packed Bed Membrane Reactor 74

Figure 16 Comparison between Experimental conversions and conversions predicted by using Table 12 for Packed Bed Membrane Reactor $\quad 76$

Figure 17 Comparison between Experimental conversions and conversions predicted by assuming infinite permeance of CO for Packed Bed Membrane Reactor $\quad 79$

Figure 18 Comparison between Experimental conversions and conversions predicted by free mixing for Packed Bed Membrane Reactor 


\section{LIST OF TABLES}

Table 1 Flow Conditions and Temperatures for Membrane Characterization

Experiments

Table 2 Flow Conditions and Temperatures in Packed Bed Membrane Reactor

Experiments

Table 3 Flow Conditions and Temperatures in Packed Bed Tubular Reactor

Experiments

Table $4 \quad$ Results of Fluxes through the Membrane Tube 42

Table 5 Results of Permeances through the Membrane Tube 43

Table 6 Results for Separation factors of $\mathrm{H}_{2}$ over $\mathrm{CO}$ in the Membrane Tube 45

Table 7 Experimental Conversions, Rates, and Fitted rates for Packed bed Tubular

Reactor Experiments at $\mathrm{T}=250^{\circ} \mathrm{C}$

$\begin{array}{lll}\text { Table } 8 & \text { Results for fitting catalyst-aging equation for data taken with sample A } & 64\end{array}$

$\begin{array}{lll}\text { Table } 9 & \text { Results for fitting catalyst-aging equation for data taken with sample B } & 65\end{array}$

$\begin{array}{lll}\text { Table } 10 & \text { Results for fitting catalyst-aging equation for data taken with both samples } & 67\end{array}$

$\begin{array}{lll}\text { Table } 11 & \text { Results for Packed Bed Membrane Reactor } & 68\end{array}$

$\begin{array}{lll}\text { Table } 12 & \text { Optimized Values of Permeances }\end{array}$

Table 13 Comparison between Performances of Packed Bed Membrane Reactor and

Packed Bed Tubular Reactor at $250^{\circ} \mathrm{C} \quad 83$ 


\section{INTRODUCTION}

The need for an automotive fuel with a high-octane rating has never been greater. The use of lead alkyls in gasoline was abandoned due to environmental problems. Aromatic molecules and methyltertiary-butyl ether have replaced lead compounds as octane enhancers. However, there are currently environmental concerns about these molecules as well. Due to this, there is a growing need to come up with some other way of increasing the octane value of gasoline. Alcohols like methanol, ethanol, propanol, and butanol not only can be mixed with gasoline to enhance octane rating but also can be used as a whole motor-fuel and as base chemicals. The mixtures of these alcohols with gasoline also exhibit other desirable characteristics such as better volatility, solubility, and water tolerance when compared with pure gasoline.

A very good prospect for the production of higher alcohols is from synthesis gas. Methanol is currently produced from $\mathrm{CO}$ and $\mathrm{H}_{2}$. Much work has already been done on the production of hydrocarbons from synthesis gas via the Fischer-Tropsch process. Research is being done on catalysts to produce higher alcohols. Different mechanisms have been proposed for the formation of higher alcohols. However, very little experimental work has been done on the type of reactor suitable for producing higher alcohols. Recent modeling [1] of different reactor configurations has advocated the use of a packed-bed membrane reactor to enhance the formation of higher alcohols.

A packed-bed membrane reactor is a type of catalytic membrane reactor which is a combination of a heterogeneous catalyst and a permselective membrane. A membrane is a barrier in the form of a 
thin film or layer that can be selectively permeated by some components of a mixture. In the case of a packed-bed membrane reactor, the membrane is in the form of a tube and is packed with a catalyst. This allows both the reaction in the catalyst bed and the separation of the mixture components through the membrane to take place simultaneously. Figure 1 illustrates the components of a packed-bed membrane reactor.

Depending on the nature of the membrane (porous or dense), there are two types of catalytic membrane reactors. If the membrane is porous, there are three different possibilities of combining the membrane with the catalyst to form the catalytic membrane reactor. One way is to pack the catalyst inside the membrane tube (forming a packed-bed membrane reactor). The other way is to impregnate the membrane with a catalyst (forming a catalyst-impregnated membrane reactor). The third possibility is that the membrane itself can act as a catalyst. Sun and Khang [3] have shown that a packed-bed membrane reactor gives higher yields than a catalyst-impregnated membrane reactor in the case of reactions with a decrease in the number of moles. The conversion of synthesis gas to alcohols involves a decrease in the number of moles and so a packed-bed membrane reactor is expected to give higher yields than a catalyst-impregnated membrane reactor.

In the second type of catalytic membrane reactor, in which the membrane is dense (for example, a Pd alloy-membrane) there are two possibilities of combining the membrane with the catalyst. Either a catalyst can be deposited on the membrane or the membrane can act as the catalyst. 


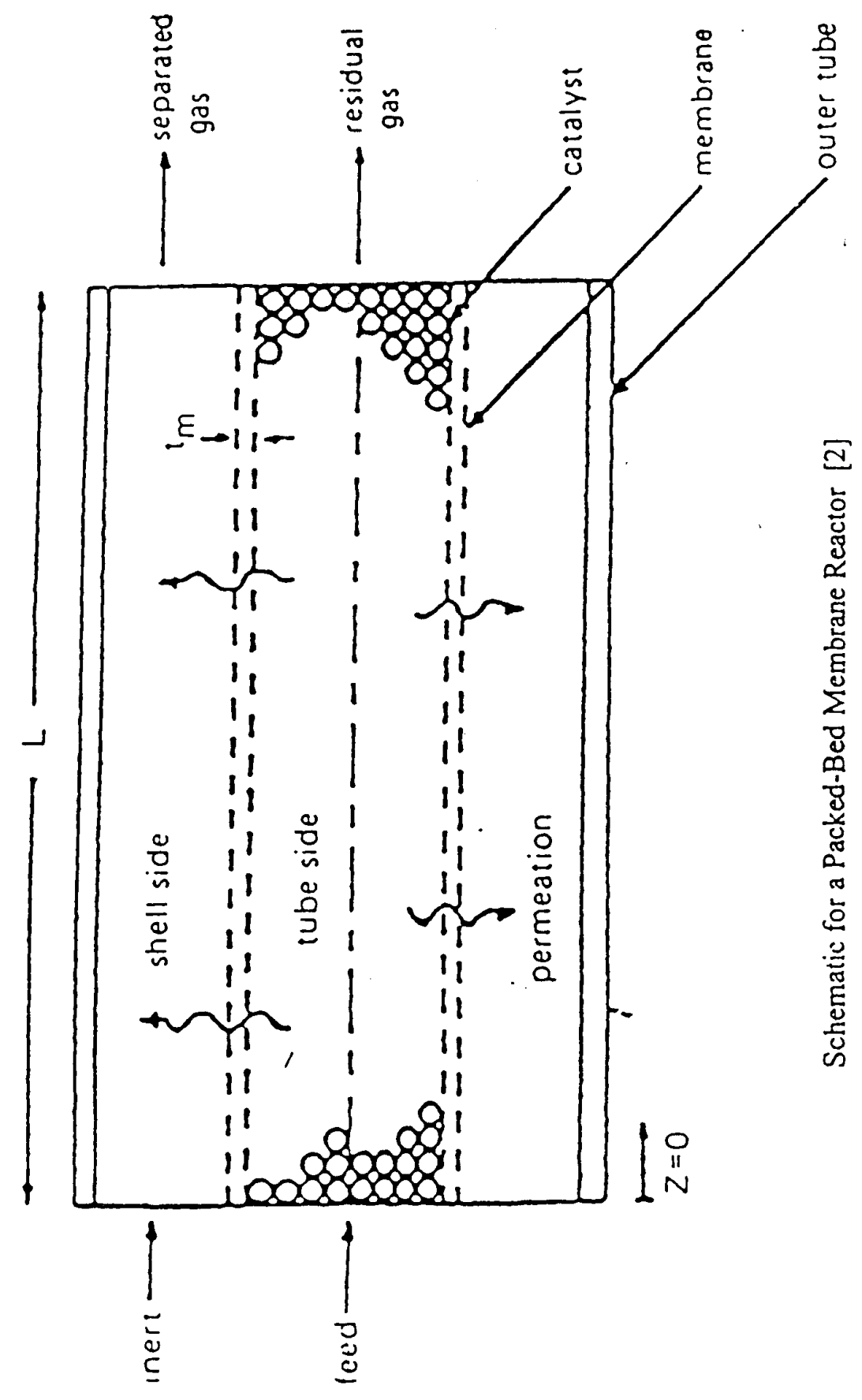

Figure 1 
Catalytic membrane reactors can have the following advantages over conventional packed-bed reactors [4]:

1) An integration of reaction and separation into a single process, thus reducing separation costs and recycle requirements.

2) An enhancement of thermodynamically limited or product-inhibited reactions resulting in higher conversions per pass.

3) A controlled contact of incompatible reactants.

4) An elimination of undesired side reactions.

In a catalytic membrane reactor the composition of gases in the reactor tube changes because of the combined effect of reaction and the permeation of gases through the membrane. The permeation can be controlled by having a knowledge of the effect of the various parameters like temperature, pressure, inlet concentrations of the fluid streams, shell-side gas flow, the pore size of the membrane, its thickness and chemical nature, etc. This kind of flexibility may help in controlling and achieving the desired composition of gases in the reactor, leading to higher conversions and selectivities.

The present work deals with experimental studies on a packed-bed membrane reactor in which the effect of the parameters mentioned above were studied. The model reaction studied in this work was the formation of methanol from synthesis gas using a S 3-86 BASF catalyst, which primarily gives methanol as the product. It was found in the literature [5] that methanol had a good separation selectivity over hydrogen in an alumina membrane at high concentrations of methanol. A $\gamma$-alumina membrane with a nominal pore size of $40 \AA$ was used in the present work. The membrane is 
commercially available under the trade name Membralox (US Filters). 


\section{LITERATURE REVIEW}

\section{$\underline{2.1}$ Membranes}

The idea of simultaneous reaction and separation with a membrane was first brought up by Michaels in 1968. It was thought that higher conversions could be obtained by using a membrane as it would allow the selective permeation of one of the reaction products, leading to a shift in the product distribution of equilibrium reactions. At that time, polymeric membranes were developing quickly after the discovery of asymmetric membranes (membrane tubes with inner and outer surfaces having different pore sizes). However, polymers can withstand only mild chemical and thermal conditions. Since many biochemical reactions are operated at low temperatures and need only mild chemical conditions, most of the research work on catalytic membrane reactors was done with biochemical reactions [6].

Lately, however, improved methods of manufacturing ceramic and metal membranes have been found. These methods can give thin (thickness of about 5 to $10 \mu \mathrm{m}$ ), defect-free, and permselective membranes which are also chemically and thermally more stable as compared to the polymeric membranes. Therefore, the research on catalytic membrane reactors is now being done even for those chemical reactions which require high temperatures and pressures. This has led to an increasing interest in the development of such membranes.

Two types of membranes, porous and nonporous (dense), have been used in catalytic membrane reactors. The nonporous metal membranes were the first ones to be used in catalytic membrane reactors. These membranes were made of Pd alloys which adsorb hydrogen atoms and then 
transport them by diffusion, thus allowing selective permeation of hydrogen. Almost complete conversion of the reactants is possible with these membranes because they allow only one component to permeate. Nonporous oxide membranes have also been used. $\mathrm{PbO}$ membranes have been used for selectively permeating oxygen.

Porous membranes are glasses with small pores, composite ceramics, and zeolites. The new developments in ceramic membranes have given rise to many possibilities for catalytic membrane reactors. These membranes can be used at high temperatures. The separation factors of porous membranes are however much lower than those of Pd alloys, unless the pores are of molecular dimensions (for example zeolite membranes).

\subsubsection{Nonporous Metallic Membranes}

Many membrane separations and some catalytic membrane reactors to date have used Pd alloy membranes, which allow completely selective permeation of $\mathrm{H}_{2}$. Mordkovich et al. [7] give details on several plants operating in the former Soviet Union capable of separating upto $2000 \mathrm{Nm}^{3} \mathrm{~h}^{-1}$ of hydrogen, at a pressure of $3 \mathrm{MPa}$, from ammonia purge gas fed at 20MPa. Philpott et al. [8] describe some mobile plants for hydrogen generation (upto $25 \mathrm{Nm}^{3} \mathrm{~h}^{-1}$ ) from the reaction between methanol and water vapors in packed-bed Pd-membrane reactors. These membranes are Pd alloys since pure Pd undergoes a structural change from the $\alpha$ phase to the $\beta$ phase as the temperature cycles, so that pure Pd becomes brittle [9].

The only other metal membrane used until now in catalytic membrane reactors is silver, through which oxygen selectively permeates. Controlled addition of oxygen through a $\mathrm{Ag}$ membrane has 
been used to carry out oxidation of $\mathrm{CH}_{3} \mathrm{OH}$ and $\mathrm{C}_{2} \mathrm{H}_{5} \mathrm{OH}$ and their mixtures to aldehydes [10]. The yield of acetaldehyde from $\mathrm{C}_{2} \mathrm{H}_{5} \mathrm{OH}$ was $83 \%$ when oxygen diffused through the membrane, whereas it was only $56 \%$ when oxygen was premixed with $\mathrm{C}_{2} \mathrm{H}_{5} \mathrm{OH}$. Silver membranes have been used to a much smaller extent than Pd alloy membranes.

Little progress has been made in large-scale catalytic membrane reactors with metal membranes because of cost, fabrication durability, and catalyst poisoning. Carbon and sulfur compounds can poison the membranes. Also, low permeabilities and metal sintering have posed big obstructions for the use of metal membranes.

\subsubsection{Nonporous Oxide Membranes}

Until now, nonporous oxide membranes have been used only for separating oxygen and hydrogen from gas-mixture streams. Therefore, their use is very limited. Dense zirconia membranes, stabilized with oxides of magnesium, scandium or calcium, have a high permselectivity to oxygen and have been used in catalytic membrane reactors. Calcia-stabilized dense zirconia membranes have been used in the thermal decomposition of water to produce hydrogen [11], and in the steam reforming and shift reactions to produce hydrogen [12]. Gavalas et al. [9] developed a method for depositing a thin layer of silica within a porous Vycor glass tube by reacting $\mathrm{SiH}_{4}$ on the tube side of the membrane with $\mathrm{O}_{2}$ on the shell side. These membranes are highly selective to $\mathrm{H}_{2}$ and are stable at $725 \mathrm{~K}$. 


\section{$\underline{\text { 2.1.3 Porous Ceramic Membranes }}$}

Ceramic membranes made of materials like alumina, ceria, titania, and zirconia are being manufactured lately. The main advantages of these membranes over polymeric membranes are greater fluxes and stability at high temperatures. For example, alumina membranes can be used at temperatures up to $1075 \mathrm{~K}$ without degradation of the pore structure [13]. These membranes have porosities as high as $59 \%$ and controlled, stable, and narrow pore size distributions. They are mechanically stable and can withstand pressure drops of $1.5 \mathrm{MPa}$. Further, they are resistant to corrosive chemicals. Catalytic materials that are deposited by impregnation can also be dispersed on ceramics and thus they can have high catalyst surface/volume ratios. The same materials used for ceramic membranes are also used as catalyst supports [14].

Ceramic membranes are often prepared by slip casting. Most of these membranes are made with layered or graded structure wherein a thin (few $\mu \mathrm{m})$ permselective layer is deposited onto a thicker (several mm) macroporous layer. For example, a thin $\gamma$-alumina layer with 4-nm diameter pores is deposited onto an $\alpha$-alumina layer with $120 \mathrm{~nm}$ pores. The $\gamma$-alumina layer acts as the separating membrane, and the $\alpha$-alumina serves as a high-temperature support. Such layered $\gamma$-alumina membranes have been used in several separation applications and for research in membrane reactors. For example, in the dehydrogenation of ethylbenzene to styrene, the conversion was increased by $20-23 \%$ over the equilibrium conversion by using a packed-bed membrane reactor with a $\gamma$-alumina membrane [9]. Ceramic membranes have been modified also with $\mathrm{MgO}$ and $\mathrm{SiO}_{2}$ to obtain better separation factors. 


\section{$\underline{\text { 2.1.4 }} \underline{\text { Porous Glass Membranes }}$}

Uniform, microporous Vycor glass membranes can be prepared with pores as small as $4 \mathrm{~nm}$. These membranes are made by acid leaching one of the phases that form in Vycor glass. These glass membranes may be limited in their applications, however, because they are brittle. Moreover, when microporous glass is heated above $575 \mathrm{~K}$ for long periods, or to higher temperatures for shorter periods, it loses its microstructure [15]. The development of composite ceramic membranes with pore diameters smaller than $4 \mathrm{~nm}$ may limit the use of glass membranes because of the various other advantages of ceramic membranes.

\section{$\underline{\text { 2.1.5 Zeolite Membranes }}$}

Although ceramic membranes have high fluxes and moderate separation factors, they are not used in high-purity separations which require very high selectivities to a single component in fluid streams. In such cases, zeolite membranes might be used because they can separate components in a fluid stream based on molecular sizes, yielding very high selectivities. Only a few cases of zeolite membranes have been reported. A patent by Suzuki [16] reports on the preparation of many zeolite membranes. These are ultrathin layers ( $1 \mathrm{~nm}$ to $10 \mathrm{~nm}$ thick) prepared by forming a thin gel film by gentle sedimentation from a mixture. According to the patent, X, Y, ZSM-5, and silicalite-type zeolite membranes can be prepared in this manner. However, many zeolites have acidic properties which may not be useful for reaction systems. Although there are some articles on preparing zeolite membranes, these membranes are not available commercially 


\section{$\underline{\text { 2.2 }}$ Terms used in Membrane Separation}

In order to select any membrane for a separation application, it is necessary to know the performance of the membrane in quantitative terms. The term most often used to describe the effect of a membrane quantitatively is the permeability, which is the amount of flow of a component in a gas-mixture stream through the membrane. Permeability is often reported in Barrers, where 1 Barrer equals $10^{-10} \mathrm{~cm}^{3}(\mathrm{STP}) / \mathrm{cm} / \mathrm{s} /(\mathrm{cm} \mathrm{Hg})$.

Other terms used in describing the performance of a membrane are the flux, permeance, and separation factor. The flux is a product of the permeability and the driving force (usually the partialpressure gradient for gases). The permeance is the ratio of the permeability to the effective membrane thickness. The permeance of the individual components in a gas mixture stream in the tube is defined as [5]:

$$
P_{i}=\frac{\left(F C_{i}\right)_{\text {sweep }}}{A P_{\text {total }} \Delta_{m, i}}
$$

where $C_{i}$ is concentration of component $\mathrm{i}\left(\mathrm{mol} / \mathrm{m}^{3}\right), \mathrm{F}$ is flow rate $(\mathrm{mol} / \mathrm{min})$, $\mathrm{A}$ is membrane permeation area $\left(\mathrm{m}^{2}\right), \mathrm{P}_{\text {total }}$ is total pressure on each side of the membrane (atm), "sweep" denotes the outlet gas stream from the shell side, and the logarithmic-mean concentration difference $\left(\Delta_{\mathrm{m}, \mathrm{i}}\right)$ of component $\mathrm{i}$ between the tube and the shell sides is defined as [5] :

$$
\Delta_{m, i}=\frac{\Delta C_{1}-\Delta C_{2}}{\ln \left(\Delta C_{1} / \Delta C_{2}\right)}
$$

where $\Delta \mathrm{C}_{1}$ is concentration difference across the membrane at the tube inlet $\left(\mathrm{mol} / \mathrm{m}^{3}\right)$, and $\Delta \mathrm{C}_{2}$ is 
concentration difference across the membrane at the tube outlet $\left(\mathrm{mol} / \mathrm{m}^{3}\right)$.

The logarithmic-mean concentration difference is particularly useful for counter-current flow in tubes in which the direction of the gas stream moving inside the membrane tube is exactly opposite to the direction of the gas stream moving outside the tube.

Finally, the separation factor measures the concentration ratio in the two sides of the membrane for one component in a gas mixture stream relative to another component. The separation factor $\alpha_{\mathrm{H} 2 / \mathrm{CO}}$ is defined as [5]:

$$
\alpha_{\mathrm{H} 2 / \mathrm{CO}}=\frac{\left(C_{\mathrm{H}_{2}} / C_{C O}\right)_{\text {sweep }}}{\left(C_{\mathrm{H}_{2}} / C_{C O}\right)_{\text {retentate }}}
$$

where "retentate" stands for the outlet gas stream from the tube side, $\mathrm{C}_{\mathrm{CO}}$ is concentration of $\mathrm{CO}$ $\left(\mathrm{mol} / \mathrm{cm}^{3}\right)$, and $\mathrm{C}_{\mathrm{H} 2}$ is concentration of $\mathrm{H}_{2}\left(\mathrm{~mol} / \mathrm{cm}^{3}\right)$.

\section{$\underline{2.3}$ Properties of an Ideal Membrane}

Membranes in catalytic membrane reactors have to be chosen properly, depending on the properties of the membrane and the characteristics required in the reactor. A suitable membrane for a catalytic membrane reactor should have high permeability and good separation selectivity, must be stable at reaction temperatures in the presence of reactive gases, and must be able to withstand a significant pressure drop. In general, for the same pressure drop, higher permeabilities are obtained with thinner membranes because the permeation rate is inversely proportional to thickness. However, the membrane must be thick enough to avoid formation of cracks and pinholes during its preparation 
and to prevent rupture from mechanical stresses that occur during its use. In fact, an optimal thickness exists because for very thick membranes the permeation rate of the products will be very small, and hence the conversion of the reactants will be low for equilibrium-limited reactions. On the other hand, for very thin membranes the permeation rate of the reactants will be very high, leading to a decrease in the conversion for equilibrium-limited reactions, unless the permeation rate of the products is high also to counter the effect.

\subsection{Mechanisms of Separation}

The extent of separation of the various components in a fluid stream by a membrane depends on the transport mechanism under those operating conditions. The transport mechanism affects the fluxes of the components which in turn affect the separating ability of the membrane.

In nonporous metal membranes, only one separation mechanism called 'atomic diffusion' is present. This mechanism is discussed below. The use of these membranes to date has only been for the permeation of $\mathrm{H}_{2}$ and $\mathrm{O}_{2}$, which are required in many industrial reactions. However, in porous membranes, there exist four different mechanisms of separation, and these membranes can be used for a variety of compounds. Those four mechanisms are: Knudsen diffusion, surface diffusion, capillary condensation, and molecular sieving. These are discussed below.

\subsubsection{Separation in Nonporous Membranes}

Palladium alloys are the nonporous membranes used most often in catalytic membrane reactors. Hydrogen molecules adsorb and dissociate into atoms on the metal surface. These atoms then diffuse through the metal membrane because $\mathrm{H}$ atoms are soluble in $\mathrm{Pd}$. At the other side, $\mathrm{H}$ atoms 
recombine and desorb from the surface. Although other gases can dissociate on $\mathrm{Pd}$, none have a significant solubility in Pd. Therefore, essentially infinite separation factors can be obtained when separating $\mathrm{H}_{2}$ from other gases. The flux of hydrogen through the membrane is found to be proportional to the square root of the partial pressure of hydrogen [9].

Oxygen permeation through $\mathrm{Ag}$ membranes is similar to $\mathrm{H}_{2}$ permeation through $\mathrm{Pd}$ alloy membranes. Apparently, oxygen atoms diffuse and the permeability into a vacuum is proportional to the square root of the partial pressure of oxygen. The permeability of oxygen is affected by the presence of other gases which adsorb on the Ag surface. The permeability of oxygen in $\mathrm{Ag}$ is much lower than that of hydrogen in $\mathrm{Pd}$.

Nonporous silica glass is also highly selective to $\mathrm{H}_{2}$ and large separation factors can be obtained. This selectivity is due to small openings in the glass network. Permeation is through adsorption and a solution/diffusion mechanism. Calcium-stabilized zirconia can be used for the permeation of $\mathrm{O}_{2}$ by dissociation on the surface and $\mathrm{O}_{2}$ conduction through the structure. Electron conduction in the opposite direction maintains charge neutrality. External electrodes are not needed. Similarly, PbO deposited on $\mathrm{MgO}$ in a ceramic membrane has been reported to transport oxide ions selectively [9].

\subsubsection{Separation in Porous Membranes}

There are four mechanisms of separation in porous membranes which are explained in the following section. More than one mechanism can be present at a time. The Knudsen mechanism gives relatively low separation factors compared to surface diffusion and capillary condensation. Molecular sieving can yield high separation factors. The separation factors for these mechanisms 
depend strongly on the pore size distribution, temperature, pressure, and the interactions between the gases being separated and the membrane surfaces. These mechanisms are described below.

\section{$\underline{\text { 2.4.2.1 }}$ Knudsen Diffusion}

Under viscous flow (Poiseuille flow), the mean free path of fluid molecules is small in comparison with the pore diameter, and molecules undergo many more collisions with each other than with the walls of the membrane. The molecules in a mixture do not behave independently in viscous flow and no separation is possible. Therefore, viscous flow is not desirable in catalytic membrane reactors. As the pressure is lowered, the mean free path of the molecules becomes longer than the pore diameter. As a result, the molecules undergo more collisions with the pore walls than with each other, and the molecules flow through the pores independently of each other. This is Knudsen diffusion. In the Knudsen diffusion regime, an equimolar mixture of feed gas will have a separation factor equal to the square root of the ratio of the molecular weights of the gases when the permeate side is a vacuum. The separation factor will be lower if a pressure is maintained in the permeate side instead of a vacuum. The small pore sizes in ceramic membranes allow separation due to Knudsen diffusion. In composite membranes, the thin permselective layer can be in the Knudsen diffusion regime and can give all the separation, while the support layers are in the viscous regime. Separation in the Knudsen regime has the limitation that only the lighter component can be preferentially removed. When the molecular weights of the components do not differ by a significant amount, an economical separation by Knudsen diffusion is not possible.

Most of the porous membranes used to date for gas-phase, catalytic membrane reactors have been operated at sufficiently low pressures that Knudsen diffusion predominates. Viscous flow can be 
present in porous membranes if the pressure or the pressure-drop is too high. But as mentioned before, viscous flow does not yield a separation.

\section{$\underline{\text { 2.4.2.2 }}$ Surface Diffusion}

During diffusion through a membrane, a gas can chemisorb or physisorb on the pore walls and migrate along the surface. This is surface diffusion. It can occur in parallel with Knudsen diffusion. Surface diffusion increases the permeability of the more strongly adsorbed components in a diffusing mixture, while simultaneously reducing the permeability of the other diffusing components by decreasing the effective pore diameter. Therefore, this diffusion is very important for membranes with small pores. When surface diffusion occurs, the effect of selective adsorption of a component from a gas-mixture on the membrane surface must be taken into account. This can be done by assuming that the total flux of diffusion is the total of the fluxes due to surface diffusion by selective adsorption, and Knudsen diffusion [9]. As the temperature increases, the gaseous species desorb from the surface and Knudsen diffusion dominates at higher temperatures .

Many examples of surface diffusion transport have been reported in the literature [15,17]. Surface diffusion of cyclohexane during its dehydrogenation was found to lower the efficiency of separation of the product $\mathrm{H}_{2}$ [18]. $\mathrm{CO}_{2}$ was found to exhibit surface diffusion on a ceramic membrane [9]. Uhlhorn et al [19] reported a separation factor of 5.6 for a $\mathrm{C}_{3} \mathrm{H}_{6} / \mathrm{N}_{2}$ mixture. This separation factor is much higher than that under Knudsen diffusion conditions which predicts a high separation factor for nitrogen in the mixture. The existence of surface diffusion must usually be determined experimentally. If the observed permeability and separation factor of a component in a gas-mixture stream are much higher than those expected under ideal Knudsen-diffusion conditions, then the 
enhanced diffusion is usually attributed to surface diffusion.

\subsubsection{Capillary Condensation}

When one of the components in a gas mixture is a condensible vapor and if the pores of the membrane are small enough, then the condensate can block gas-phase diffusion through the pores. This condensate will evaporate on the low-partial-pressure side of the membrane.

The Kelvin equation represents thermodynamic equilibrium between gas and condensate in pores:

$$
\frac{P}{P_{s}}=\exp \left(\frac{-2 \gamma \cos \theta}{r_{p} \rho R T}\right)
$$

where $\gamma$ is the surface tension of the condensed fluid in the pore $\left(\mathrm{J} / \mathrm{m}^{2}\right), \mathrm{P}$ is vapor pressure in the gas phase $(\mathrm{atm}), \mathrm{P}_{\mathrm{s}}$ is the condensation vapor pressure in the bulk phase at the experimental temperature (atm), $r_{p}$ is mean pore radius $(\mathrm{m}), \theta$ is the contact angle between the condensed fluid and the pore wall, $\rho$ is molar density of the condensed liquid $\left(\mathrm{mol} / \mathrm{m}^{3}\right), \mathrm{T}$ is temperature of fluid in the pore $(\mathrm{K})$, and $\mathrm{R}$ is the universal gas constant ( 0.082 lit.atm $/ \mathrm{mol} / \mathrm{K})$.

The Kelvin equation predicts that condensation can occur in small pores, although the partial pressure of the condensible vapor component in the gas mixture stream is below the normal equilibrium vapor pressure of that component [9]. Because of capillary condensation, the pores can completely fill with the condensed liquid of that vapor component. For a narrow distribution of pore 
sizes, all the pores will be filled and the fluxes of the other components through the membrane will be quite small and limited by their solubility in the condensible component. Thus, extremely high separation factors are possible. As an example, separation factors as high as 460 were reported for $\mathrm{H}_{2} \mathrm{O}$ /air separation, and 1000 for $\mathrm{SO}_{2} / \mathrm{H}_{2}$ separation, due to the condensation of $\mathrm{H}_{2} \mathrm{O}$ and $\mathrm{SO}_{2}$ respectively.

\subsubsection{Molecular Sieve Separation}

Most of the ceramic membranes and glass membranes used for separation have pores sizes which are not small enough to separate the gas mixtures solely based on their molecular sizes. Therefore, the separation factors with these membranes are low. However, some membranes have pores which are of the size of the gas molecules. In these membranes, the smallest molecule has the greatest ability to diffuse through the pores whereas the other gas molecules are almost totally excluded. This yields very high separation factors. This mechanism is called molecular sieve separation. It has also been called shape selective or configurational diffusion. Zeolite membranes are good examples exhibiting this mechanism. Suzuki [9] has presented examples of the selective separation that can be obtained with shape-selective zeolite membranes. He claims that zeolite membranes with pore sizes from 0.3 to $1.2 \mathrm{~nm}$ could be prepared so larger molecules could also diffuse through these materials.

\section{$\underline{2.5}$ Operating Characteristics of Membrane Reactors}

Catalytic membrane reactors can be operated in various ways, depending on the contact of reactants (whether on one side or on both sides of the membrane), the type of flow of reactant and sweep gases (whether cocurrent or countercurrent), reactions on one side or both sides of the membrane, and the pressure drop across the membrane (whether equal or unequal pressures are 
present across the membrane).

\section{$\underline{\text { 2.5.1 }}$ Contact of Reactants}

There are two ways of feeding reactants to the catalytic membrane reactor. One way is to feed both the reactants through the tube and no reactant on the shell side. The other way is to feed at least one reactant on the shell side and the others through the tube. These are discussed below.

\subsubsection{Reactants on One Side}

In the normal configuration of a membrane reactor, the reactants flow through the tube and only the sweep gases (usually inert) flow on the shell side. In such reactors, the purpose of the sweep gas is to sweep away the permeating products and to decrease their concentration on the shell side. This results in an increase in the permeation rates of the products. Although the conversion may increase due to the continuous removal of the products, there is the problem of mixing of the products with the sweep gas which is usually an inert. This might create another problem of separating the products from the inert gas after it comes out from the membrane reactor. In such cases, the membrane reactor usually becomes uneconomical, unless the production rate or the conversion is high enough to counter the extra cost of separation equipment.

\section{$\underline{\text { 2.5.1.2 }}$ Reactants on Both Sides}

Recently some catalytic-membrane reactors have been run with one reactant fed to the tube side of the membrane and a second reactant fed to the shell side. The studies show the advantages of this mode of operation $[20,21]$. In traditional packed-bed reactors, the reactant concentration decreases monotonically from the entrance toward the exit of the reactor, provided no intermediate feed is 
supplied. Especially at the inlet, the selectivity is comparatively low for reactions such as partial hydrogenations or oxidations, which require low reactant concentrations. When a reactant is supplied through the membrane, the concentration of that reactant inside the reactor can be kept at a sufficiently low and constant level. This limits side reactions such as deeper hydrogenations or oxidations, and avoids the need to separate unconverted reactants. By simply keeping separated the bulk of two reactants, the undesired side reactions are avoided.

Moreover, the separation of reactants allows better control of the reaction by varying the flow rates, concentrations, and pressures of the two reactants independently. For instance, Nagamoto and Inoue [20] succeeded in getting good control of the reaction rate of butene and butadiene hydrogenations by modifying the hydrogen partial pressure on one side of a $\mathrm{Pd}$ membrane reactor.

When the membrane is sufficiently permselective to the supplied reactant, the reactants can be fed in a dilute form, the undesired compounds being rejected by the membrane itself. For instance, Omata et al. [22] used air instead of pure oxygen for the oxidative coupling of methane on a dense $\mathrm{PbO}$ membrane; thus nitrogen was kept apart from products and unconverted reactants ( the separation of methane from nitrogen is difficult and expensive).

Also, in this way, the volume of the off-gases containing the products is reduced. Kiratsis and Stoukides [23], during their study on one-step $\mathrm{HCN}$ production from $\mathrm{CH}_{4}, \mathrm{NH}_{3}$ and air, were able to halve the off-gas volume in comparison to the conventional Andrussow process. They kept nitrogen separated from the reaction zone by means of a stabilized zirconia membrane which is permeable only to oxygen. In a similar way, it is also possible to prevent any gaseous poison from reaching the 
catalyst in a packed-bed membrane reactor by using the proper membrane which will not allow permeation of the poison.

Moreover, regarding safety, the formation of explosive mixtures is hampered if fuel and air (or oxygen) are fed from opposite sides of a membrane combustor, thus allowing the use of an undiluted fuel. Veldsink et al. [21] studied CO combustion on such a reactor using a porous alumina membrane. They pointed out that the risks of thermal overruns and related damage of catalysts could be significantly reduced with such a system, because it is simply controlled by transport phenomena, which are less temperature sensitive than kinetic phenomena.

There are cases of hydrogenation reactions in which the addition of hydrogen through a palladium membrane from the shell side improved the membrane performance. A recent article by Itoh [24] has discussed the advantages of this operation. Hydrogenation of phenol to cyclohexanone was carried out using palladium-based membranes as catalysts. The hydrogen permeating from the shell side through the membranes was found to have higher reactivity than the hydrogen premixed with phenol on the tube side. The surface concentration of hydrogen on the membrane can be easily controlled by adjusting the amount of permeating hydrogen. Hydrogen molecules decompose to atoms on the membrane surface, dissolve into bulk palladium and diffuse in the palladium matrix. The reaction rate can be considerably increased by supplying active atomic hydrogen whose concentration on the membrane surface is controllable by varying the partial pressure of hydrogen. 


\subsubsection{Type of Flow}

There are two ways of flowing gases through a shell-and-tube reactor. When the direction of gases flowing on both the sides is the same, the flow is cocurrent. On the other hand, if the direction of the gases on both sides is opposite, the flow is countercurrent. Since the concentration difference across the membrane is the highest in a countercurrent flow, the usual preference for flow in membrane separation systems is countercurrent. However, the condition is not the same with reactive systems. In catalytic membrane reactors, the concentrations of reactants and products on each side of the membrane affect both the reaction and permeation rates. In such reactors, the purpose is not only to separate the required product but also to avoid permeation of reactants through the membrane, to maintain the required concentration of reactants for reaction inside the tube. Therefore, countercurrent flow may not be advantageous.

When the reactants are fed on the tube-side of the reactor, two means are available to reduce the reactant permeation to the shell-side. The first method is back diffusion of the reactant from the shell-side to the tube-side. For this approach two conditions are necessary. First, the reactor has to be operated cocurrently. In this mode, the reactant concentration on the shell-side can exceed the feed side as one moves down the length of the reactor. This driving force makes reactants permeate from the shell-side into the tube. Secondly, the total pressure on each side of the membrane should be the same, so that the driving force for reactant permeation is reduced.

The second approach is recycling of the unreacted feed. Recycling can work if the permeances of reactants lie in between the permeances of the products. In this manner, the unreacted feed is enriched in the reactants relative to one of the products. However, product accumulation in the 
recycled stream can limit the extent of conversion. The effect of the direction of the tube-side and shell-side gases has been studied by Mohan and Govind [2,25]. They found that the choice between the two depends on the system parameters.

\subsubsection{Simultaneous Reactions}

In a catalytic membrane reactor, since the products permeate to the shell side of the membrane, it may prove advantageous if the products can be used for some other reaction on the shell side. In such a case, the permeating product gets continuously used in the reaction occurring on the shell side. This leads to increased permeation of the product, ultimately resulting in increased conversion in the tube. For example, a nonporous Pd alloy membrane was used to carry out dehydrogenation of cyclohexanol on one side of the membrane and hydrogenation of phenol to cyclohexanone on the other side [9]. This approach has many advantages other than the one mentioned above. The hydrogen formed as product in one reaction is used as a reactant in the other. The reactants from the two reactions are not mixed. The heat of reaction from the exothermic hydrogenation reaction is transferred across the membrane to supply energy for the endothermic reaction.

\section{$\underline{\text { 2.5.4 Pressure Drop across the Membrane }}$}

Pressure drop across a membrane is the driving force for permeation of gases. In a catalytic membrane reactor, the permeating gases include the reactants and the products. The decision of maintaining a pressure drop across the membrane depends on the selectivity of the reactants over the products through the membrane. If the permselectivity of the membrane to the products is high, then maintaining a low pressure on the shell side will be advantageous. The low pressure increases the permeability of the products, leading to higher conversions. However, if the permselectivity of 
the products over the reactants is not high, then it is better to keep equal pressures across the membrane. This will reduce the loss of reactants and allow a modest amount of permeation of the products through the membrane. In most of the reactions carried out until now, the products have had high selectivity over the reactants, the majority of these reactions being dehydrogenations with hydrogen as the product. Therefore, in these cases, the reactor performance could be improved by keeping a lower pressure on the shell side as compared with that on the tube side.

\subsection{Characteristics of Membrane Separation}

Separation of vapors/gases is a function of the flow configuration and the pressure drop across the membrane. If the pressure ratio (ratio of the pressure on the outside of the membrane tube to the pressure inside the tube) is close to one, then back diffusion of gases from the outside of the membrane tube to inside will lead to smaller separation factors than that predicted by theory. As the pressure ratio decreases, the amount of back diffusion decreases and the separation factors approach those predicted by theory. As the flux through the membrane becomes a significant fraction of the feed flow rate, the configuration of the reactor (counter-current/cocurrent) determines the separation factor.

In spite of research on preparing membranes with very small pore sizes, commercial membranes typically have pore sizes from $4 \mathrm{~nm}$ to $20 \mathrm{~nm}$. This pore size is not suitable for separating small molecules exclusively from a mixture of gases. The current work deals with the synthesis of methanol from $\mathrm{CO}$ and $\mathrm{H}_{2}$. This reaction requires continuous removal of product methanol through the membrane for increasing conversion beyond equilibrium. Methanol has a larger molecular size than the reactants. Therefore, membranes with pore sizes in the above range might prove useful for 
this reaction, depending on the mechanism of separation. A purely Knudsen-diffusion mechanism would give a low separation of methanol, since methanol has greater molecular weight than both the reactants. Surface diffusion and capillary condensation of methanol will increase the separation of methanol. As mentioned before, the literature [5] suggests that an alumina membrane yields good separation selectivity for methanol with respect to hydrogen at high concentrations of methanol. The increase is supposedly due to surface diffusion. An alumina membrane is used in the current work.

\section{$\underline{2.7}$ Engineering Issues}

The field of catalytic membrane reactor systems is relatively new. There are many critical issues which require attention for operating the reactor with the desired characteristics. Armor [4] has pointed out some of these issues.

a) A need for crack-free and uniform sub- $8 \AA$ membranes which are stable for extended use from $200-600^{\circ} \mathrm{C}$ and which are chemically inert.

b) Fabrication of very thin, flaw-free layers over large areas. The thickness of the membrane layer controls the flux/permeability of the permeating species. As discussed before, the thickness of the membrane has to be optimized to get the best results.

c) Sealing the membrane into a device operating at high temperatures. According to the procedure frequently adopted, the ends of the membranes are coated with enamel or ceramic compounds so as to fill the pores, thus preventing the permeate (shell side stream) from remixing with the retentate 
(tube side stream) or, more likely, the retentate from leaking to the permeate side. Further, a proper sealing material, capable of matching both the reaction environment and the differential thermal expansion, is employed. Polymer-based sealing cannot be used at high temperatures (above $200^{\circ} \mathrm{C}$ ). At temperatures higher than these, pure graphite gaskets can be used till about $450^{\circ} \mathrm{C}$. Very recently, Velterop B.V. has successfully developed a new sealing technique. In this technique, a ceramic membrane tube is joined to a dense ceramic ring which has an expansion coefficient quite close to that of the tube and which has much higher mechanical strength than the graphite gaskets. These seals are claimed to withstand temperatures up to $800^{\circ} \mathrm{C}$ and repeated temperature cycling.

d) Adherence of membrane layer to the support under repetitive temperature cycling. This issue is not as severe as the previous ones.

e) Use of large amounts of sweep gas. This leads to the problem of dealing with the separation of the products from the sweep gas. This issue has been discussed previously. Another problem in this context is that economic and availability considerations strongly suggest the use of air or steam for cases involving the use of large amounts of sweep gas. The use of gases other than these would probably be much too expensive for practical applications. However, the presence of oxygen (in the air used as the sweep gas) may be undesirable for the particular reaction under consideration, while steam may affect the stability of the membrane.

f) Limited availability of microporous inorganic membranes with pore sizes less than $20 \AA$. This is a very important issue, because the size of the membrane pores plays a big role in the selectivity to the required products. Though research is going on in preparing membranes of very small pore 
sizes, these membranes are not yet readily available for experimental purposes.

g) Susceptibility of membranes to poisoning and fouling. Fouling is caused by the intrusion of fine particles into the pores of the membrane. The fine particles can be either present in the inlet flows or generated within the reactor. This may affect the permeability of the membrane. In particular, the problem of coke formation, especially when dealing with high-temperature reactions involving hydrocarbons, may affect the performance of catalytic membrane reactors. Carbon deposits from secondary reactions may accumulate within the membrane pores, completely blocking the smaller pores. Thus, these deposits may affect the permeability and the catalytic activity. One method to prevent coke deposits is to introduce steam as a gaseous diluent in the reactant feed. However, steam itself can affect the stability of alumina membranes [26,27]. Another method of reducing coke formation is to provide an oxidizing atmosphere in order to burn coke selectively without interfering with the main reaction, if possible.

h) Decrease of permeability with pore size. As the pores of the membranes get smaller, the permeability decreases. Though the decrease in pore size might prove desirable for getting higher separation factors, low permeabilities tend to make the use of membranes uneconomical.

i) Techniques for measuring pore sizes. The determination of pore size of the membrane is another challenge for producing membranes of the correct (required) size. It is very difficult to measure porosity below $10 \AA$ accurately even for a powdered material. The standard methods used for measuring pore sizes in membranes are mercury porosimetry and nitrogen adsorption/desorption. Commercial mercury porosimeters can usually provide pore-diameter distribution data in the range 
of $3.5 \mathrm{~nm}-7.5$ microns. For pore sizes less than $3.5 \mathrm{~nm}$, the nitrogen adsorption/desorption method based on the Kelvin equation can be employed. However, this technique is only good for pore sizes ranging from $1.5 \mathrm{~nm}$ to $100 \mathrm{~nm}$. The difficulty in analyzing membranes with a wide pore-size distribution lies in the very small percentage of pore volume contributed by the thin membrane film compared with that of the support layer(s). Another recent method for measuring pore size distributions has been developed and tested at Oak Ridge National Laboratory [28]. This method is different from the previous methods in that it is based on gas transport rather than volume. The method is not sensitive to the amount of gas adsorbed and is particularly suitable for gas separation applications. It uses the Kelvin equation of capillary condensation for determining the pore size distribution. This method is suitable for pore sizes from $1.5-2.0 \mathrm{~nm}$ to 1 micron.

Very little work has been done on hydrogenation reactions in membrane reactor systems in which the permeation of hydrogen should be as low as possible. The purpose of the present work therefore was also to fill out this lacuna by working on the hydrogenation of carbon-monoxide to produce methanol. Methanol is an important chemical used as an intermediate for the production of many other chemicals like formaldehyde, methyl-ether, and higher alcohols. It is also used in fuel for motor vehicles. As the synthesis of methanol is an equilibrium-limited reaction, a catalytic membrane reactor can prove to be advantageous if the membrane removes methanol continuously. If the selectivity of methanol over the reactants through the membrane is high, this will yield conversions higher than the conversion at equilibrium. Therefore, the reaction of methanol synthesis was studied in a catalytic membrane reactor system. 


\section{EXPERIMENTAL DESIGN}

The purpose of the present work was to study the packed bed membrane reactor and to compare it with the conventional packed bed tubular reactor. The experimental conditions were chosen to accomplish both objectives simultaneously. The overall experimental work was done in two stages.

\subsection{Equipment Setup}

The first stage involved setting up the reactor unit and running lines through the laboratory to send gases to the reactor unit and the gas chromatographs. As shown in Figure 2, the experimental setup consisted of a membrane-reactor unit and two Hewlett-Packard 5890 gas chromatographs. Stainless-steel lines were used to feed gases to the various pieces of equipment. This included the lines to run the feed gases (viz. $\mathrm{H}_{2}, \mathrm{CO}, \mathrm{N}_{2}$, and the $\mathrm{H}_{2} / \mathrm{CO}$ mixture) to the reactor, and the line for the carrier gas argon to the sampling valves. The lines connecting the reactor, the sampling valves, the gas-liquid separator, and the back-pressure regulator were also made of stainless steel. The flows of all feed gases were controlled by mass-flow controllers. A pressure gauge indicated the total system pressure. A back-pressure regulator after the gas-liquid separator maintained a constant and equal pressure on both the sides of the membrane tube.

The membrane-reactor unit (membrane module), as shown in Figure 3, consisted of a tubular $\gamma$ alumina membrane tube surrounded by a stainless steel tube (SST). The membrane used was an asymmetric, composite ceramic membrane commercially available under the trade name Membralox (US Filter) and had a nominal pore size of $40 \AA$. The membrane tube was connected to 


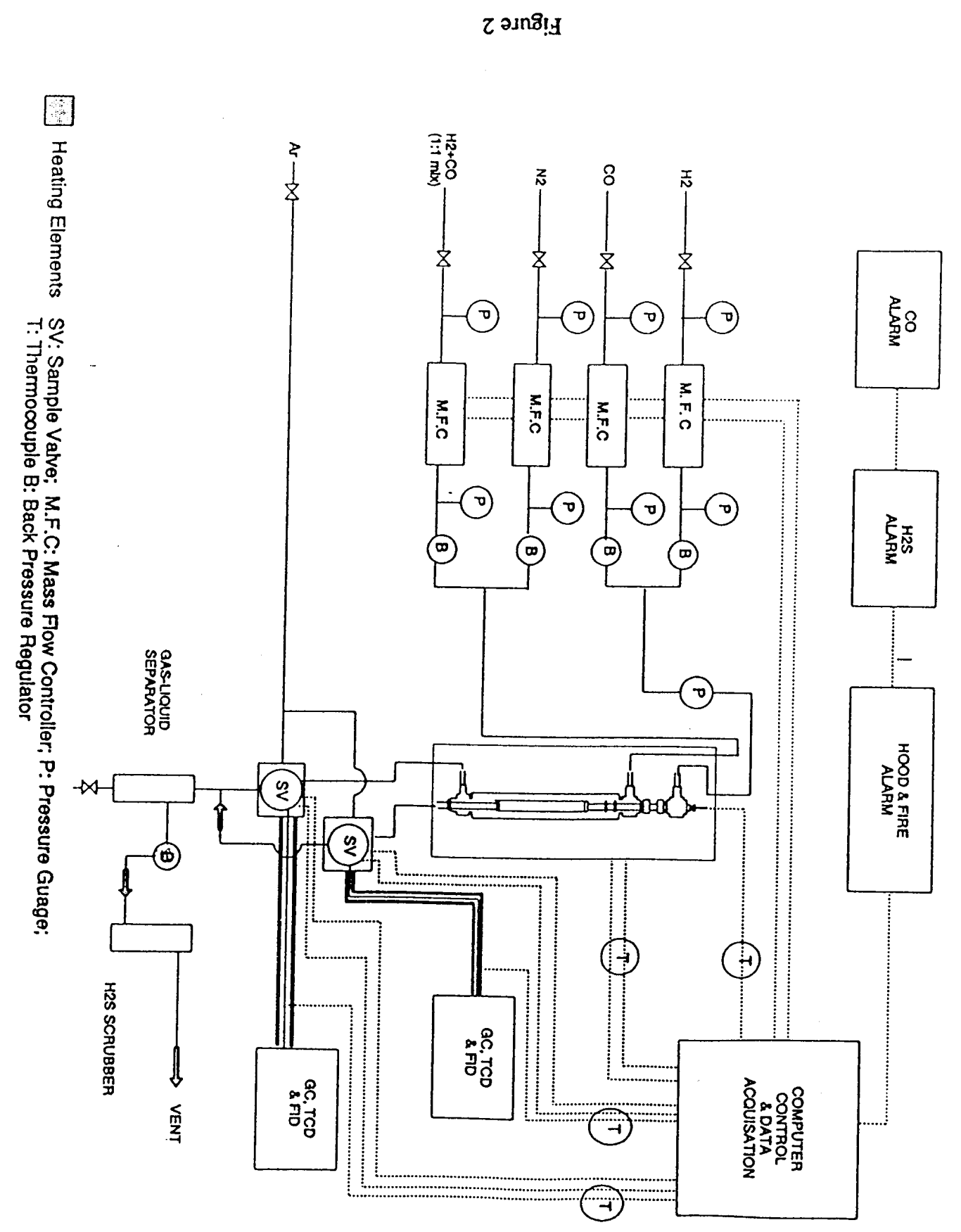




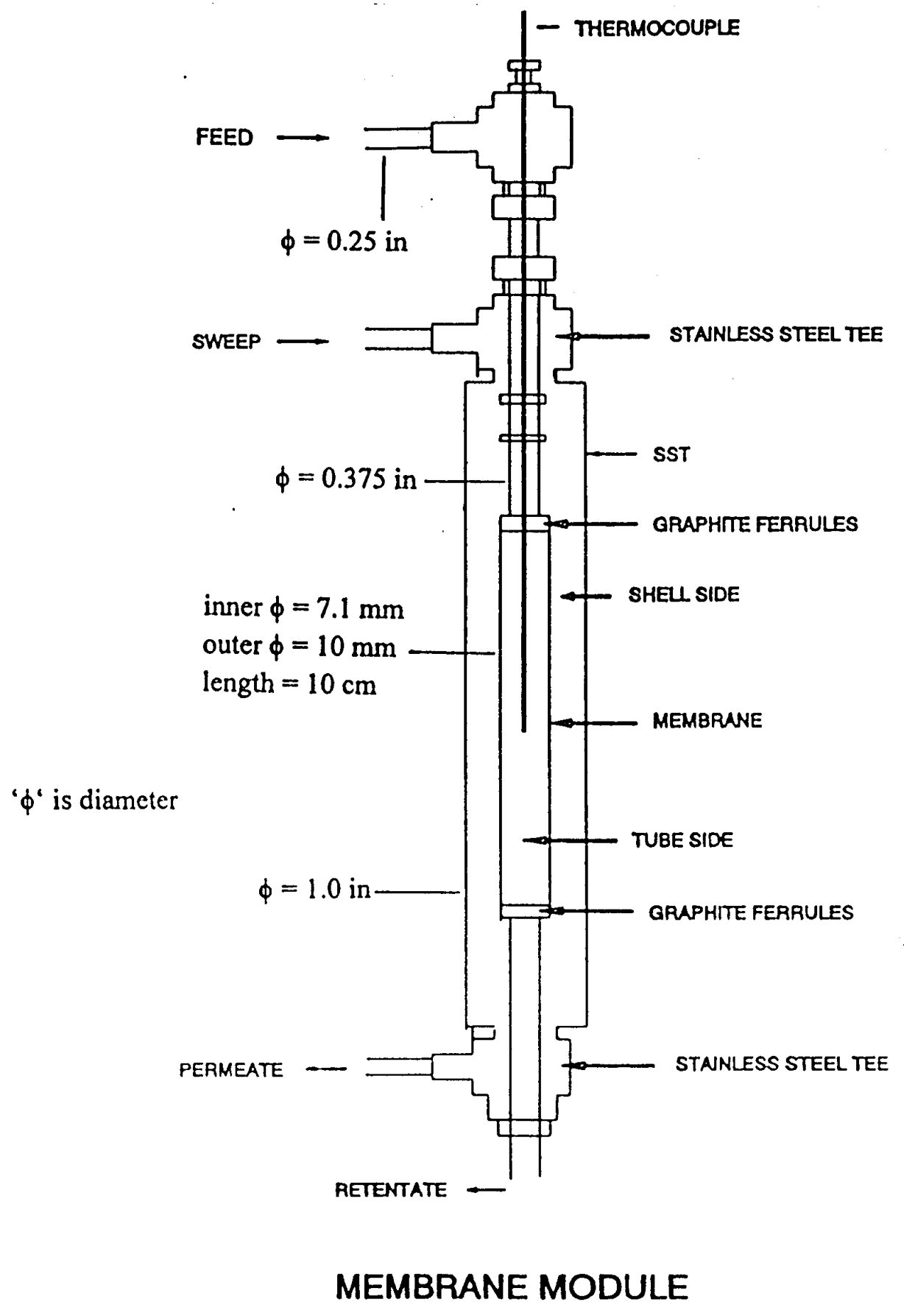

Figure 3 
the feed and sweep lines by stainless-steel unions and tees so that the tube stayed inside the SST at its center, and there was sufficient gap between the outer surface of the membrane and the inner surface of the SST for the sweep gas to flow through. Graphite ferrules were used for connecting the membrane tube to the stainless-steel unions, thus allowing any expansion due to temperature increase during reaction runs, and at the same time not allowing any escape of gases. A thermocouple inserted inside the reactor measured the reaction temperature. The temperature inside the reactor was computer-controlled. The heating furnace heated the reactor to the desired temperature which was set through the computer.

The same setup for the membrane-reactor unit described above was also used for the packed-bed tubular reactor experiments. The only change in the unit setup was that the membrane tube was replaced by a stainless steel tube of equal length.

Gas-chromatographic analysis of the outlet gases from the reactor was done to obtain the compositions of the two gas streams leaving the reactor. Each gas chromatograph had two detectors: a thermal conductivity detector (TCD) and a flame ionization detector (FID). A TCD is normally used for inorganic gases like $\mathrm{CO}, \mathrm{H}_{2}, \mathrm{CO}_{2}$ etc. A FID is used for gases/vapors like hydrocarbons and alcohols. A sampling valve collected samples of the gas streams coming out of the reactor. These samples were swept by a carrier gas to the gas chromatographs which gave the compositions of the gas streams.

During the experiments for measuring the fluxes and permeances in the empty membrane tube, the outlet gas stream from the shell side (permeate) and the outlet gas stream from tube side (retentate) 
were analyzed by the two gas chromatographs. However, during the experiments with the loaded catalyst in the packed-bed reactors, one gas chromatograph analyzed the permeate stream, and the other gas chromatograph analyzed the mixture of the permeate and retentate streams. The analysis of the mixture stream instead of the retentate stream was done due to the unavailability of two backpressure regulators to simultaneously analyze and measure the flow rates of the retentate and permeate gas streams. The purpose of the analysis was to be able to calculate the conversions in the packed-bed reactors. The analysis of the permeate stream was done with an objective of getting more insight about the membrane tube.

\section{$\underline{\text { 3.2 }} \underline{\text { Experimental Procedure }}$}

The second stage of the work involved the calibration of the mass-flow controllers, obtaining response factors for the gas components in the gas chromatographs, and carrying out experiments in the reactor. Each mass-flow controller was calibrated by adjusting the reading of the flow controller so that it was close enough to the actual flow rate of the gas through the controller. The response factors for $\mathrm{CO}, \mathrm{H}_{2}$, and $\mathrm{N}_{2}$ were obtained by calibration on each gas chromatograph. The response factors for methanol in both gas chromatographs were found by saturating methanol with nitrogen at different temperatures and using the equilibrium compositions at those temperatures. Argon was used as the carrier gas for the gas chromatographs, instead of helium, to get a better response for hydrogen.

Experiments were first carried out on the empty membrane tube in order to test the permeability characteristics of the membrane under the same operating conditions as the reactor. These experiments were followed by experiments on the packed-bed membrane reactor and the packed- 
bed tubular reactor. The procedures for all these experiments are described below.

\subsubsection{Membrane Characterization Experiments}

These experiments were used to study the effects of parameters such as the temperature, the flow rate of sweeping gas, and the concentration of tube-side feed gas on the permeability characteristics of the membrane. Table 1 shows the experiments carried out for this study. There was no change in the setup of the reactor as shown in Figure 2. The membrane tube was filled with quartz chips (2040 mesh size) so as to resemble the packed-bed membrane reactor loaded with catalyst. As mentioned before, the permeate and retentate streams were analyzed separately by the two gas chromatographs. A mixture of $\mathrm{CO}$ and $\mathrm{H}_{2}$ with different concentrations of $\mathrm{CO}$ was fed through the membrane tube, and nitrogen was passed with varying flow rates on the outside of the tube (shell side) at a fixed temperature. This procedure was then repeated at different temperatures. The total flow rate of the tube-side feed gas was kept constant (at $100 \mathrm{ml} \mathrm{STP} / \mathrm{min}$ ) for all the experiments. The flow of gases on both sides of the membrane tube was co-current. The operating pressure was kept constant at 750 psig. For each experiment, the compositions of the outlet gas streams from the membrane tube were obtained from the gas-chromatographic analysis. The analysis of these composition data is discussed in the next chapter.

\subsubsection{Experiments on Packed-Bed Reactors}

The synthesis of methanol with the BASF catalyst number S 3-86 has been described in literature [29], and the operating conditions and products obtained are known. As the reactants and products both could be detected by the TCD of the gas chromatograph, the FID was not used for the gaschromatographic analysis of the outlet gases from both the packed-bed reactors, viz. $\mathrm{H}_{2}, \mathrm{CO}, \mathrm{N}_{2}$, 
Table 1

Flow Conditions and Temperatures for

Membrane Characterization Experiments

\begin{tabular}{|c|c|c|c|c|}
\hline \multirow{2}{*}{$\begin{array}{c}\text { Flow } \\
\text { Condition } \\
\text { (Number) }\end{array}$} & \multicolumn{2}{|c|}{$\begin{array}{l}\text { Tube Side Feed } \\
\text { (cc STP /min) }\end{array}$} & $\begin{array}{l}\text { Shell Side Feed } \\
\text { (cc STP/min) }\end{array}$ & $\begin{array}{c}\text { Temperatures } \\
\left({ }^{\circ} \mathrm{C}\right)\end{array}$ \\
\hline & $\mathrm{H}_{2}$ & $\mathrm{CO}$ & $\mathrm{N}_{2}$ & \\
\hline MC1 (1) & 80 & 20 & 50 & 200 \\
\hline MC1 (2) & 80 & 20 & 50 & 250 \\
\hline MC1 (3) & 80 & 20 & 50 & 300 \\
\hline MC2 (4) & 50 & 50 & 150 & 200 \\
\hline MC2 (5) & 50 & 50 & 150 & 250 \\
\hline MC2 (6) & 50 & 50 & 150 & 300 \\
\hline MC3 (7) & 20 & 80 & 50 & 200 \\
\hline MC3 (8) & 20 & 80 & 50 & 250 \\
\hline MC3 (9) & 20 & 80 & 50 & 300 \\
\hline
\end{tabular}


and methanol. The experimental procedures for operating both these reactors are described below.

\subsubsection{Packed-Bed Membrane Reactor}

The purpose of carrying out experiments in the packed-bed membrane reactor was to study the effect of changing the reaction conditions on the conversions obtained from the reactor. Table 2 shows the experiments carried out in this reactor. The experiments in the reactor were carried out in the same order as shown in Table 2. The reaction conditions changed were the temperature, the flow rate of sweeping gas, the flow rate of tube-side feed gas, and the composition of the sweeping gas. At the time of reactor operation, the membrane tube was loaded with the catalyst from BASF. The catalyst was loaded in a diluted form, mixed with enough quartz chips to fill the membrane-tube ( $0.5 \mathrm{~g}$ catalyst $20-40$ mesh size $+3 \mathrm{~g}$ quartz chips $20-40$ mesh size $)$. The operating pressure was kept constant at 750 psig. The composition of the tube-side feed gas was also kept constant. The flows of gases on both sides of the membrane tube were cocurrent. There was no change in the equipment setup relative to Figure 2.

The experiments for the first Flow Condition (MR1) were carried out with a fresh sample of the catalyst. The experiments for the Flow Conditions MR2-MR5 in the Table 2 were carried out with the same sample of catalyst as used for Flow Condition MR1. Another fresh sample of the catalyst was used for Flow Condition MR6 in the Table 2. Experiments for Flow Conditions MR7-MR9 were carried out with the same sample of the catalyst used for Flow Condition MR6.

The compositions of the permeate stream and the mixture of the permeate and retentate streams were obtained from the TCD's of the two gas chromatographs. The analysis of these composition 
Table 2

Flow Conditions and Temperatures

in Packed-Bed Membrane Reactor Experiments

\begin{tabular}{|c|c|c|c|c|c|c|c|c|c|}
\hline $\begin{array}{c}\text { Flow } \\
\text { Condition } \\
\text { (Number)* }\end{array}$ & $\begin{array}{c}\text { Catalyst } \\
\text { Sample }\end{array}$ & \multicolumn{3}{|c|}{$\begin{array}{c}\text { Flow Rate of component in } \\
\text { feed stream (cc STP/min) }\end{array}$} & \multicolumn{3}{|c|}{$\begin{array}{r}\text { Time Range after Catalyst } \\
\text { introduction (hrs) }\end{array}$} \\
\hline & & \multicolumn{2}{|c|}{ Tube Side } & \multicolumn{2}{|c|}{ Shell Side } & T=250 ${ }^{\circ} \mathrm{C}$ & T=225 ${ }^{\circ} \mathrm{C}$ & T=200 ${ }^{\circ} \mathrm{C}$ \\
\hline MR1 (1) & A & 50 & 50 & 0 & 0 & 40 & $0-22$ & $22-36$ & $36-54$ \\
\hline MR2 (2) & A & 50 & 50 & 0 & 0 & 60 & $54-66$ & NR & NR \\
\hline MR3 (3) & A & 50 & 50 & 0 & 0 & 100 & $66-82$ & $82-96$ & $96-108$ \\
\hline MR4 (4) & A & 40 & 40 & 0 & 0 & 40 & $120-134$ & $108-120$ & $134-146$ \\
\hline MR5 (5) & A & 40 & 40 & 10 & 10 & 40 & $158-172$ & $146-158$ & NR \\
\hline MR6 (6) & B & 40 & 40 & 0 & 10 & 40 & $9-19$ & $0-9$ & NR \\
\hline MR7 (7) & B & 40 & 40 & 10 & 0 & 40 & $19-29$ & $29-38$ & NR \\
\hline MR8 (8) & B & 50 & 50 & 20 & 20 & 0 & $38-48$ & NR & NR \\
\hline MR9 (9) & B & 50 & 50 & 50 & 50 & 0 & $48-57$ & NR & NR \\
\hline
\end{tabular}

NR: Not Run

* Numbers are for experiments at $250^{\circ} \mathrm{C}$, and are used later in graphs. 
data is discussed in the next chapter.

\subsubsection{Packed-Bed Tubular Reactor}

The purpose of conducting experiments in the packed-bed tubular reactor was to be able to compare the performance of the packed-bed membrane reactor with that of the conventional packed-bed tubular reactor. The results of these experiments also enabled the kinetics of the methanol synthesis reaction to be obtained unambiguously under the conditions of the packed-bed membrane reactor. As the comparison between the two reactors was based on equal inlet flow rates of the reactants and equal gas hourly space velocities, the experimental conditions in the packed-bed tubular reactor were fixed appropriately. Table 3 shows the experiments carried out in this reactor. The catalyst was loaded in the reactor in the same manner as the packed-bed membrane reactor, described previously. The operating pressure was kept constant at 750 psig for all experiments. The compositions of the shell-side outlet stream, and, the mixture of the tube side and the shell-side outlet streams were obtained separately by two gas chromatographs. The analysis of these composition data is discussed in the next chapter. 
Table 3

Flow Conditions and Temperatures in

Packed-Bed Tubular Reactor Experiments

\begin{tabular}{|c|c|c|c|c|c|c|c|}
\hline $\begin{array}{c}\text { Flow } \\
\text { Condition } \\
\text { (Number)* }\end{array}$ & \multicolumn{2}{|c|}{$\begin{array}{c}\text { Tube Side Feed } \\
\text { (cc STP/min) }\end{array}$} & \multicolumn{2}{c|}{$\begin{array}{c}\text { Shell Side Feed } \\
\text { (cc STP/min) }\end{array}$} & $\begin{array}{c}\text { Temperatures } \\
\left({ }^{\circ} \mathrm{C}\right)\end{array}$ \\
\hline & $\mathrm{H}_{2}$ & CO & $\mathrm{N}_{2}$ & $\mathrm{H}_{2}$ & $\mathrm{CO}$ & $\mathrm{N}_{2}$ & \\
\hline TR1 (1) & 50 & 50 & 0 & 0 & 0 & 40 & 225,250 \\
\hline TR2 (2) & 40 & 40 & 0 & 0 & 0 & 40 & 225,250 \\
\hline TR3 (3) & 50 & 50 & 40 & 0 & 0 & 0 & 225,250 \\
\hline TR4 (4) & 40 & 40 & 40 & 0 & 0 & 0 & 225,250 \\
\hline TR5 (5) & 40 & 50 & 0 & 0 & 0 & 40 & 225,250 \\
\hline TR6 (6) & 50 & 40 & 0 & 0 & 0 & 40 & 225,250 \\
\hline TR7 (7) & 40 & 50 & 40 & 0 & 0 & 0 & 225,250 \\
\hline TR8 (8) & 50 & 40 & 40 & 0 & 0 & 0 & 225,250 \\
\hline TR9 (9) & 50 & 50 & 100 & 0 & 0 & 0 & 250 \\
\hline TR10 (10) & 70 & 70 & 0 & 0 & 0 & 0 & 250 \\
\hline
\end{tabular}

* Numbers are for experiments at $250^{\circ} \mathrm{C}$, and are used later in graphs. 


\section{DATA ANALYSIS AND RESULTS}

\subsection{Analysis of Experiments for Membrane Characterization}

For the experiments on membrane characterization, the compositions of the permeate and the retentate streams from the reactor were obtained from the two gas chromatographs as mentioned before. The values of the fluxes and the permeances of $\mathrm{H}_{2}, \mathrm{CO}$, and $\mathrm{N}_{2}$ through the membrane tube were obtained by performing material balances for the gases.

$$
\begin{aligned}
& F_{\mathrm{H} 2 \text { in }}=F_{\mathrm{r}} \cdot \mathrm{x}_{\mathrm{H} 2}+\mathrm{F}_{\mathrm{p}} \cdot \mathrm{y}_{\mathrm{H} 2} \\
& \mathrm{~F}_{\mathrm{COin}}=\mathrm{F}_{\mathrm{r}} \cdot \mathrm{x}_{\mathrm{CO}}+\mathrm{F}_{\mathrm{p}} \cdot \mathrm{y}_{\mathrm{CO}} \\
& \mathrm{F}_{\text {totalin }}=\mathrm{F}_{\mathrm{p}}+\mathrm{F}_{\mathrm{r}}
\end{aligned}
$$

where $F_{p}=$ flow rate of permeate stream $\left(\mathrm{cm}^{3} / \mathrm{min}\right.$ at $\left.\mathrm{STP}\right), \mathrm{F}_{\mathrm{r}}=$ flow rate of retentate stream $\left(\mathrm{cm}^{3} / \mathrm{min}\right.$ at STP), $\mathrm{F}_{\text {Coin }}=$ total feed flow rate of $\mathrm{CO}$ through the membrane reactor $\left(\mathrm{cm}^{3} / \mathrm{min}\right.$ at STP), $\mathrm{F}_{\mathrm{H} 2 \mathrm{in}}=$ total feed flow rate of $\mathrm{H}_{2}$ through the membrane reactor $\left(\mathrm{cm}^{3} / \mathrm{min}\right.$ at STP), $\mathrm{F}_{\text {totalin }}=$ total feed flow rate of $\mathrm{H}_{2}$ and $\mathrm{CO}$ through the membrane reactor $\left(\mathrm{cm}^{3} / \mathrm{min}\right.$ at STP), $\mathrm{x}_{\mathrm{H} 2}=$ mole-fraction of tube-side $\mathrm{H}_{2}, \mathrm{y}_{\mathrm{H} 2}=$ mole-fraction of shell-side $\mathrm{H}_{2}, \mathrm{x}_{\mathrm{CO}}=$ mole-fraction of tube-side $\mathrm{CO}$, and $\mathrm{y}_{\mathrm{CO}}=$ mole-fraction of shell-side $\mathrm{CO}$.

Equations 5 and 6 were solved simultaneously to obtain $F_{p}$ and $F_{r}$ at a single flow condition and temperature. These values of $F_{p}$ and $F_{r}$ were put in Equation 7 to obtain $F_{\text {totalin. }}$. As the total flow rate of the gases flowing in is the sum of the inlet flow rates of $\mathrm{H}_{2}, \mathrm{CO}$, and $\mathrm{N}_{2}$, this known sum was checked to be equal to the above obtained $\mathrm{F}_{\text {totalin. This }}$ procedure was repeated for every flow condition and temperature. 
The shell-side fluxes $\mathrm{J}_{\mathrm{H} 2}$ and $\mathrm{J}_{\mathrm{CO}}$ of $\mathrm{H}_{2}$ and $\mathrm{CO}$ respectively were calculated from:

$$
J_{i}=\frac{\left(F_{p} \cdot y_{i}\right) \cdot P_{a}}{A \cdot R \cdot T_{a}}
$$

The tube-side fluxes $\mathrm{J}_{\mathrm{N} 2}$ of $\mathrm{N}_{2}$ were calculated from

$$
\mathrm{J}_{\mathrm{N} 2}=\frac{\left(\mathrm{F}_{\mathrm{r}} \cdot \mathrm{X}_{\mathrm{N} 2}\right) \cdot \mathrm{Pa}_{\mathrm{a}}}{\mathrm{A} \cdot \mathrm{R} \cdot \mathrm{T}_{\mathrm{a}}}
$$

where $i=\mathrm{H}_{2}$ or $\mathrm{CO}, \mathrm{A}=$ membrane permeation area $\left(\mathrm{m}^{2}\right), \mathrm{p}_{\mathrm{a}}=$ ambient pressure (one atm), $\mathrm{R}=$ Universal gas constant $(0.082 \mathrm{lit} . \mathrm{atm} / \mathrm{mol} / \mathrm{K}), \mathrm{T}_{\mathrm{a}}=$ standard temperature $(298 \mathrm{~K})$, $\mathrm{x}_{\mathrm{N} 2}=$ mole-fraction of tube-side $\mathrm{N}_{2}$.

Table 4 shows the results for the fluxes through the membrane. The permeances, $\mathrm{P}_{\mathrm{H} 2}, \mathrm{P}_{\mathrm{CO}}, \mathrm{P}_{\mathrm{N} 2}$, of all three gases were calculated from Equations 1 and 2 given in the Literature Review, Chapter 2, reproduced below :

$$
\begin{aligned}
& P_{i}=\frac{\left(F C_{i}\right)_{\text {sweep }}}{A P_{\text {total }} \Delta_{m, i}} \\
& \Delta_{m, i}=\frac{\Delta C_{1}-\Delta C_{2}}{\ln \left(\Delta C_{1} / \Delta C_{2}\right)}
\end{aligned}
$$

where $i=\mathrm{H}_{2}$, $\mathrm{CO}$ (see section 2.2 for review of symbols). During the calculation of the permeance of $\mathrm{N}_{2}$, the retentate flow rate $\left(\mathrm{F}_{\mathrm{r}}\right)$ and concentration $\mathrm{C}_{\mathrm{N} 2}$ were used in place of the sweep flow rate and concentration, as $\mathrm{N}_{2}$ was fed on the shell side. Table 5 shows the results of the permeances through the membrane. 
Table 4

\section{Results of Fluxes through the Membrane Tube}

\begin{tabular}{|c|c|c|c|c|c|c|c|}
\hline \multirow{2}{*}{$\begin{array}{c}\text { Flow } \\
\text { Condition } \\
\text { (Number) }\end{array}$} & \multicolumn{2}{|c|}{$\begin{array}{l}\text { Tube Side Feed } \\
\text { (cc STP/min) }\end{array}$} & \multirow{2}{*}{$\begin{array}{l}\text { Shell Side Feed } \\
\text { (cc STP/min) } \\
\mathrm{N} 2\end{array}$} & \multirow{2}{*}{$\begin{array}{c}\text { Temperature } \\
\left({ }^{\circ} \mathrm{C}\right)\end{array}$} & \multicolumn{3}{|c|}{ Flux $\left(\mathrm{mol} / \mathrm{m}^{2} / \mathrm{sec}\right) \times 10^{3}$} \\
\hline & $\mathrm{H} 2$ & $\mathrm{CO}$ & & & $\mathrm{H} 2$ & $\mathrm{CO}$ & N2 \\
\hline MC1 (1) & 80 & 20 & 50 & 200 & 2.751 & 0.349 & 6.67 \\
\hline MC1 (2) & 80 & 20 & 50 & 250 & 2.198 & 0.302 & 6.258 \\
\hline MC1 (3) & 80 & 20 & 50 & 300 & 1.84 & 0.298 & 5.73 \\
\hline MC2 (4) & 50 & 50 & 150 & 200 & 3.42 & 3.02 & 22.6 \\
\hline MC2 (5) & 50 & 50 & 150 & 250 & 2.907 & 2.556 & 22.05 \\
\hline MC2 (6) & 50 & 50 & 150 & 300 & 2.263 & 1.825 & 23.76 \\
\hline $\operatorname{MC} 3(7)$ & 20 & 80 & 50 & 200 & 0.784 & 3.3 & 8.4 \\
\hline MC3 (8) & 20 & 80 & 50 & 250 & 0.66 & 2.47 & 7.29 \\
\hline MC3 (9) & 20 & 80 & 50 & 300 & 0.554 & 2.074 & 6.75 \\
\hline
\end{tabular}


Table 5

Results of Permeances through the Membrane Tube

\begin{tabular}{|c|c|c|c|c|c|c|c|}
\hline $\begin{array}{c}\text { Flow } \\
\text { Condition } \\
\text { (Number) }\end{array}$ & \multicolumn{2}{|c|}{$\begin{array}{c}\text { Tube Side Feed } \\
\text { (cc/min) }\end{array}$} & $\begin{array}{c}\text { Shell Side Feed } \\
\text { (cc STP/min) }\end{array}$ & $\begin{array}{c}\text { Temperature } \\
\left({ }^{\circ} \mathrm{C}\right)\end{array}$ & \multicolumn{3}{|c|}{$\begin{array}{c}\text { Permeance } \\
\left(\mathrm{mol} / \mathrm{min} / \mathrm{m}^{2} / \mathrm{Pa}\right)\end{array}$} \\
\hline $\mathrm{H} 2$ & $\mathrm{CO}$ & $\mathrm{N} 2$ & & \\
\hline MC1 (1) & 80 & 20 & 50 & 200 & 0.905 & 0.353 & 2.435 \\
\hline MC1 (2) & 80 & 20 & 50 & 250 & 0.744 & 0.329 & 2.05 \\
\hline MC1 (3) & 80 & 20 & 50 & 300 & 0.623 & 0.305 & 1.89 \\
\hline MC2 (4) & 50 & 50 & 150 & 200 & 2.39 & 2.376 & 8.35 \\
\hline MC2 (5) & 50 & 50 & 150 & 250 & 2.042 & 2.01 & 10.23 \\
\hline MC2 (6) & 50 & 50 & 150 & 300 & 1.588 & 1.435 & 10.9 \\
\hline MC3 (7) & 20 & 80 & 50 & 200 & 1.176 & 1.64 & 3.29 \\
\hline MC3 (8) & 20 & 80 & 50 & 250 & 1.21 & 1.17 & 5.88 \\
\hline MC3 (9) & 20 & 80 & 50 & 300 & 0.823 & 1.035 & 3.65 \\
\hline
\end{tabular}


The separation factors of $\mathrm{H}_{2}$ over $\mathrm{CO}$ were calculated from the Equation 3 given in the Literature Review, Chapter 2, reproduced below :

$$
\alpha_{H 2 / C O}=\frac{\left(C_{H_{2}} / C_{C O}\right)_{\text {sweep }}}{\left(C_{H_{2}} / C_{C O}\right)_{\text {retentate }}}
$$

(see section 2.2 for review of symbols).

Table 6 gives the results of the separation factors of $\mathrm{H}_{2}$ over $\mathrm{CO}$ through the membrane.

\subsection{Analysis of Data from Packed Bed Reactors}

The experimental data obtained from the packed-bed tubular reactor and the packed-bed membrane reactor were the compositions of the gas streams leaving the reactor. As methanol was the only product observed in these gas streams, the conversions of $\mathrm{CO}$ to methanol were calculated by taking a carbon balance. As one mole of $\mathrm{CO}$ reacts to give one mole of methanol, each mole of methanol observed corresponds to a mole of $\mathrm{CO}$ reacted. Therefore, the conversions of $\mathrm{CO}\left(\mathrm{X}_{\mathrm{CO}}\right)$ for the experiments in both the reactors were calculated by :

$$
X_{C O}=\frac{\frac{A_{M e o h}}{w_{M e o h}}}{\frac{A_{M e o h}}{w_{M e o H}}+\frac{A_{C O}}{w_{C O}}}
$$

where $\mathrm{A}_{\mathrm{CO}}=$ gas chromatograph area of $\mathrm{CO}$ in the mixture stream of retentate and permeate (counts), $A_{\text {meoh }}=$ gas chromatograph area of methanol in the mixture stream of retentate and permeate (counts), $\mathrm{w}_{\mathrm{CO}}=$ response factor of $\mathrm{CO}$ relative to nitrogen in the gas chromatograph, $\mathrm{w}_{\mathrm{MeoH}}=$ response factor of methanol relative to nitrogen in gas chromatograph, $\mathrm{X}_{\mathrm{CO}}=$ conversion of CO. 
Table 6

\section{Results for Separation factors of $\underline{\mathrm{H}_{2}} \underline{\text { over }} \underline{\mathrm{CO}}$}

in the Membrane Tube

$$
\begin{aligned}
\text { Ideal value } & =\sqrt{(\mathrm{Mol} . \mathrm{Wt} \text { of } \mathrm{CO}) /\left(\mathrm{Mol} . \mathrm{Wt} \text { of } \mathrm{H}_{2}\right)} \\
= & 3.74
\end{aligned}
$$

\begin{tabular}{|c|c|c|c|c|c|}
\hline $\begin{array}{c}\text { Flow } \\
\text { Condition } \\
\text { (Number) }\end{array}$ & $\begin{array}{l}\text { Tube } \\
\text { (cc) }\end{array}$ & $\begin{array}{l}\text { Feed } \\
\min )\end{array}$ & $\begin{array}{l}\text { Shell Side Feed } \\
\text { (cc STP/min) }\end{array}$ & $\begin{array}{c}\text { Temperature } \\
\left({ }^{\mathrm{o}} \mathrm{C}\right)\end{array}$ & $\begin{array}{c}\text { Separation } \\
\text { factor of } \mathrm{H}_{2} \\
\text { over } \mathrm{CO}\end{array}$ \\
\hline & $\mathrm{H} 2$ & $\mathrm{CO}$ & $\mathrm{N} 2$ & & \\
\hline MC1 (1) & 80 & 20 & 50 & 200 & 2.14 \\
\hline MC1 (2) & 80 & 20 & 50 & 250 & 1.89 \\
\hline MC1 (3) & 80 & 20 & 50 & 300 & 1.69 \\
\hline MC2 (4) & 50 & 50 & 150 & 200 & 1.184 \\
\hline MC2 (5) & 50 & 50 & 150 & 250 & 1.189 \\
\hline MC2 (6) & 50 & 50 & 150 & 300 & 1.29 \\
\hline MC3 (7) & 20 & 80 & 50 & 200 & 0.94 \\
\hline MC3 (8) & 20 & 80 & 50 & 250 & 1.077 \\
\hline MC3 (9) & 20 & 80 & 50 & 300 & 1.084 \\
\hline
\end{tabular}


The peak areas (A) were the data obtained from the gas chromatographs, and the response factors (w) were determined experimentally as discussed previously in Chapter 3.

In order to develop a model for the packed-bed membrane reactor, a rate expression for the conversion of $\mathrm{CO}$ to methanol was obtained from the experimental conversion data of the packedbed tubular reactor. The method for obtaining this rate expression is described below.

\subsubsection{Rate-Expression for Methanol Synthesis}

The rates of methanol formation $\left(\mathrm{r}_{\mathrm{MeoH}}\right)$ in the packed-bed tubular reactor were calculated from the conversions of $\mathrm{CO}$ using :

$$
r_{M e o H}=\frac{\left(X_{C O}\right) \cdot\left(F_{C O i n}\right) \cdot P_{a}}{W_{c a t} \cdot R \cdot T_{a}} \quad(\mathrm{~mol} / \mathrm{min} / \mathrm{kgcat})
$$

where $\mathrm{W}_{\text {cat }}=$ weight of catalyst $(\mathrm{Kg})$. The experimental values of the conversions and the rates are given in Table 7. These correspond to the flow conditions given in Table 3. To fit these rates, a rate expression of the power-law form for $\mathrm{H}_{2}$ and $\mathrm{CO}$ was assumed :

$$
\mathrm{r}_{\mathrm{MeoH}}=\mathrm{k} \cdot\left(\mathrm{C}_{\mathrm{CO}}\right)^{\mathrm{a}} \cdot\left(\mathrm{C}_{\mathrm{H} 2}\right)^{\mathrm{b}} \quad(\mathrm{mol} / \mathrm{min} / \mathrm{kgcat})
$$

The rates were fitted with this expression and the values of the associated constants $\mathrm{k}$, a and $\mathrm{b}$ were determined.

The rate expression assumed an irreversible reaction. As the conversions in the packed-bed tubular reactor were low, the concentrations of $\mathrm{H}_{2}$ and $\mathrm{CO}$ used in the rate expression were the averages of the inlet and the outlet concentrations. The results of the fitted values of $\mathrm{a}, \mathrm{b}$, and $\mathrm{k}$ were :

$$
a=0.75
$$


Table 7

Experimental Conversions, Rates, and Fitted rates for

Packed-Bed Tubular Reactor Experiments at $\mathbf{T}=250^{\circ} \mathrm{C}$

\begin{tabular}{|c|c|c|c|c|}
\hline $\begin{array}{c}\text { Flow } \\
\text { Condition } \\
\text { (Number) }\end{array}$ & $\begin{array}{c}\text { Experimental } \\
\text { CO Conversion } \\
(\%)\end{array}$ & $\begin{array}{l}\text { Experimental Rates } \\
\text { (mol/min/kgcat.) }\end{array}$ & $\begin{array}{c}\text { Fitted Rates for } \\
\text { Power-Law } \\
\text { Rate Expression, } \\
\text { Equation } 12 \\
\text { (mol/min/kgcat.) }\end{array}$ & $\begin{array}{l}\text { Fitted Rates for } \\
\text { 8-Parameter } \\
\text { Rate Expression, } \\
\text { Equation } 13 \\
\text { (mol/min/kgcat.) }\end{array}$ \\
\hline & & & & \\
\hline TR1 (1) & 3.5 & 0.1429 & 0.1409 & 0.141 \\
\hline TR2 (2) & 3.95 & 0.1290 & 0.1406 & 0.1403 \\
\hline TR3 (3) & 1.52 & 0.0620 & 0.0722 & 0.0722 \\
\hline $\mathrm{TR} 4$ (4) & 1.7 & 0.0555 & 0.0626 & 0.0628 \\
\hline TR5 (5) & 3.35 & 0.1367 & 0.1304 & 0.1304 \\
\hline TR6 (6) & 4.7 & 0.1535 & 0.1474 & 0.1475 \\
\hline TR7 (7) & 1.65 & 0.0670 & 0.0627 & 0.0624 \\
\hline TR8 (8) & 2.25 & 0.0735 & 0.0706 & 0.0710 \\
\hline TR9 (9) & 1.1 & 0.0449 & 0.0352 & 0.0352 \\
\hline
\end{tabular}




$$
\begin{aligned}
& \mathrm{b}=1.27 \\
& \mathrm{k}=467820 \quad\left(\mathrm{~cm}^{6.06} / \mathrm{mol}^{1.02} / \mathrm{min} / \mathrm{kgcat}\right)
\end{aligned}
$$

The $\mathrm{r}^{2}$ value for the fit was 0.95 . The fitted rates calculated from the Equation 12 are also given in Table 7. Figure 4 shows a plot of the fitted rates against the experimental rates.

Another rate expression derived from a kinetic model given in the literature [30,31] for the production of higher alcohols was also used for fitting the rate-data. The expression is given by :

$$
r_{\mathrm{MeoH}}=\frac{\left(k 1 \cdot p_{\mathrm{CO}} \cdot p_{\mathrm{H} 2}-k 2 \cdot p_{\mathrm{MeOH}} / p_{\mathrm{H} 2}\right)}{\left(1+k 4 \cdot p_{\mathrm{H} 2}^{0.5} \cdot p_{\mathrm{CO}}+k 5 \cdot \frac{p_{\mathrm{MeOH}}}{p_{\mathrm{H} 2}}+k 6 \cdot p_{\mathrm{MeOH}}+k 7 \cdot p_{\mathrm{CO}}\right) \cdot\left(1+k 3 \cdot p_{\mathrm{H} 2}^{0.5}\right)}
$$

where $\mathrm{k} 1, \mathrm{k} 2, \mathrm{k} 3, \mathrm{k} 4, \mathrm{k} 5, \mathrm{k} 6, \mathrm{k} 7$ are rate constants, $\mathrm{p}_{\mathrm{CO}}=$ partial pressure of $\mathrm{CO}(\mathrm{atm}), \mathrm{p}_{\mathrm{H} 2}=$ partial pressure of $\mathrm{H}_{2}(\mathrm{~atm}), \mathrm{p}_{\mathrm{MeoH}}=$ partial pressure of Methanol (atm). The values of the constants $\mathrm{k} 1, \mathrm{k} 2$, $\mathrm{k} 3, \mathrm{k} 4, \mathrm{k} 5, \mathrm{k} 6, \mathrm{k} 7$ associated with this rate expression were:

$$
\begin{aligned}
& \mathrm{k} 1=2.24 \mathrm{e}-4 \mathrm{~mol} / \mathrm{min} / \mathrm{kgcat} / \mathrm{atm}^{2} \\
& \mathrm{k} 2=2.85 \mathrm{e}-8 \mathrm{~mol} / \mathrm{min} / \mathrm{kgcat} \\
& \mathrm{k} 3=3.99 \mathrm{e}-9 \mathrm{~atm}^{-0.5} \\
& \mathrm{k} 4=1.56 \mathrm{e}-4 \mathrm{~atm}^{-1.5} \\
& \mathrm{k} 5=1.46 \mathrm{e}-6 \\
& \mathrm{k} 6=5.47 \mathrm{e}-8 \mathrm{~atm}^{-1} \\
& \mathrm{k} 7=0.1 \mathrm{~atm}^{-1}
\end{aligned}
$$

The $\mathrm{r}^{2}$ value for the fit was 0.95 . The calculated values of the rates using equation 13 are also given in Table 7. 
Rate Expression fit for Packed-Bed Tubular Reactor from Power-Law Model (Equation 12)

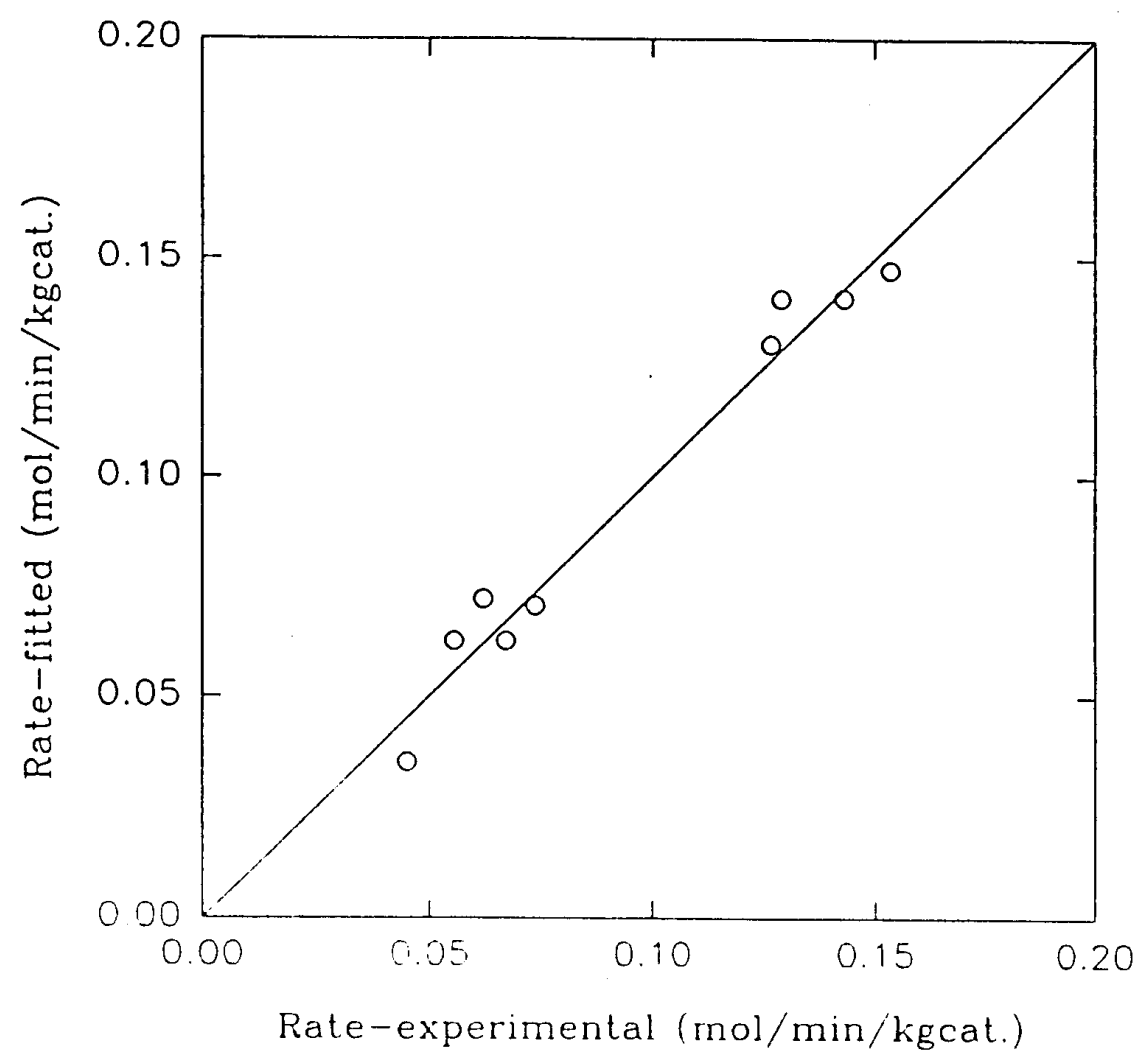

Figure 4 
Figure 5 shows the plot of the fitted rates against the experimental rates.

It can be observed that the values of the rates fitted using Equations 12 and 13 were not very different from each other. The values of $\mathrm{r}^{2}$ are equal upto two significant figures. As Equation 12 was simpler and easier to use than Equation 13, Equation 12 was used as the rate expression for the reaction.

\subsubsection{Packed-Bed Membrane Reactor Data}

The experimental data for studies on the packed-bed membrane reactor are given in Appendix A. As mentioned previously, the experiments for the first flow condition (MR1) were carried out with a fresh sample of the catalyst. The experiments for the flow conditions MR2-to-MR5 shown in Table 2 (Chapter 3, Experimental Design) were carried out with the same sample of catalyst as used for flow condition MR1. Another fresh sample of the catalyst was used for Flow Condition MR6 in Table 2. Experiments for Flow Conditions MR7-to-MR9 were carried out with the same sample of the catalyst used for Flow Condition MR6.

Figures 6-14 show the data of observed conversions for all the flow conditions in the packed bed membrane reactor. The points indicate the observed (experimental) data. It can be noted that, for each catalyst sample, the conversions decreased as time progressed. This indicates catalyst deactivation. Further, it can be seen that the starting values of conversions for each different flow condition were different. For instance, the starting value of conversion for Flow Condition MR1 was greater than that for Flow Condition MR2. Also, the conversions for the same flow condition but at different temperatures were different (for example: Flow Condition MR1). 
Rate Expression fit for Packed-Bed Tubular Reactor

from 8-Parameter Model (Equation 13)

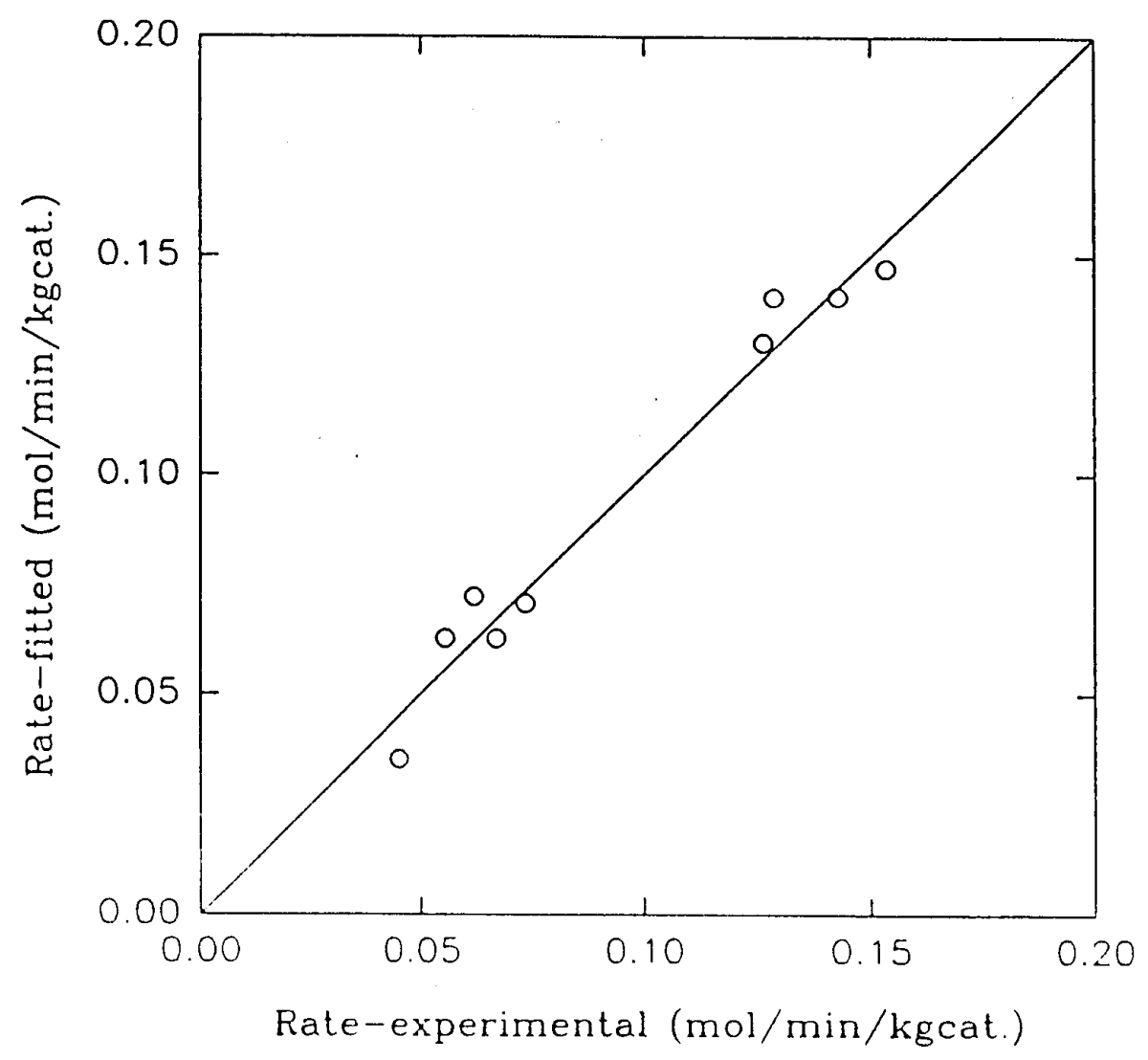

Figure 5 
Overall Fit for Catalyst Aging

Flow Condition MR1

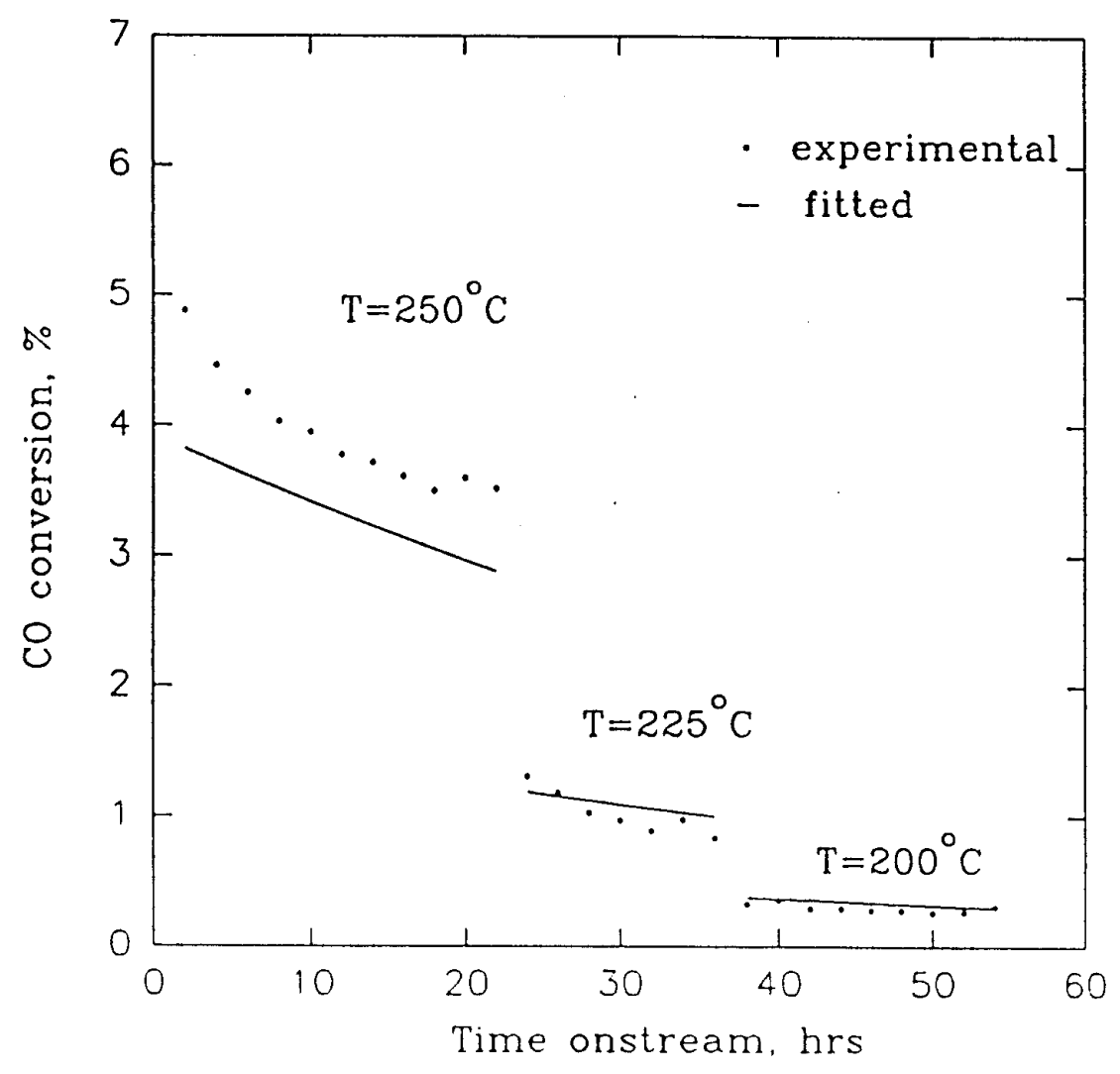

Figure 6 


\section{Overall Fit for Catalyst Aging}

Flow Condition MR2

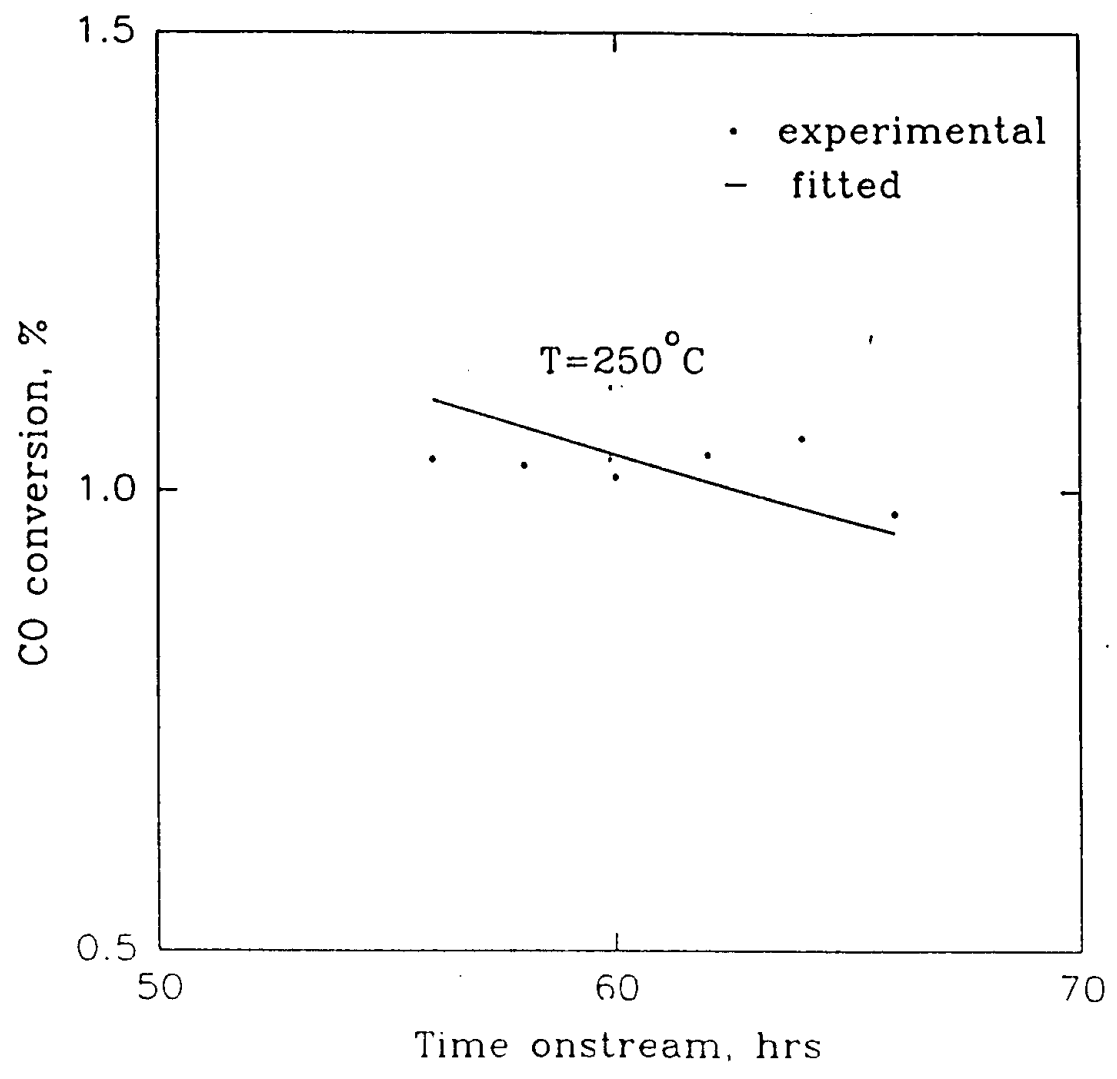

Figure 7 
Overall Fit for Catalyst Aging

Flow Condition MR3

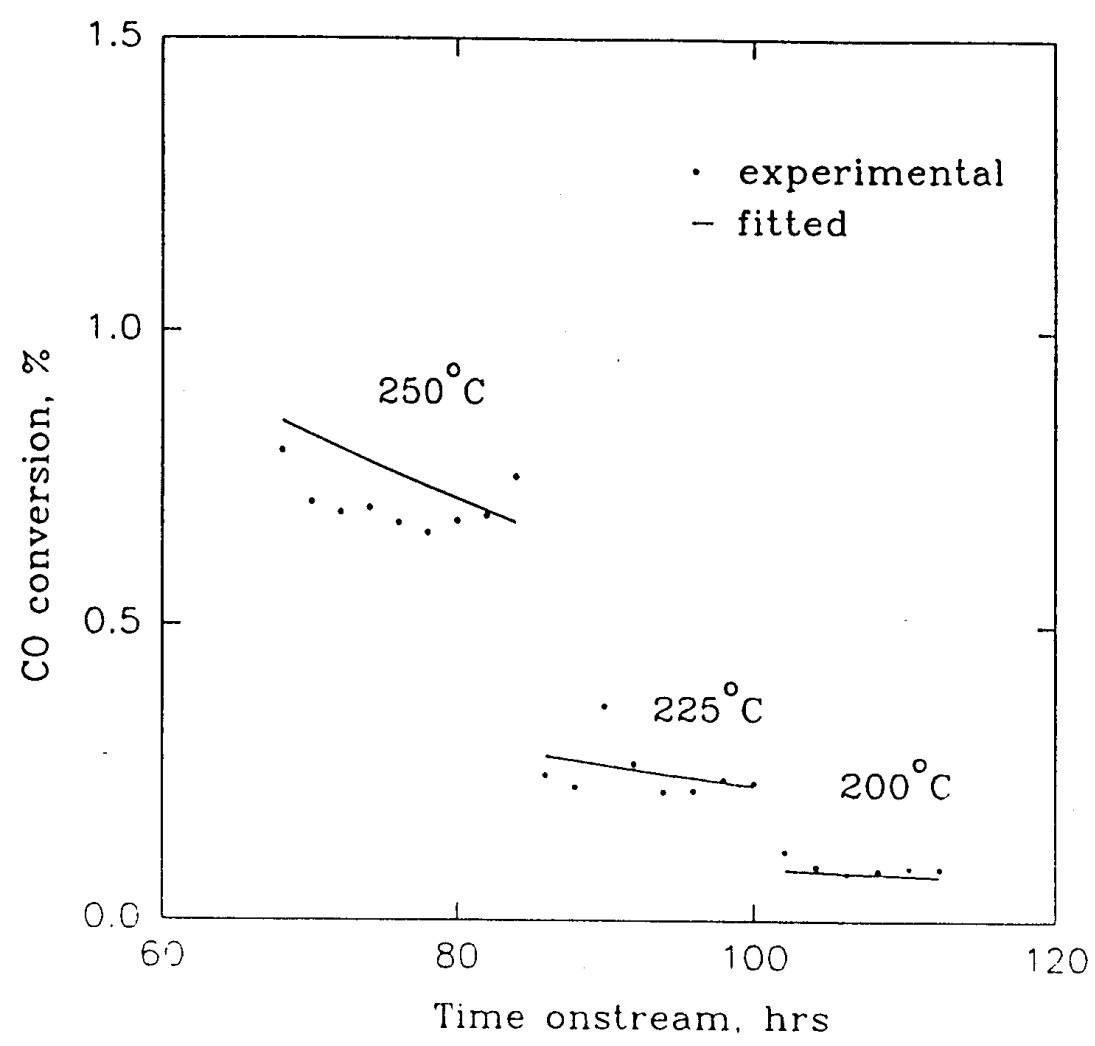

Figure 8 
Overall Fit for Catalyst Aging

Flow Condition MR4

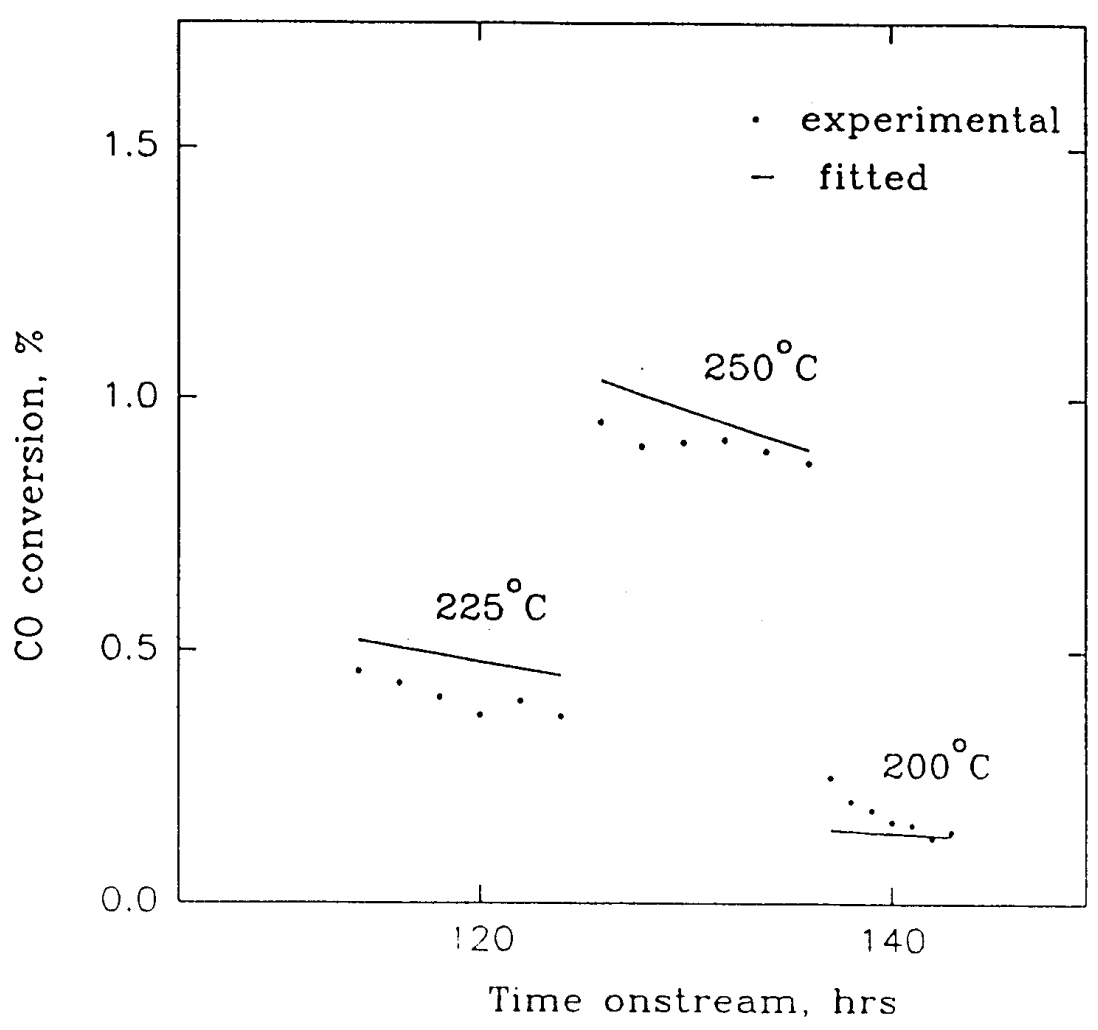

Figure 9 
Overall Fit for Catalyst Aging

Flow Condition MR5

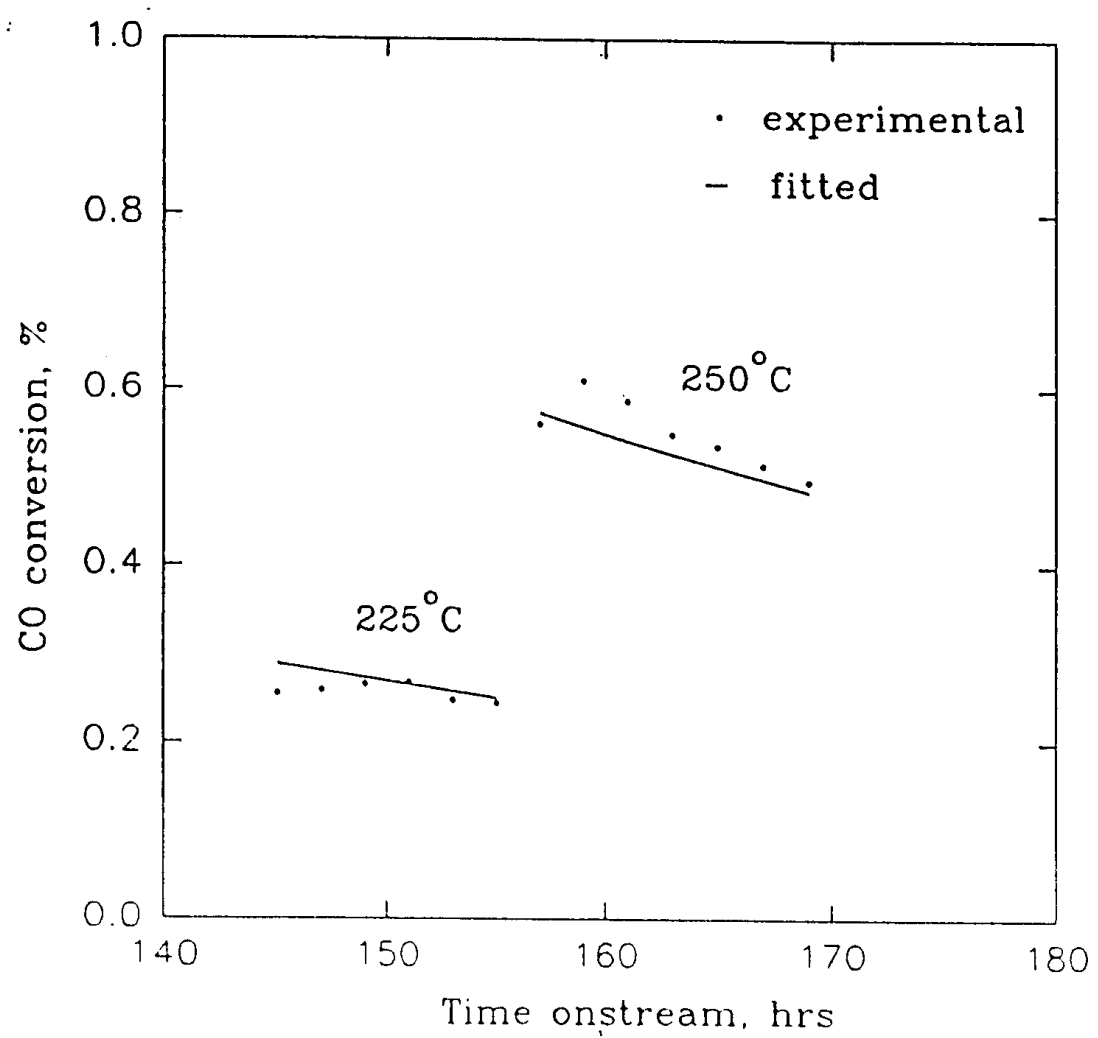

Figure 10 
Overall Fit for Catalyst Aging

Flow Condition MR6

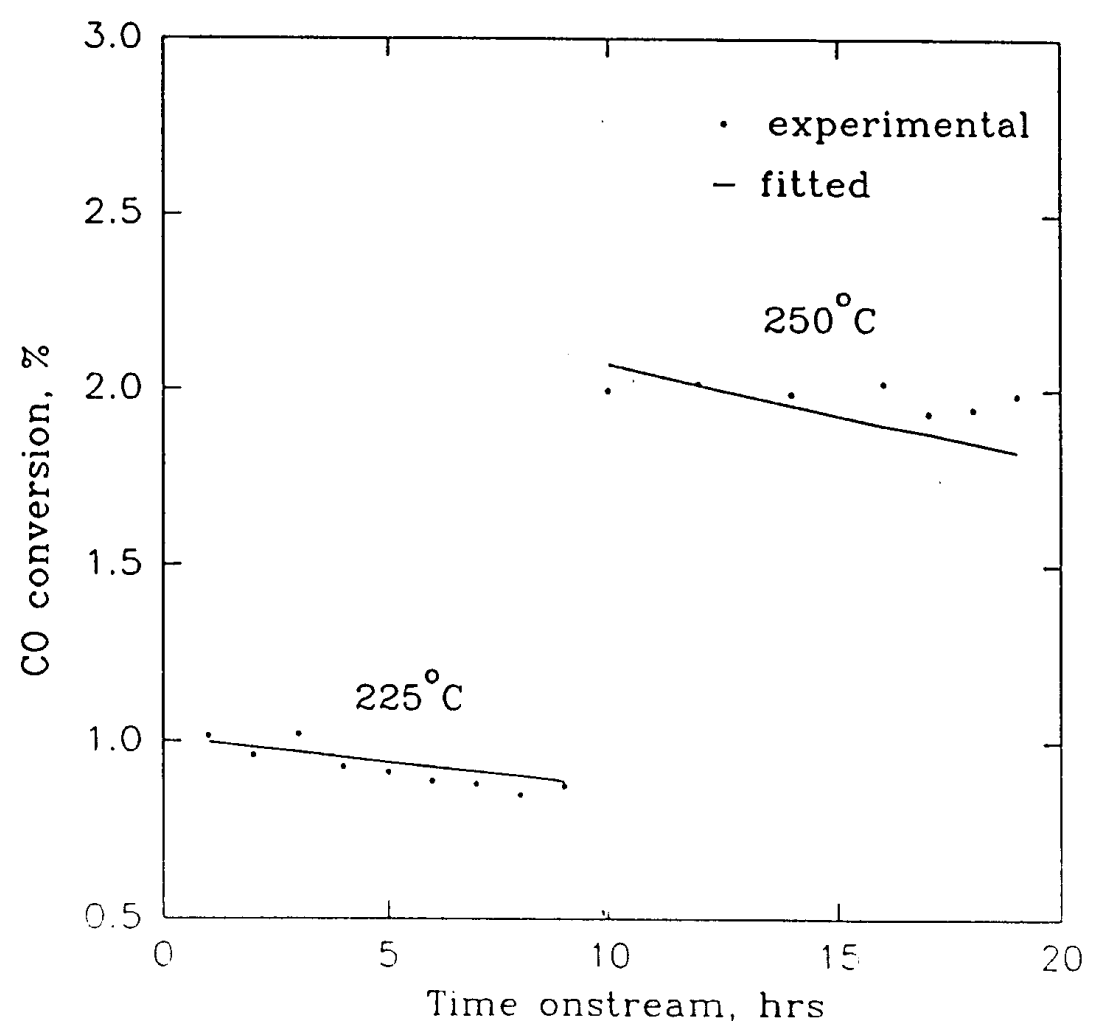

Figure 11 


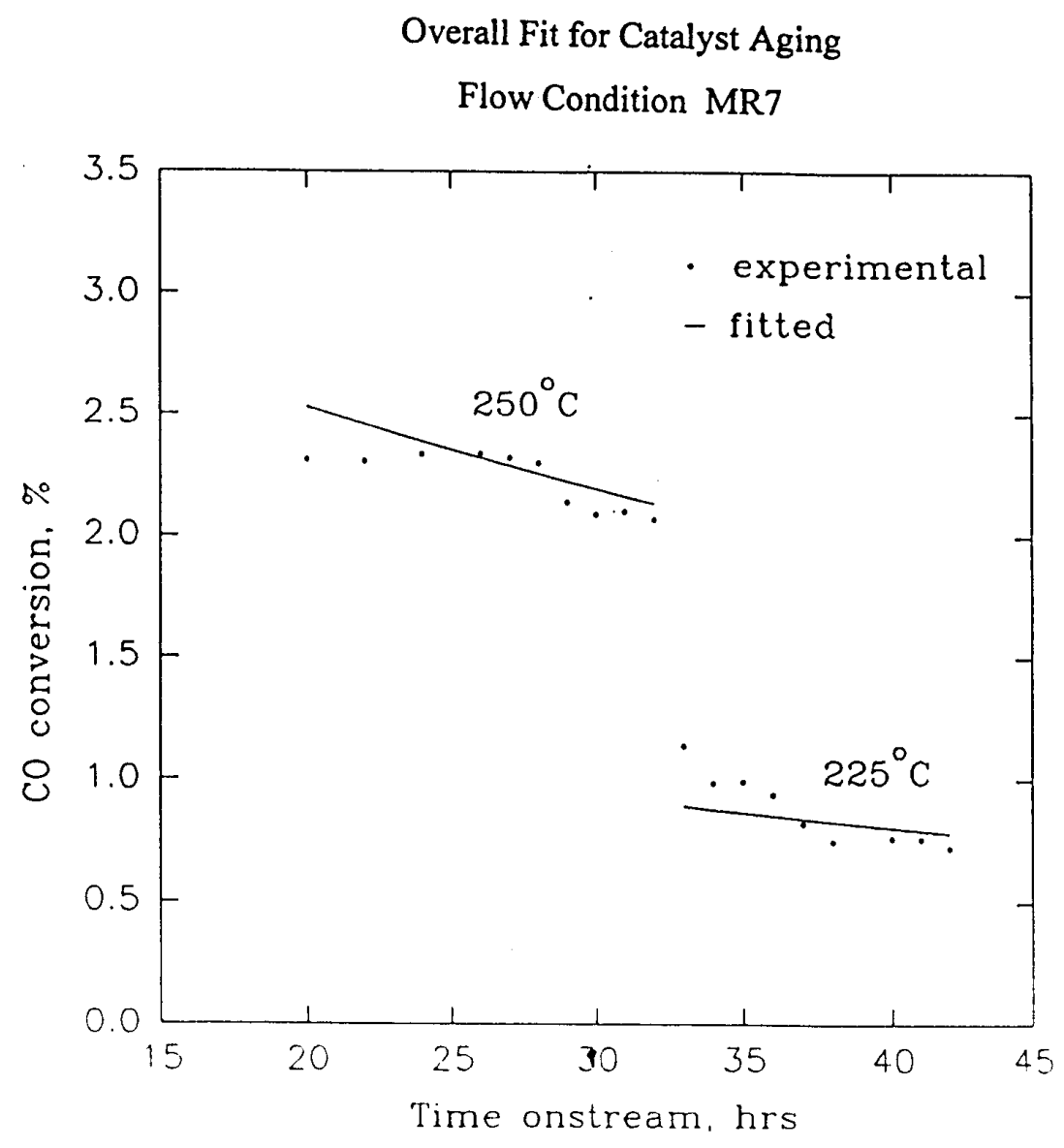

Figure 12 


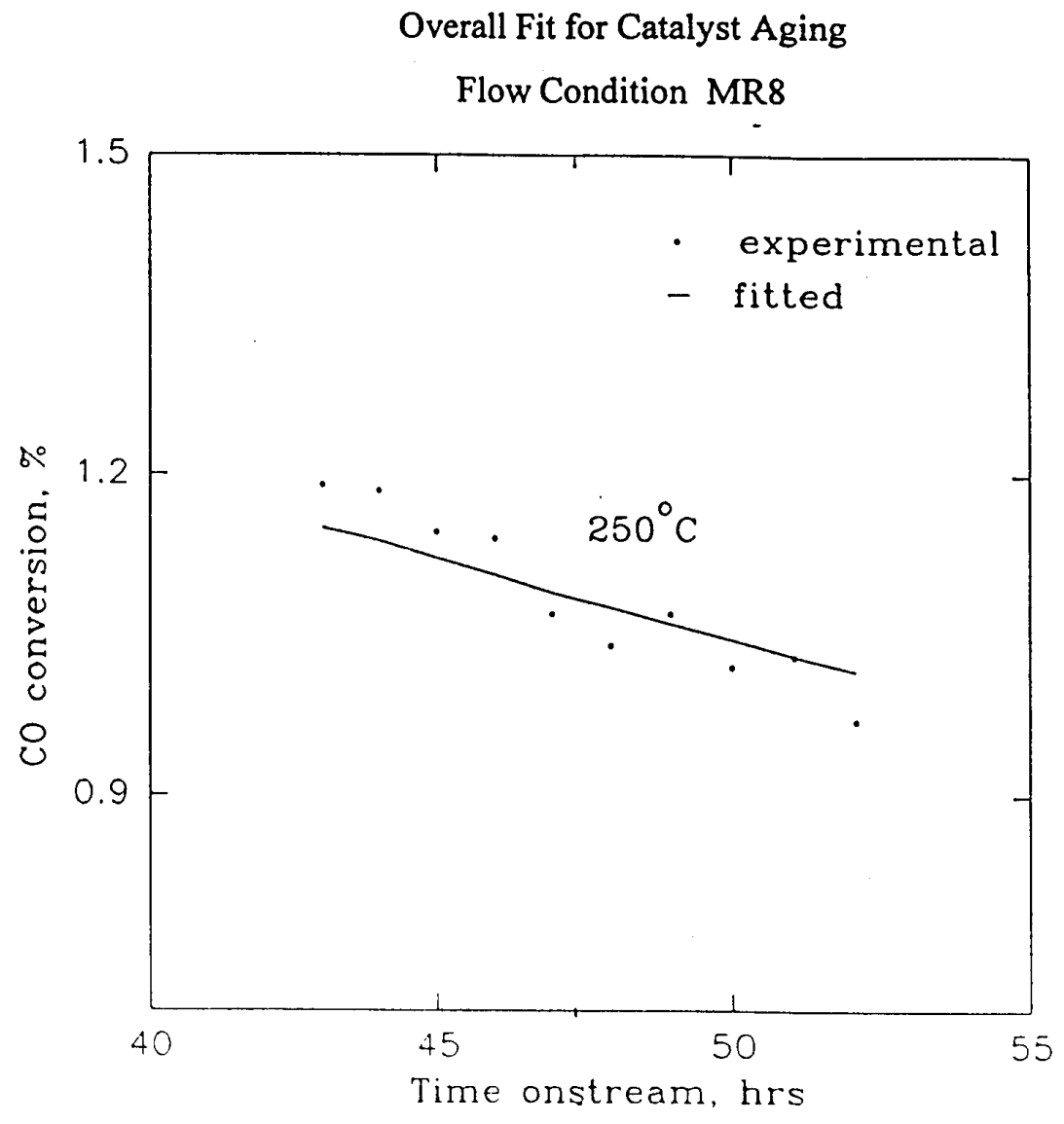

Figure 13 


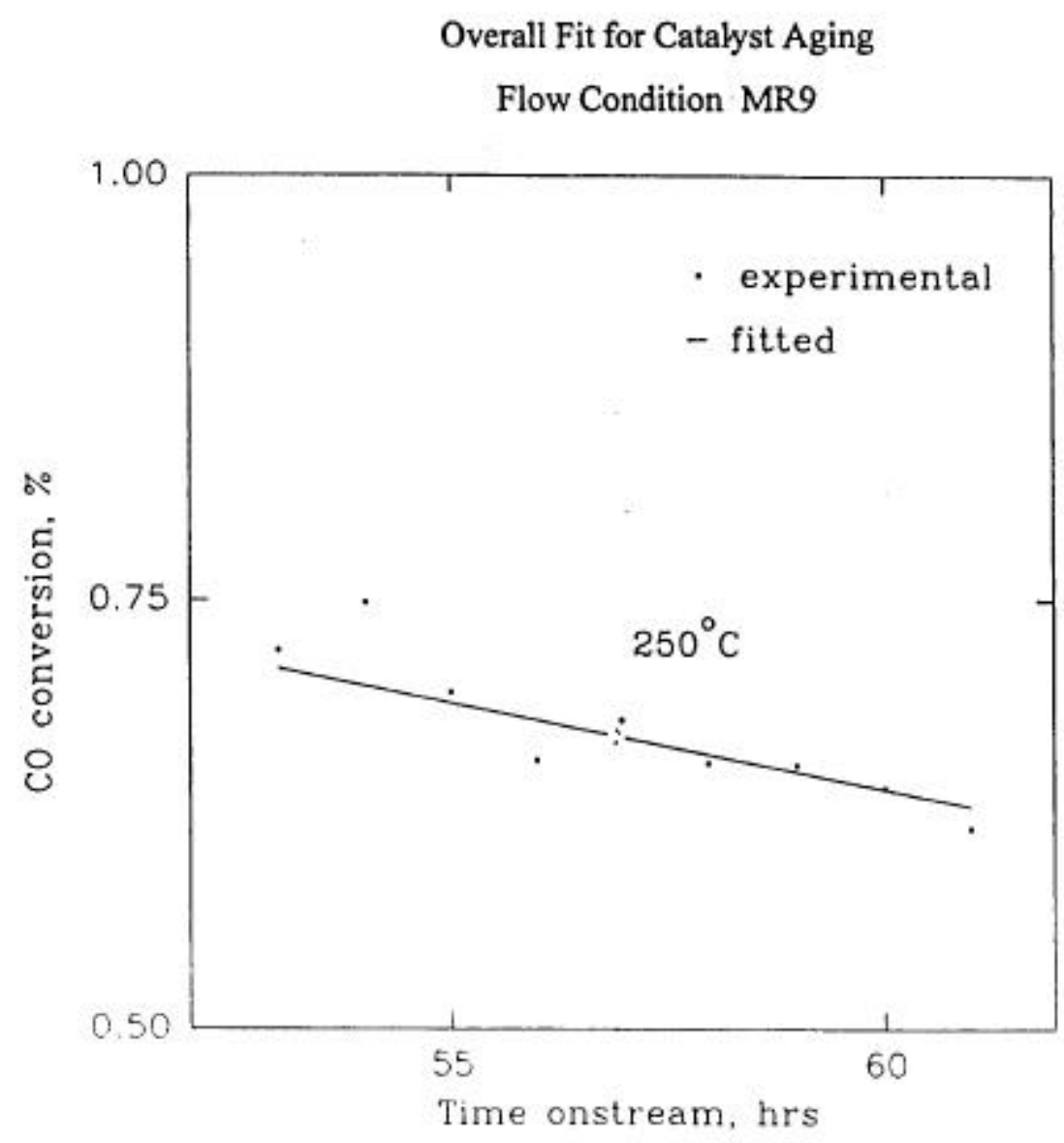

Figure 14 
These observations are discussed below.

\subsubsection{Model for Packed-Bed Membrane Reactor}

In order to explain the observed conversions in the packed-bed membrane reactor, a mathematical model was developed for the reactor. Some simplifying assumptions were made in the model. Since the catalyst pellets are spherical and the ratio of the tube diameter to the catalyst pellet diameter is about 18 , flow inside the tube can be considered to be plug flow. The fluid flow on the shell-side is laminar since, for a flow rate of $100 \mathrm{sccm}$ (standard $\mathrm{cm}^{3} / \mathrm{min}$ ), the Reynolds number is 2.7. Small changes in the total pressure inside the reactor during reactor operation can be neglected. As the catalyst is packed only inside the tube, the absence of any reaction is assumed in the shell side. As the reaction in the catalyst bed and the permeation through the membrane take place simultaneously, the model involves the solution of simultaneous ordinary differential equations incorporating the effect of both the permeation and the reaction in the catalyst bed. Previous work [1] was used for the development of the model. The differential equations are solved by iteration with starting points as the inlet flow rates of the gases through the reactor. A mathematical routine is used which takes these values as parameters and goes through a loop of calculating conversions till the error level and tolerance are reached to the desired values. The tolerance and error can be used as parameters in the program. As methanol is the only product of the reaction, the gases inside the reactor system are $\mathrm{H}_{2}, \mathrm{CO}, \mathrm{N}_{2}$, and methanol. Therefore, the number of differential equations to be solved are eight - one equation for every gas inside the membrane tube, and one equation for every gas on the shell side. 
The relations used for gases inside the tube are :

$$
\begin{aligned}
& \mathrm{df}_{1} / \mathrm{dz}=-2 \cdot\left(\mathrm{r} \cdot \mathrm{RT}_{\mathrm{a}} / \mathrm{p}_{\mathrm{a}}\right) \cdot \pi \mathrm{r}_{1}{ }^{2} \cdot \rho_{\mathrm{b}}-2 \pi \mathrm{r}_{\mathrm{m}} \cdot\left(\mathrm{P}_{\mathrm{H} 2} \cdot \mathrm{R} \cdot \mathrm{T}_{\mathrm{a}} / \mathrm{p}_{\mathrm{a}}\right) \cdot \mathrm{p}_{\mathrm{t}} \cdot\left(\mathrm{x}_{\mathrm{H} 2}-\mathrm{y}_{\mathrm{H} 2}\right) \\
& \mathrm{df}_{2} / \mathrm{dz}=-1 \cdot\left(\mathrm{r} \cdot \mathrm{RT}_{\mathrm{a}} / \mathrm{p}_{\mathrm{a}}\right) \cdot \pi \mathrm{r}_{1}{ }^{2} \cdot \rho_{\mathrm{b}}-2 \pi \mathrm{r}_{\mathrm{m}} \cdot\left(\mathrm{P}_{\mathrm{CO}} \cdot \mathrm{R} \cdot \mathrm{T}_{\mathrm{a}} / \mathrm{p}_{\mathrm{a}}\right) \cdot \mathrm{p}_{\mathrm{t}} \cdot\left(\mathrm{x}_{\mathrm{CO}}-\mathrm{y}_{\mathrm{CO}}\right) \\
& \mathrm{df}_{3} / \mathrm{dz}=-2 \pi \mathrm{r}_{\mathrm{m}} \cdot\left(\mathrm{P}_{\mathrm{N} 2} \cdot \mathrm{R} \cdot \mathrm{T}_{\mathrm{a}} / \mathrm{p}_{\mathrm{a}}\right) \cdot \mathrm{p}_{\mathrm{t}} \cdot\left(\mathrm{x}_{\mathrm{N} 2}-\mathrm{y}_{\mathrm{N} 2}\right) \\
& \mathrm{df}_{4} / \mathrm{dz}=\left(\mathrm{r} \cdot \mathrm{RT}_{\mathrm{a}} / \mathrm{p}_{\mathrm{a}}\right) \cdot \pi \mathrm{r}_{1}{ }^{2} \cdot \rho_{\mathrm{b}}-2 \pi \mathrm{r}_{\mathrm{m}} \cdot\left(\mathrm{P}_{\mathrm{MeoH}} \cdot \mathrm{R} \cdot \mathrm{T}_{\mathrm{a}} / \mathrm{p}_{\mathrm{a}}\right) \cdot \mathrm{p}_{\mathrm{t}} \cdot\left(\mathrm{x}_{\mathrm{MeoH}}-\mathrm{y}_{\mathrm{MeoH}}\right)
\end{aligned}
$$

The relations used for gases on the shell side are :

$$
\begin{aligned}
& \mathrm{df}_{5} / d z=2 \pi r_{\mathrm{m}} \cdot\left(\mathrm{P}_{\mathrm{H} 2} \cdot \mathrm{R} \cdot \mathrm{T}_{\mathrm{a}} / \mathrm{p}_{\mathrm{a}}\right) \cdot \mathrm{p}_{\mathrm{t}} \cdot\left(\mathrm{x}_{\mathrm{H} 2}-\mathrm{y}_{\mathrm{H} 2}\right) \\
& \mathrm{df}_{6} / \mathrm{dz}=2 \pi \mathrm{r}_{\mathrm{m}} \cdot\left(\mathrm{P}_{\mathrm{CO}} \cdot \mathrm{R} \cdot \mathrm{T}_{\mathrm{a}} / \mathrm{p}_{\mathrm{a}}\right) \cdot \mathrm{p}_{\mathrm{t}} \cdot\left(\mathrm{x}_{\mathrm{CO}}-\mathrm{y}_{\mathrm{CO}}\right) \\
& \mathrm{df}_{7} / \mathrm{dz}=2 \pi \mathrm{r}_{\mathrm{m}} \cdot\left(\mathrm{P}_{\mathrm{N} 2} \cdot \mathrm{R} \cdot \mathrm{T}_{\mathrm{a}} / \mathrm{p}_{\mathrm{a}}\right) \cdot \mathrm{p}_{\mathrm{t}} \cdot\left(\mathrm{x}_{\mathrm{N} 2}-\mathrm{y}_{\mathrm{N} 2}\right) \\
& \mathrm{df}_{8} / \mathrm{dz}=2 \pi \mathrm{r}_{\mathrm{m}} \cdot\left(\mathrm{P}_{\mathrm{MeoH}} \cdot \mathrm{R} \cdot \mathrm{T}_{\mathrm{a}} / \mathrm{p}_{\mathrm{a}}\right) \cdot \mathrm{p}_{\mathrm{t}} \cdot\left(\mathrm{x}_{\mathrm{MeoH}}-\mathrm{y}_{\mathrm{MeoH}}\right)
\end{aligned}
$$

where $\mathrm{f}_{1}=$ flow rate of $\mathrm{H}_{2}$ inside the tube $\left(\mathrm{cm}^{3} / \mathrm{min}\right.$ at STP $), \mathrm{f}_{2}=$ flow rate of $\mathrm{CO}$ inside the tube $\left(\mathrm{cm}^{3} / \mathrm{min}\right.$ at STP $), \mathrm{f}_{3}=$ flow rate of $\mathrm{N}_{2}$ inside the tube $\left(\mathrm{cm}^{3} / \mathrm{min}\right.$ at STP $), \mathrm{f}_{4}=$ flow rate of methanol inside the tube $\left(\mathrm{cm}^{3} / \mathrm{min}\right.$ at STP $), \mathrm{f}_{5}=$ flow rate of $\mathrm{H}_{2}$ in the shell side $\left(\mathrm{cm}^{3} / \mathrm{min}\right.$ at $\left.\mathrm{STP}\right), \mathrm{f}_{6}=$ flow rate of $\mathrm{CO}$ in the shell side $\left(\mathrm{cm}^{3} / \mathrm{min}\right.$ at STP $), \mathrm{f}_{7}=$ flow rate of $\mathrm{N}_{2}$ in the shell side $\left(\mathrm{cm}^{3} / \mathrm{min}\right.$ at STP), $\mathrm{f}_{8}=$ flow rate of methanol in the shell side $\left(\mathrm{cm}^{3} / \mathrm{min}\right.$ at STP $), \mathrm{z}=$ distance across the length of tube $(\mathrm{cm}), \mathrm{r}_{\mathrm{m}}=$ log-mean radius of tube $(\mathrm{cm})$. See the 'Symbols and Notations' section for symbols.

As noted earlier, the rate expression used in these equations was the power-law expression (Equation 12), since it was easier to use than the other expression with eight parameters (Equation 13). The conversions predicted by the model for all the flow conditions in the reactor are compared with the observed conversions in the reactor in the next chapter. 


\subsubsection{Catalyst Aging}

As mentioned before, the experimental values of conversions for both the catalyst samples (Figures 6-14) decreased as time progressed. The catalyst deactivates with time. This is in contrast to the values of conversions observed in the packed-bed tubular reactor, where no catalyst deactivation was observed. The deactivation of catalyst sample in the packed-bed membrane reactor is probably due to an unexpected reactor stop during the experiments in that reactor. In order to be able to compare the conversions in the packed-bed membrane reactor with that in the packed-bed tubular reactor for the same flow conditions, the time-dependent conversions for each flow condition need to be extrapolated to zero time. This would give the conversion expected for that flow condition with a fresh catalyst. Therefore the data of time-dependent conversions for each flow condition were fitted with a deactivation equation :

$$
\mathrm{X}_{\mathrm{CO}}=\mathrm{X}_{\mathrm{o}} \cdot \exp (-\mathrm{c} / \mathrm{T}) \cdot \exp (\mathrm{d} . \mathrm{t})
$$

where $\mathrm{Xo}=$ pre-exponential factor, $\mathrm{T}=$ temperature $(\mathrm{K}), \mathrm{c}$ and $\mathrm{d}$ are constants

As the first step, the data of conversions for each individual catalyst-sample were independently fitted to Equation 22. Thus the first catalyst sample had five values of $\mathrm{X}_{\mathrm{o}}$ (one for each flow condition for the first five flow conditions in Table 2) and a single value for each of $\mathrm{c}$ and d. Table 8

shows these values. The $r^{2}$ value for the fit was 0.9635 . The second catalyst-sample had four values of $\mathrm{X}_{\mathrm{o}}$ (for Flow Conditions MR6 through MR9 in Table 2) and a single value for each of $\mathrm{c}$ and $\mathrm{d}$. Table 9 gives these values. The $\mathrm{r}^{2}$ value for this fit was 0.9868 . 
Table 8

Results for fitting catalyst-aging equation

for data taken with sample $A$

(Flow Conditions MR 1-5 as in Table 2)

\begin{tabular}{|c|c|c|c|}
\hline Flow Condition & $\operatorname{Ln}\left(\mathrm{X}_{\mathrm{o}}\right)$ & $\mathrm{c}(\mathrm{K})$ & $\mathrm{d}\left(\mathrm{hr}^{-1}\right)$ \\
\cline { 1 - 2 } MR1 & 18.45 & & \\
\cline { 1 - 2 } MR2 & 17.97 & & \\
\cline { 1 - 2 } MR3 & 17.89 & & \multirow{2}{*}{0.0143} \\
\cline { 1 - 2 } MR4 & 18.91 & & \\
\cline { 1 - 2 } MR5 & 18.76 & & \\
\hline
\end{tabular}


Table 9

Results for fitting catalyst-aging equation

for data taken with sample $B$

(Flow Conditions MR 6-9 as in Table 2)

\begin{tabular}{|c|c|c|c|}
\hline Flow Condition & $\operatorname{Ln}\left(\mathrm{X}_{\mathrm{o}}\right)$ & $\mathrm{c}(\mathrm{K})$ & $\mathrm{d}\left(\mathrm{hr}^{-1}\right)$ \\
\hline MR6 & 17.74 & & \\
\cline { 1 - 2 } MR7 & 18.05 & \multirow{2}{*}{8836.38} & 0.0127 \\
\cline { 1 - 2 } MR8 & 17.58 & & \\
\hline MR9 & 17.22 & & \\
\hline
\end{tabular}


Then the data of conversions given in Appendix A for both the catalyst-samples were fit collectively so as to obtain a single value for each of $\mathrm{c}$ and $\mathrm{d}$. This gave an overall (global) fit for all the data. The values of $X_{o}, c$ and $d$ for this fit are given in Table 10. The $\mathrm{r}^{2}$ value for this overall fit was 0.9664.

It is not reasonable to compare values of $r^{2}$ from Tables 8 and 9 with values of $r^{2}$ from Table 10 as different numbers of points are used. Hence $r^{2}$ was calculated for the parameters of Table 10 only for the first five flow conditions. This value is 0.9491 , lower than the value of $\mathrm{r}^{2}$ from Table 8 . In a similar way, $\mathrm{r}^{2}$ for the last four conditions of Table 10 is 0.9732 , lower than the value of $\mathrm{r}^{2}$ from Table 9. This can be expected, as Table 10 has more adjustable parameters than Tables 8 and 9. It can be noted that the values of the parameters in Tables 8 and 9 are not much different from those in Table 10. Moreover, it would seem reasonable that different samples of the same catalyst have the same activation energy and aging characteristics. Therefore, the parameters from Table 10 were used in the expression for catalyst aging for all the flow conditions. The lines in Figures 6-14 represent the fitted conversions for every flow condition using the parameters from Table 10. The values of the conversions for all the flow conditions were extrapolated to zero time. Table 11 shows the results of the extrapolated values of the conversions in the packed-bed membrane reactor. 
Table 10

Results for fitting aging equation for data taken with both catalyst-samples together

(Flow Conditions MR1-9 as in Table 2)

\begin{tabular}{|c|c|c|c|}
\hline Flow Condition & $\operatorname{Ln}\left(X_{0}\right)$ & $\mathrm{c}(\mathrm{K})$ & $\mathrm{d}\left(\mathrm{hr} \mathrm{r}^{-1}\right)$ \\
\hline MR1 & 18.45 & \multirow{9}{*}{8933.15} & \multirow{9}{*}{0.0141} \\
\hline MR2 & 17.96 & & \\
\hline MR3 & 17.87 & & \\
\hline MR4 & 18.89 & & \\
\hline MR5 & 18.74 & & \\
\hline MR6 & 17.95 & & \\
\hline MR7 & 18.28 & & \\
\hline MR8 & 17.83 & & \\
\hline MR9 & 17.49 & & \\
\hline
\end{tabular}


Table 11

\section{Results for Packed-Bed Membrane Reactor}

\begin{tabular}{|c|c|c|c|c|c|c|c|c|}
\hline \multirow{2}{*}{$\begin{array}{c}\text { Flow } \\
\text { Condition } \\
\text { (Number)** }\end{array}$} & \multirow[t]{2}{*}{$\begin{array}{l}\text { Catalyst } \\
\text { Sample }\end{array}$} & \multicolumn{2}{|c|}{$\begin{array}{l}\text { Tube Side Feed } \\
\text { (cc STP/min) }\end{array}$} & \multicolumn{3}{|c|}{$\begin{array}{l}\text { Shell Side Feed } \\
\text { (cc STP/min) }\end{array}$} & \multirow[t]{2}{*}{$\begin{array}{c}\text { Temperature } \\
\left({ }^{\mathrm{o}} \mathrm{C}\right)\end{array}$} & \multirow[t]{2}{*}{$\begin{array}{c}\text { Conversion * } \\
(\%)\end{array}$} \\
\hline & & $\mathrm{H}_{2}$ & $\mathrm{CO}$ & $\mathrm{H}_{2}$ & $\mathrm{CO}$ & $\mathrm{N}_{2}$ & & \\
\hline \multirow{3}{*}{ MR1 (1) } & \multirow{3}{*}{ A } & 50 & 50 & 0 & 0 & 40 & 250 & 3.93 \\
\hline & & 50 & 50 & 0 & 0 & 40 & 225 & 1.67 \\
\hline & & 50 & 50 & 0 & 0 & 40 & 200 & 0.65 \\
\hline MR2 (2) & A & 50 & 50 & 0 & 0 & 60 & 250 & 2.41 \\
\hline \multirow{3}{*}{ MR3 (3) } & \multirow{3}{*}{ A } & 50 & 50 & 0 & 0 & 100 & 250 & 2.20 \\
\hline & & 50 & 50 & 0 & 0 & 100 & 225 & 0.93 \\
\hline & & 50 & 50 & 0 & 0 & 100 & 200 & 0.36 \\
\hline \multirow{3}{*}{ MR4 (4) } & \multirow{3}{*}{ A } & 40 & 40 & 0 & 0 & 40 & 225 & 2.59 \\
\hline & & 40 & 40 & 0 & 0 & 40 & 250 & 6.0 \\
\hline & & 40 & 40 & 0 & 0 & 40 & 200 & 1.0 \\
\hline \multirow[t]{2}{*}{ MR5 (5) } & \multirow[t]{2}{*}{$\mathrm{A}$} & 40 & 40 & 10 & 10 & 40 & 225 & 2.23 \\
\hline & & 40 & 40 & 10 & 10 & 40 & 250 & 5.2 \\
\hline \multirow[t]{2}{*}{ MR6 (6) } & \multirow[t]{2}{*}{ B } & 40 & 40 & 0 & 10 & 40 & 225 & 1.01 \\
\hline & & 40 & 40 & 0 & 10 & 40 & 250 & 2.38 \\
\hline \multirow[t]{2}{*}{ MR7 (7) } & \multirow[t]{2}{*}{ B } & 40 & 40 & 10 & 0 & 40 & 250 & 3.32 \\
\hline & & 40 & 40 & 10 & 0 & 40 & 225 & 1.41 \\
\hline MR8 (8) & B & 50 & 50 & 20 & 20 & 0 & 250 & 2.14 \\
\hline MR9 (9) & $\mathrm{B}$ & 50 & 50 & 50 & 50 & 0 & 250 & 1.51 \\
\hline
\end{tabular}

* Extrapolated to zero time using Equation 22 and Table 10

** Numbers are for experiments at $250^{\circ} \mathrm{C}$, and are later used for graphs 


\section{RESULTS \& DISCUSSIONS}

\subsection{Membrane Characterization}

It can be seen from Tables 4 and 5, that the fluxes and permeances of all gases decrease with an increase in the temperature and with all other conditions remaining the same. This effect is commonly observed in the literature [26,32]. On comparing the average of the fluxes of each gas for Flow Conditions $\mathrm{MC} 1$ and $\mathrm{MC} 3$ with the flux for Flow condition MC2, at equal temperatures, it can be seen that, the fluxes of $\mathrm{CO}$ and $\mathrm{H}_{2}$ increase with an increase in the shell-side flow rate. The same effect is also observed for the permeances. This can be expected since the increase in shell-side flow rates causes the concentrations of $\mathrm{CO}$ and $\mathrm{H}_{2}$ on the shell side to decrease, leading to an increase in the concentration differences across the tube. This increases the driving force for permeation and thus increases the fluxes and the permeances. The fluxes and permeances of $\mathrm{H}_{2}$ (or $\mathrm{CO}$ ) decrease with a decrease in the concentration of $\mathrm{H}_{2}$ (or $\mathrm{CO}$ ) inside the tube. This is because at low concentration of a gas component inside the tube, the driving force for permeation of that component is less, giving lower values of fluxes and permeances. The values of the permeances obtained in this study are in the same order of magnitude as the values of permeances found in the literature[5]. In literature[26], the permeances decreased with an increase in the temperature. Further, the permeances increased when the shell-side flow rate was increased.

The ideal value and observed values of separation factors of $\mathrm{H}_{2}$ over $\mathrm{CO}$ are shown in Table 6. For an ideal Knudsen-diffusion regime, the separation factor is equal to the square root of the ratio of the molecular weights of the gases. Therefore, the separation factor should be 3.74 ideally. It can be seen that the separation factors of $\mathrm{H}_{2}$ over $\mathrm{CO}$ are significantly different from those expected under an ideal Knudsen-diffusion regime. However, the ideal value is only applicable to cases where no 
gas flows on the shell side. Previous studies in the literature [26] have found that the separation factor is reduced significantly in the presence of a flowing gas on the shell side, instead of simply a pressure difference across the membrane (with no gas flowing on the shell side). Therefore the lower values of separation factors found in the present study can be expected. It can be further noted that the separation factor is reduced with a decrease in the concentration of $\mathrm{H}_{2}$ inside the tube. This is because of the fact that the concentration difference of $\mathrm{H}_{2}$ across the tube decreases as the concentration inside the tube decreases, leading to a reduction in the separation factor. The separation factor shows a decrease with an increase in temperature. However, the change is negligible.

\subsection{Packed-Bed Membrane Reactor}

The effects of changes in the reaction temperature, the shell-side flow rates, the residence time of reactants inside the tube, the concentrations of reactants in the shell-side gas stream, and substitution of $\mathrm{N}_{2}$ on the shell side by the reactants are discussed here.

\subsubsection{Effect of the Reaction-Temperature}

It can be seen from Table 11, that for each flow condition performed at different temperatures, the conversion decreases with a decrease in the temperature. This can be expected as the reaction rate decreases with a decrease in the temperature, thus giving a lower conversion

\subsubsection{Effect of the Flow Rate in the Shell Side}

From Table 11, it can be observed that the conversions for Flow Conditions MR1, MR2, and MR3 decrease when the flow rate on the shell side increases at a constant temperature. This effect has been observed in the literature [9,32]. As the flow rate on the shell side increases, the concentrations 
of the gases permeating from the tube-side to the shell-side get lowered on the shell-side. This leads to an increase in the concentration gradients for the permeating gases and yields higher permeation rates of the gases. As the permeances of the reactants are high in comparison with the product methanol, more reactants than products are lost when the flow rate on the shell-side is increased. Therefore, the conversion decreases.

\subsubsection{Effect of the Residence Time of Reactants inside the Tube}

The results for Flow Conditions MR1 and MR4 in Table 11 show that the conversion increases when the flow rate of the reactants through the tube is decreased, i.e., when the residence time of the reactants inside the tube is increased. This is expected because, when the residence time increases, the reactants get more time for reaction inside the tube, giving higher values of conversions.

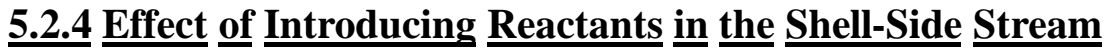

As can be seen from Table 11, the conversion is greater for Flow Condition MR7 than for Flow Condition MR6. The presence of $\mathrm{H}_{2}$ in the shell side for Flow Condition 7 and the presence of $\mathrm{CO}$ on the shell side for Flow Condition MR6 increases the concentrations of $\mathrm{H}_{2}$ and $\mathrm{CO}$ on the shell side respectively. However, as $\mathrm{H}_{2}$ has a higher power in the rate-expression for methanol formation (Equation 12) than does $\mathrm{CO}$, the effect of $\mathrm{H}_{2}$ is more pronounced than that of $\mathrm{CO}$, and therefore the conversion for Flow Condition MR7 is higher than that for Flow Condition MR6.

The conversion for Flow Condition MR5 is higher than those for Flow Conditions MR6 and MR7. This is expected because the presence of both the reactants on the shell side increases their 
concentrations on that side and, as both $\mathrm{H}_{2}$ and $\mathrm{CO}$ have positive powers in the rate expression for methanol formation (Equation 12), the conversion for Flow Condition MR5 is higher than those for Flow Conditions MR6 and MR7.

On comparing the conversions for Flow Condition MR4 with those for Flow Conditions MR5, MR6, and MR7, it can be observed that the conversion decreases when the reactants are introduced in the shell-side stream. This is the result of the increase in the shell-side total flow. Although the introduction of the reactants in the shell-side stream increases their concentration on that side, the conversion drops because the total shell-side flow rate increases. It can be noted from the values of the conversions for Flow Conditions MR1, MR2, and MR3 that the conversion decreases drastically as the shell-side flow rate is increased.

\section{$\underline{5.2 .5}$ Effect of Replacing Nitrogen with the Reactants on the Shell Side}

From the results for Flow Conditions MR1 and MR8 in Table 11, it can be observed that the conversion is greater when nitrogen is used on the shell-side as the sweep gas than when the reactants are used on the shell-side. The presence of $\mathrm{CO}$ and $\mathrm{H}_{2}$ on the shell side poses a greater barrier for the permeation of the product methanol through the membrane than that offered by nitrogen, leading to the observed result. The same effect is also observed when the results for Flow Conditions MR3 and MR9 are compared.

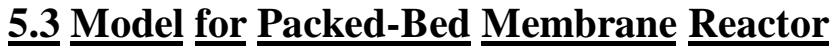

The experimental values of conversions observed in the packed-bed membrane reactor are compared below with the conversions predicted by the model for the packed-bed membrane reactor. 


\subsubsection{Model With Experimental Values of Permeances}

As the first step, the experimental values of the conversions for all flow conditions were compared with the values of conversions predicted by the experimental values of permeances at $250^{\circ} \mathrm{C}$ obtained from Table 5. Figure 15 shows this comparison. The difference in values is probably because the values of permeances are not obtained at the conditions used for the reactor operation.

\subsubsection{Model with Optimized Values of Permeances}

\subsubsection{Optimization Routine}

After developing the mathematical model for the packed-bed membrane reactor, an optimization routine was included in the model to minimize the errors between the experimental and the model values of conversions. This routine accounted for the lack of accuracy in the experimental results of gas-permeances (given in Table 5) obtained from the membrane-characterization experiments.

The optimization routine used the simplex method for optimization and the method of least squares for calculating the error. It optimized the values of the gas-permeances so that the sum of the square of the differences between the experimental and the model values of conversions for all flow conditions at $250^{\circ} \mathrm{C}$ (total error) was the least possible. The method used five trial points with guess values of permeances. It yielded the optimized values after going through an iterative loop which stopped after the required tolerance level was reached. The program for the mathematical model was run along with the optimization routine to give the optimized values of the permeances of the four gases. The complete program is given in Appendix B. The optimized values of permeances are shown in Table 12. The total error obtained with these values was 10.56. Figure 16 shows the comparison between experimental conversions and those calculated using the optimized values. 
Comparison between Experimental conversions and conversions predicted by using Table 5 for Packed-Bed Membrane Reactor at $250^{\circ} \mathrm{C}$

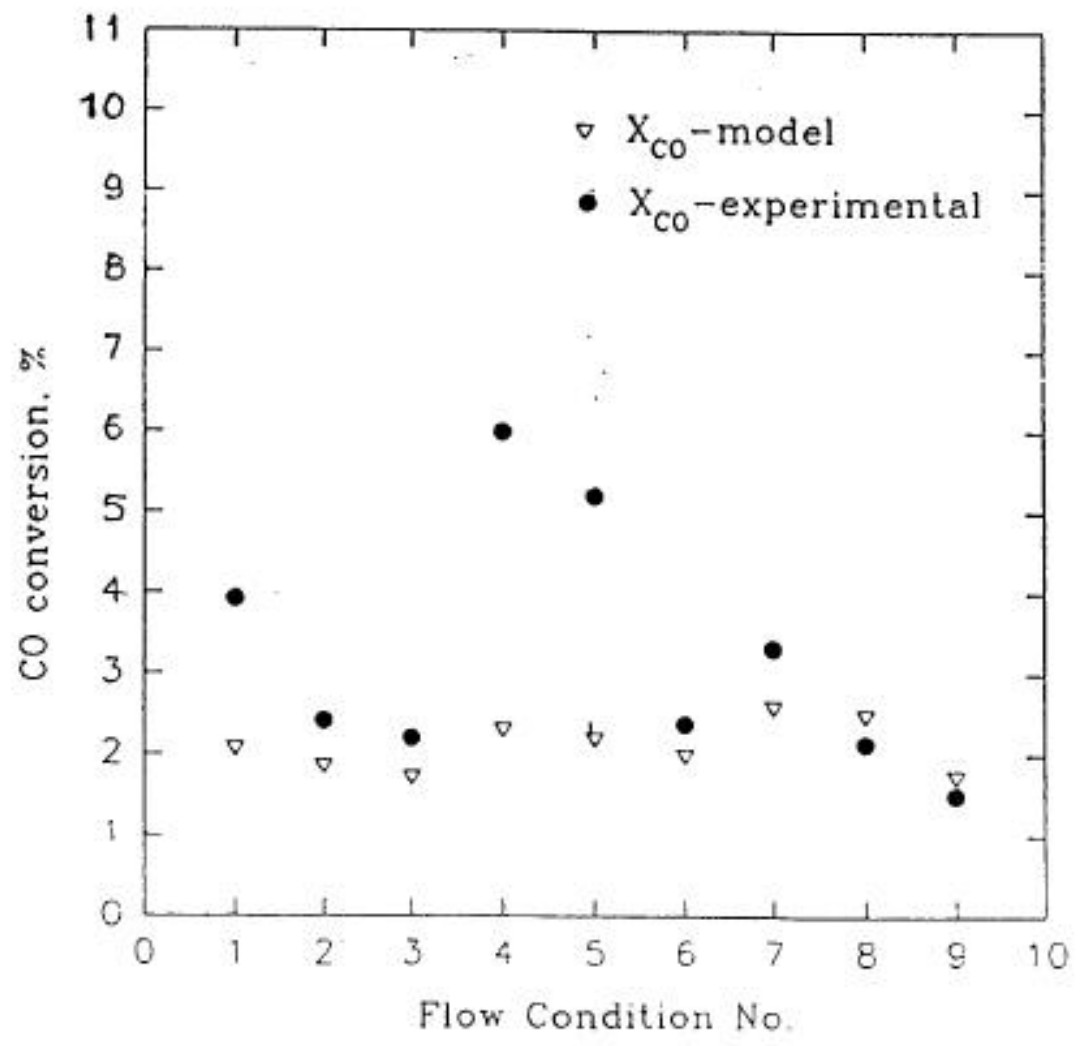

Figure 15 
Table 12

\section{Optimized Values of Permeances}

\begin{tabular}{|c|c|}
\hline Gas & $\begin{array}{r}\text { Optimized values of Permeances } \\
\left(\mathrm{mol} / \mathrm{min} / \mathrm{m}^{2} / \mathrm{Pa}\right) \times 10^{7}\end{array}$ \\
\hline $\mathrm{H}_{2}$ & 2.967 \\
\hline $\mathrm{CO}$ & 77.4 \\
\hline $\mathrm{N}_{2}$ & 0.087 \\
\hline Methanol & 18.5 \\
\hline
\end{tabular}


Comparison between Experimental conversions and conversions predicted by using Table 12 for

Packed-Bed Membrane Reactor at $250^{\circ} \mathrm{C}$

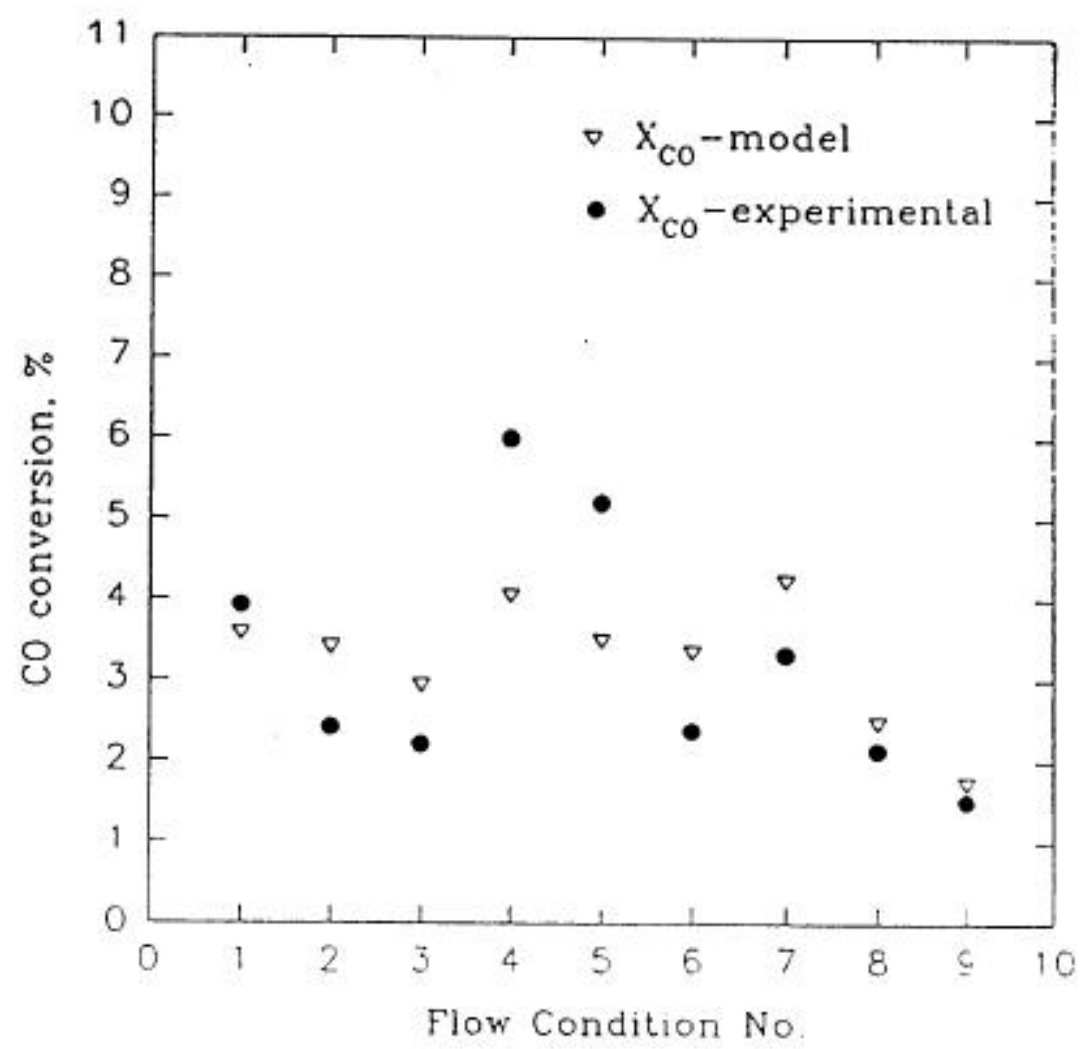

Figure 16 
This model seems to predict reasonable values for the conversions for all the flow conditions when compared to the experimental values.

\subsection{Model with Infinite Permeance of CO}

While running the optimization routine, it was observed that the value of CO-permeance was much larger than the permeances of $\mathrm{H}_{2}$ and $\mathrm{N}_{2}$. As the routine could optimize values within a certain range, it was not able to optimize the very small values of $\mathrm{H}_{2}$ and $\mathrm{N}_{2}$. Therefore, the routine was run again to search for optimum values of $\mathrm{H}_{2}$ and $\mathrm{N}_{2}$ permeances and assuming that $\mathrm{CO}$ had infinite permeance. This was accomplished by allowing for the condition $\mathrm{x}_{\mathrm{CO}}=\mathrm{y}_{\mathrm{CO}}$ in Equations 14 through 21 . The final form of the equations is :

Tube Side Equations :

$$
\begin{aligned}
& \mathrm{df}_{1} / \mathrm{dz}=-2 \cdot\left(\mathrm{r} \cdot \mathrm{RT}_{\mathrm{a}} / \mathrm{p}_{\mathrm{a}}\right) \cdot \pi \mathrm{r}_{1}{ }^{2} \cdot \rho_{\mathrm{b}}-2 \pi \mathrm{r}_{\mathrm{m}} \cdot\left(\mathrm{P}_{\mathrm{CO}} \cdot \mathrm{R} \cdot \mathrm{T}_{\mathrm{a}} / \mathrm{p}_{\mathrm{a}}\right) \cdot \mathrm{p}_{\mathrm{t}} \cdot\left(\mathrm{x}_{\mathrm{H} 2}-\mathrm{y}_{\mathrm{H} 2}\right) \\
& \mathrm{df}_{2} / \mathrm{dz}=-1 \cdot\left(\mathrm{r} \cdot \mathrm{RT}_{\mathrm{a}} / \mathrm{p}_{\mathrm{a}}\right) \cdot \pi \mathrm{r}_{1}{ }^{2} \cdot \rho_{\mathrm{b}} \\
& \mathrm{df}_{3} / \mathrm{dz}=-2 \pi \mathrm{r}_{\mathrm{m}} \cdot\left(\mathrm{P}_{\mathrm{N} 2} \cdot \mathrm{R} \cdot \mathrm{T}_{\mathrm{a}} / \mathrm{p}_{\mathrm{a}}\right) \cdot \mathrm{p}_{\mathrm{t}} \cdot\left(\mathrm{x}_{\mathrm{N} 2}-\mathrm{y}_{\mathrm{N} 2}\right) \\
& \mathrm{df}_{4} / \mathrm{dz}=\left(\mathrm{r} \cdot \mathrm{RT}_{\mathrm{a}} / \mathrm{p}_{\mathrm{a}}\right) \cdot \pi \mathrm{r}_{1}{ }^{2} \cdot \rho_{\mathrm{b}}-2 \pi \mathrm{r}_{\mathrm{m}} \cdot\left(\mathrm{P}_{\mathrm{MeoH}} \cdot \mathrm{R} \cdot \mathrm{T}_{\mathrm{a}} / \mathrm{p}_{\mathrm{a}}\right) \cdot \mathrm{p}_{\mathrm{t}} \cdot\left(\mathrm{x}_{\mathrm{MeoH}}-\mathrm{y}_{\mathrm{MeoH}}\right)
\end{aligned}
$$

Shell Side Equations :

$$
\begin{aligned}
& \mathrm{df}_{5} / \mathrm{dz}=2 \pi \mathrm{r}_{\mathrm{m}} \cdot\left(\mathrm{P}_{\mathrm{H} 2} \cdot \mathrm{R} \cdot \mathrm{T}_{\mathrm{a}} / \mathrm{p}_{\mathrm{a}}\right) \cdot \mathrm{p}_{\mathrm{t}} \cdot\left(\mathrm{x}_{\mathrm{H} 2}-\mathrm{y}_{\mathrm{H} 2}\right) \\
& \mathrm{df}_{6} / \mathrm{dz}=0 \\
& \mathrm{df}_{7} / \mathrm{dz}=2 \pi \mathrm{r}_{\mathrm{m}} \cdot\left(\mathrm{P}_{\mathrm{N} 2} \cdot \mathrm{R} \cdot \mathrm{T}_{\mathrm{a}} / \mathrm{p}_{\mathrm{a}}\right) \cdot \mathrm{p}_{\mathrm{t}} \cdot\left(\mathrm{x}_{\mathrm{N} 2}-\mathrm{y}_{\mathrm{N} 2}\right) \\
& \mathrm{df}_{8} / \mathrm{dz}=2 \pi \mathrm{r}_{\mathrm{m}} \cdot\left(\mathrm{P}_{\mathrm{MeoH}} \cdot \mathrm{R} \cdot \mathrm{T}_{\mathrm{a}} / \mathrm{p}_{\mathrm{a}}\right) \cdot \mathrm{p}_{\mathrm{t} \cdot\left(\mathrm{x}_{\mathrm{MeoH}}-\mathrm{y}_{\mathrm{MeoH}}\right)}
\end{aligned}
$$

See 'Symbols and Notations' section for review of symbols. 
The values of permeances obtained were :

$$
\begin{aligned}
& \mathrm{P}_{\mathrm{H} 2}=3.88 \times 10^{-8} \mathrm{~mol} / \mathrm{min} / \mathrm{m}^{2} / \mathrm{Pa} \\
& \mathrm{P}_{\mathrm{N} 2}=7.12 \times 10^{-10} \mathrm{~mol} / \mathrm{min} / \mathrm{m}^{2} / \mathrm{Pa} \\
& \mathrm{P}_{\mathrm{MeOH}}=18.2 \times 10^{-7} \mathrm{~mol} / \mathrm{min} / \mathrm{m}^{2} / \mathrm{Pa}
\end{aligned}
$$

The total error with these values of permeances was 11.23. Figure 17 shows the comparison between the observed values of conversions and the conversions obtained with the above values of permeances.

It was observed that the permeances and total error obtained from this run were not significantly different from the values given in Table 12 above. Also, the total error was slightly greater than the previous value (10.56). Therefore, the values of permeances given in Table 12 were considered to be the optimum values.

It can be noted that the optimum values of the permeances of $\mathrm{CO}$ and methanol are very high compared to those of $\mathrm{H}_{2}$ and $\mathrm{N}_{2}$. These values are not expected for the case of a purely Knudsendiffusion mechanism for diffusion of the gases. However, the values indicate that, during reaction inside the membrane tube, there is a considerable surface diffusion of methanol and $\mathrm{CO}$ through the tube. The surface diffusion of methanol can be expected from the literature [5]. 


\section{Comparison between Experimental conversions}

and conversions predicted by assuming infinite permeance of $\mathrm{CO}$

in Packed-Bed Membrane Reactor at $250^{\circ} \mathrm{C}$

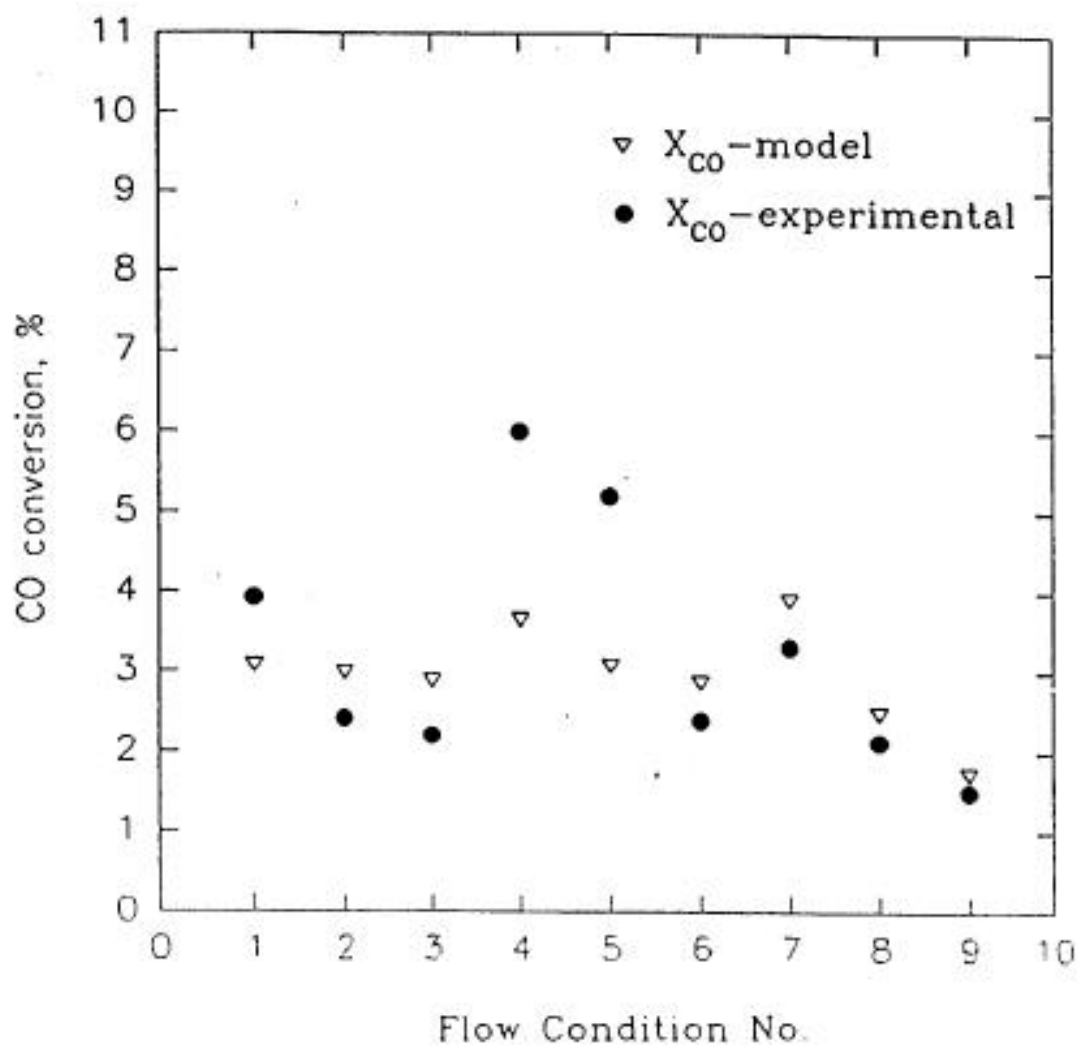

Figure 17 


\subsubsection{Model Assuming Free Mixing through Membrane}

Finally, the experimental values of the conversions were compared with the values obtained in an extreme case of free mixing through the membrane. In this case, all the gases in both the shell-side and the tube-side of the reactor mix together, i.e., all permeances tend to infinity. As the concentration of all the gas components on both sides of the tube is the same during free mixing, therefore in Equations 14 through 21, $\mathrm{x}_{\mathrm{i}}=\mathrm{y}_{\mathrm{i}}$ for each gas component. The equations therefore are as follows:

Tube Side Equations :

$$
\begin{aligned}
& \mathrm{df}_{1} / \mathrm{dz}=-2 \cdot\left(\mathrm{r} \cdot \mathrm{RT}_{\mathrm{a}} / \mathrm{p}_{\mathrm{a}}\right) \cdot \pi \mathrm{r}_{1}{ }^{2} \cdot \rho_{\mathrm{b}} \\
& \mathrm{df}_{2} / \mathrm{dz}=-1 \cdot\left(\mathrm{r} \cdot \mathrm{RT}_{\mathrm{a}} / \mathrm{p}_{\mathrm{a}}\right) \cdot \pi \mathrm{r}_{1}{ }^{2} \cdot \rho_{\mathrm{b}} \\
& \mathrm{df}_{3} / \mathrm{dz}=0 \\
& \mathrm{df}_{4} / \mathrm{dz}=\left(\mathrm{r} \cdot \mathrm{RT}_{\mathrm{a}} / \mathrm{p}_{\mathrm{a}}\right) \cdot \pi \mathrm{r}_{1}{ }^{2} \cdot \rho_{\mathrm{b}}
\end{aligned}
$$

Shell Side Equations :

$$
\begin{aligned}
& \mathrm{df}_{5} / \mathrm{dz}=0 \\
& \mathrm{df}_{6} / \mathrm{dz}=0 \\
& \mathrm{df}_{7} / \mathrm{dz}=0 \\
& \mathrm{df}_{8} / \mathrm{dz}=0
\end{aligned}
$$

See 'Symbols and Notations' section for review of symbols.

These equations were solved simultaneously to give the conversions for free mixing. These conversions were compared with the experimental conversions. Figure 18 shows the comparison. 


\section{Comparison between Experimental conversions}

and conversions predicted by free mixing for

Packed-Bed Membrane Reactor at $250^{\circ} \mathrm{C}$

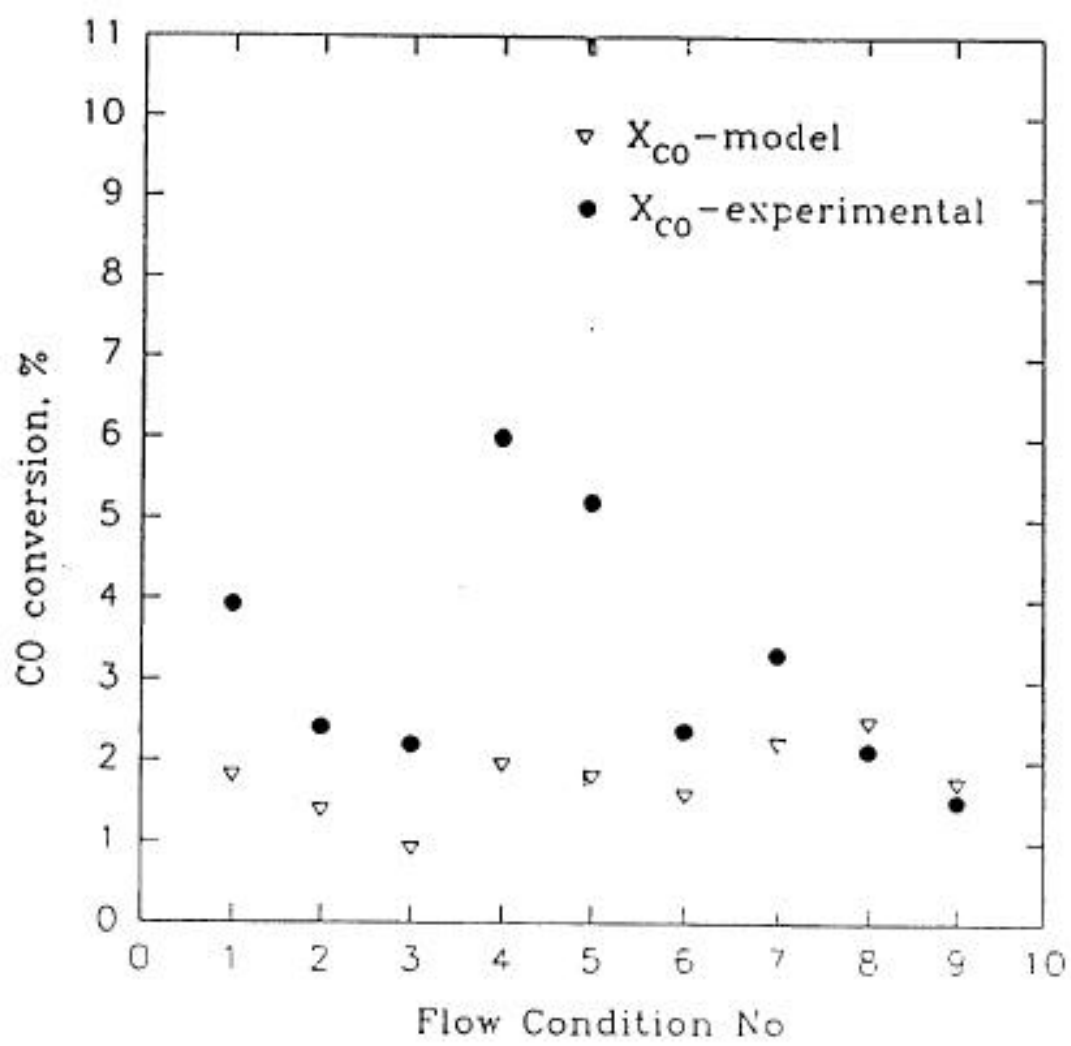

Figure 18 
It can be seen that the conversions for this model are significantly lower than the experimental values. Therefore, it can be said that the packed-bed membrane reactor does not allow free permeation of gases through the membrane tube.

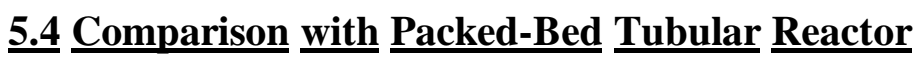

The conversions obtained in the packed-bed membrane reactor were compared with the conversions from a packed-bed tubular reactor on the basis of equal total inlet flow-rates of both the reactants. Table 13 shows the comparison.

It can be seen that the conversions in the packed-bed membrane reactor for Flow Conditions MR1,MR7, and MR6 are almost equal to those in the packed-bed tubular reactor for Flow Conditions TR1, TR6 and TR5 respectively. The conversion in the packed-bed membrane reactor for Flow Condition MR4 is slightly greater than that for Flow Condition TR2 in the packed-bed tubular reactor.

Therefore, it can be concluded that the packed-bed membrane reactor behaves in the same way as the packed-bed tubular reactor. It performs slightly better than the packed-bed tubular reactor when the tube-side flow rate is reduced. 
Table 13

Comparison between Performances of Packed-Bed Membrane Reactor and Packed-bed Tubular at $250^{\circ} \mathrm{C}$

\begin{tabular}{|c|c|c|c|c|c|}
\hline $\begin{array}{c}\text { Flow Condition } \\
\text { for Packed-Bed } \\
\text { Tubular } \\
\text { Reactor }\end{array}$ & $\begin{array}{c}\text { Flow Condition for } \\
\text { Packed-Bed } \\
\text { Membrane Reactor }\end{array}$ & $\begin{array}{c}\text { Total Inlet Flow } \\
\text { Rate of Reactants } \\
\text { (cc STP/min) }\end{array}$ & $\begin{array}{c}\text { Conversions in } \\
\text { Packed-Bed } \\
\text { Membrane } \\
\text { Reactor (\%) }\end{array}$ & $\begin{array}{c}\text { Conversions } \\
\text { in Packed-Bed } \\
\text { Tubular } \\
\text { Reactor (\%) }\end{array}$ \\
\hline TR1 & MR1 & 50 & 50 & 3.93 & 3.5 \\
\hline TR2 & MR4 & 40 & 40 & 6.01 & 3.95 \\
\hline TR6 & MR7 & 50 & 40 & 3.32 & 4.7 \\
\hline TR5 & MR6 & 40 & 50 & 2.38 & 3.35 \\
\hline
\end{tabular}




\section{CONCLUSIONS AND RECOMMENDATIONS}

\section{$\underline{6.1}$ Conclusions}

The membrane-tube used for the packed-bed membrane reactor studies was characterized in terms of its fluxes, permeances, and the separation factors of $\mathrm{H}_{2}$ over $\mathrm{CO}$.

The effects of various flow conditions in the packed-bed membrane reactor were studied and evaluated. It was found that the conversion decreases with a decrease in the reaction temperature. The conversion decreases when the flow rate on the shell side increases at a constant temperature. The conversion increases when the flow rate of the reactants through the tube is decreased, i.e., when the residence time of reactants inside the tube is increased. The conversion decreases when reactants are fed on the shell side. The conversion obtained by feeding $\mathrm{H}_{2}$ on the shell side is greater than that obtained by feeding $\mathrm{CO}$ on the shell side at a constant total shell side feed rate.

Experiments were performed on a packed-bed tubular reactor and a rate expression for methanol formation was obtained from that data. The rate expression is :

$$
\mathrm{r}_{\mathrm{MeoH}}=467820\left(\mathrm{C}_{\mathrm{CO}}\right)^{0.75} \cdot\left(\mathrm{C}_{\mathrm{H} 2}\right)^{1.27}(\mathrm{~mol} / \mathrm{min} / \mathrm{kgcat})
$$

See 'Symbols and Notations section' for review of symbols.

A model was developed for the packed-bed membrane reactor in order to explain the observed effects. The model involved solution of eight simultaneous differential equations incorporating the effect of both the permeation of gases and reaction in the catalyst bed. An optimization routine was 
also included in the model to optimize the values of the permeances of gases. It was found that the model gives a reasonable prediction of the observed values of conversions. The optimized values of the gas permeances are very different from the ideal values expected under Knudsen diffusion regime. The permeance of $\mathrm{CO}$ through the tube is very high.

Finally, the performance of the packed-bed membrane reactor was compared with that of the packed-bed tubular reactor on the basis of equal total inlet flow-rates of the reactants $\mathrm{H}_{2}$ and $\mathrm{CO}$, and equal space velocities. It was found that the packed-bed membrane reactor behaves in the same way as the packed-bed tubular reactor.

\section{$\underline{6.2}$ Recommendations}

a) The analysis of data obtained from the packed-bed membrane reactor took a longer time than expected. It could have been easier if the flow rates of the retentate and permeate streams coming out of the membrane reactor were directly available, along with independant gas-chromatographic concentration data for both the streams. For future work it is recommended to have this kind of data for analyzing the packed-bed membrane reactor. Two different pressure regulators can be used for the permeate and retentate streams coming out of the reactor. The flow rates of the permeate and the retentate streams can be measured by two bubble flow meters connected in line after the gas chromatographs and the pressure regulators. A common high-pressure cylinder can also be used to maintain equal pressure on both sides of the membrane tube.

b) In the present study, the annulus between the membrane tube and the surrounding stainless tube was large in comparison with the inner volume of the membrane tube. Therefore, the flow in the 
annulus was slow compared to the flow through the tube. As this is close to a state of free mixing on the shell side, the equations 14 through 21 derived during the development of the model for the packed-bed membrane reactor may not be correct, leading to error in the model.

However, if the annulus region is packed with some solid matter like quartz chips or glass beads this difference can be significantly reduced. This would eliminate the need to take this effect into consideration during modeling, and would subsequently reduce the errors in the model as much as possible. In future work, it is also recommended to use the surrounding stainless-steel tube of such size so that the inner volume of the membrane tube and the volume of the annulus are nearly the same. 


\section{SYMBOLS AND NOTATIONS}

$\mathrm{A}_{\mathrm{CO}} \quad$ Gas chromatograph area of $\mathrm{CO}$ in the mixture stream of retentate and permeate (counts), Equation 10

$\mathrm{A}_{\text {meoh }} \quad$ Gas chromatograph area of methanol in the mixture stream of retentate and permeate (counts), Equation 10

A

a

b

$\mathrm{C}_{\mathrm{i}}$

$\mathrm{C}_{\mathrm{CO}}$

$\mathrm{C}_{\mathrm{H} 2}$

c

d

$\mathrm{F}$

$\mathrm{F}_{\mathrm{p}}$

$\mathrm{F}_{\mathrm{r}}$

$\mathrm{F}_{\mathrm{COin}}$

$\mathrm{F}_{\mathrm{H} 2 \mathrm{in}}$
Membrane permeation area $\left(\mathrm{m}^{2}\right)$, Equations 1,8 and 9

Power of CO concentration in the power-law rate expression, Equation 12

Power of $\mathrm{H}_{2}$ concentration in the power-law rate expression, Equation 12

Concentration of component i $\left(\mathrm{mol} / \mathrm{m}^{3}\right)$, Equation 1

Concentration of $\mathrm{CO}\left(\mathrm{mol} / \mathrm{cm}^{3}\right)$, Equations 3 and 12

Concentration of $\mathrm{H}_{2}\left(\mathrm{~mol} / \mathrm{cm}^{3}\right)$, Equations 3 and 12

A temperature-constant in the expression for catalyst deactivation (K),

Equation 22

A time-constant in the expresson for catalyst deactivation $\left(\mathrm{hr}^{-1}\right)$,

Equation 22

Flow rate (mol/min), Equation 1

Flow rate of permeate stream $\left(\mathrm{cm}^{3} / \mathrm{min}\right.$ at STP), Equations 5, 6, 7 and 8

Flow rate of retentate stream $\left(\mathrm{cm}^{3} / \mathrm{min}\right.$ at STP), Equations $5,6,7$ and 9

Total feed flow rate of $\mathrm{CO}$ through the membrane reactor $\left(\mathrm{cm}^{3} / \mathrm{min}\right.$ at

STP), Equations 6 and 11

Total feed flow rate of $\mathrm{H}_{2}$ through the membrane reactor $\left(\mathrm{cm}^{3} / \mathrm{min}\right.$ at 
STP), Equation 5

$\mathrm{F}_{\text {totalin }} \quad$ Total feed flow rate of $\mathrm{H}_{2}$ and $\mathrm{CO}$ through the membrane reactor $\left(\mathrm{cm}^{3} / \mathrm{min}\right.$ at STP), Equation 7

FID Flame Ionization Detector

$\mathrm{f}_{1} \quad$ Flow rate of $\mathrm{H}_{2}$ inside the tube $\left(\mathrm{cm}^{3} / \mathrm{min}\right.$ at $\left.\mathrm{STP}\right)$, Equation 14

$\mathrm{f}_{2} \quad$ Flow rate of CO inside the tube $\left(\mathrm{cm}^{3} / \mathrm{min}\right.$ at STP), Equation 15

$\mathrm{f}_{3} \quad$ Flow rate of $\mathrm{N}_{2}$ inside the tube $\left(\mathrm{cm}^{3} / \mathrm{min}\right.$ at $\left.\mathrm{STP}\right)$, Equation 16

$\mathrm{f}_{4} \quad$ Flow rate of methanol inside the tube $\left(\mathrm{cm}^{3} / \mathrm{min}\right.$ at STP), Equation 17

$\mathrm{f}_{5} \quad$ Flow rate of $\mathrm{H}_{2}$ in the shell side $\left(\mathrm{cm}^{3} / \mathrm{min}\right.$ at STP), Equation 18

$\mathrm{f}_{6} \quad$ Flow rate of $\mathrm{CO}$ in the shell side $\left(\mathrm{cm}^{3} / \mathrm{min}\right.$ at STP), Equation 19

$\mathrm{f}_{7} \quad$ Flow rate of $\mathrm{N}_{2}$ in the shell side $\left(\mathrm{cm}^{3} / \mathrm{min}\right.$ at STP), Equation 20

$\mathrm{f}_{8} \quad$ Flow rate of methanol in the shell side $\left(\mathrm{cm}^{3} / \mathrm{min}\right.$ at STP), Equation 21

$\mathrm{J}_{\mathrm{i}} \quad$ Flux of component i $\left(\mathrm{mol} / \mathrm{m}^{2} / \mathrm{sec}\right)$, Equation $8 \mathrm{a}$

$\mathrm{J}_{\mathrm{N} 2} \quad$ Flux of $\mathrm{N}_{2}\left(\mathrm{~mol} / \mathrm{m}^{2} / \mathrm{sec}\right)$, Equation $8 \mathrm{~b}$

$\mathrm{k} \quad$ Rate constant in the power-law rate expression for PBTR, Equation 12

k1 A constant in the 8-parameter rate expression for PBTR, Equation 13

k2 A constant in the 8-parameter rate expression for PBTR, Equation 13

k3 A constant in the 8-parameter rate expression for PBTR, Equation 13

k4 A constant in the 8-parameter rate expression for PBTR, Equation 13

k5 A constant in the 8-parameter rate expression for PBTR, Equation 13

k6 A constant in the 8-parameter rate expression for PBTR, Equation 13

k7 A constant in the 8-parameter rate expression for PBTR, Equation 13 


\begin{tabular}{|c|c|}
\hline $\mathrm{p}_{\mathrm{a}}$ & Ambient Pressure (one atm), Equations 14 through 21 \\
\hline $\mathrm{p}_{\mathrm{CO}}$ & Partial pressure of $\mathrm{CO}(\mathrm{atm})$, Equation 13 \\
\hline $\mathrm{p}_{\mathrm{H} 2}$ & Partial pressure of $\mathrm{H}_{2}$ (atm), Equation 13 \\
\hline $\mathrm{p}_{\mathrm{MeoH}}$ & Partial pressure of Methanol (atm), Equation 13 \\
\hline $\mathrm{p}_{\mathrm{s}}$ & Normal vapor pressure in the bulk phase (atm), Equation 4 \\
\hline $\mathrm{p}_{\mathrm{t}}$ & Reaction Pressure (750 psig), Equations 14 through 21 \\
\hline ptotal & Total pressure on each side of the membrane (atm), Equation 1 \\
\hline $\mathrm{P}$ & Vapor pressure in the bulk phase in the presence of capillary pores (atm), \\
\hline & Equation 4 \\
\hline $\mathrm{P}_{\mathrm{i}}$ & Permeance of component i (mol/min $\left./ \mathrm{m}^{2} / \mathrm{Pa}\right)$, Equation 1 \\
\hline $\mathrm{P}_{\mathrm{co}}$ & Permeance of carbon-monoxide ( $\left.\mathrm{mol} / \mathrm{min} / \mathrm{m}^{2} / \mathrm{Pa}\right)$, Equations 15 and 19 \\
\hline $\mathrm{P}_{\mathrm{H} 2}$ & Permeance of hydrogen $\left(\mathrm{mol} / \mathrm{min} / \mathrm{m}^{2} / \mathrm{Pa}\right)$, Equations 14 and 18 \\
\hline $\mathrm{P}_{\mathrm{MeoH}}$ & Permeance of methanol $\left(\mathrm{mol} / \mathrm{min} / \mathrm{m}^{2} / \mathrm{Pa}\right)$, Equations 17 and 21 \\
\hline $\mathrm{P}_{\mathrm{N} 2}$ & Permeance of nitrogen $\left(\mathrm{mol} / \mathrm{min} / \mathrm{m}^{2} / \mathrm{Pa}\right)$, Equations 16 and 20 \\
\hline PBMR & Packed Bed Membrane Reactor \\
\hline PBTR & Conventional Packed Bed Tubular Reactor \\
\hline $\mathrm{R}$ & $\begin{array}{l}\text { Universal gas constant ( } 0.082 \text { lit.atm/mol/K), Equations } 4,8,14 \text { through } \\
21,23 \text { through } 30 \text {, and } 31 \text { through } 38\end{array}$ \\
\hline $\mathrm{r}$ & Rate of reaction (mol/min/kg.catalyst), Equations 14, 15, 17 \\
\hline$r_{1}$ & Inner radius of tube $(\mathrm{cm})$, Equations $14,15,17$ \\
\hline $\mathrm{r}_{\mathrm{MeoH}}$ & Rate of methanol formation (mol/min/kg.catalyst), Equations $11,12,13$ \\
\hline $\mathrm{r}_{\mathrm{m}}$ & Log mean radius of tube $(\mathrm{cm})$, Equations 14 through 21 \\
\hline$r_{p}$ & Mean pore radius (m), Equation 4 \\
\hline
\end{tabular}


sccm Standard Cubic Centimetre per minute flow (flow rate at S.T.P condiitons)

SST Stainless steel tube

$\mathrm{T}_{\mathrm{a}} \quad$ Standard temperature $(298 \mathrm{~K})$, Equations 14 through 21

$\mathrm{T}_{\mathrm{t}} \quad$ Temperature of reaction run $(\mathrm{K})$, Equation 22

$\mathrm{T} \quad$ Temperature of fluid in the pore $(\mathrm{K})$, Equation 4

TCD Thermal Conductivity Detector

$\mathrm{t} \quad$ Time on stream for catalyst deactivation (hr), Equation 22

$\mathrm{w}_{\mathrm{CO}}$ Response factor of $\mathrm{CO}$ relative to nitrogen in the gas chromatograph,

Equation 10

$\mathrm{W}_{\mathrm{MeoH}}$ Response factor of methanol relative to nitrogen in the gas chromatograph,

Equation 10

$\mathrm{W}_{\text {cat }} \quad$ Weight of the catalyst $(\mathrm{kg})$, Equation 11

$\mathrm{X}_{\mathrm{o}} \quad$ Parameter analogous to the pre-exponential factor in the expression for catalyst aging, Equation 22

$\mathrm{X}_{\mathrm{CO}} \quad$ Conversion of CO to methanol (\%), Equations 11 and 22

X

Mole-fraction in the tube, Equations 14 through 21

y Mole-fraction in the shell side, Equations 14 through 21

z Distance across the membrane tube $(\mathrm{cm})$, Equations 14 through 21

Greek Symbols :

$\alpha_{\mathrm{H} 2 / \mathrm{CO}} \quad$ Separation factor for $\mathrm{H}_{2}$ over CO, Equation 3

$\gamma \quad$ Surface tension of the condensed fluid in the pore $\left(\mathrm{J} / \mathrm{m}^{2}\right)$, Equation 4

$\Delta \mathrm{C}_{1} \quad$ Concentration difference across the membrane at the tube inlet $\left(\mathrm{mol} / \mathrm{m}^{3}\right)$, 


\section{Equation 2}

$\Delta \mathrm{C}_{2} \quad$ Concentration difference across the membrane at the tube oulet $\left(\mathrm{mol} / \mathrm{m}^{3}\right)$,

\section{Equation 2}

$\Delta_{\mathrm{m}, \mathrm{i}}$

Logarithmic-mean concentration difference of component $\mathrm{i}$ between the tube and the shell sides $\left(\mathrm{mol} / \mathrm{m}^{3}\right)$, Equation 2

Contact angle between the condensed fluid and the pore wall, Equation 4

Molar density of the condensed liquid $\left(\mathrm{mol} / \mathrm{m}^{3}\right)$, Equation 4

$\rho_{\mathrm{b}} \quad$ Density of catalyst in the bed $\left(\mathrm{kg} / \mathrm{cm}^{3}\right)$, Equations 14,15 , and 17 


\section{BIBLIOGRAPHY}

1. Subramaniam, A (1994). M.S. Thesis 'Modelling and Simulation of catalytic reactors used in the production of higher alcohols from synthesis gas', West Virginia University

2. Mohan, K ; Govind, R (1988). Sep. Sci. Technol., $\underline{23}$, 1715

3. Sun, Y.M ; Khang, S.J (1990 ). Ind. Eng. Chem. Res., 29, 232

4. Armor, J.N. (1989). Applied Catalysis., 49, 1

5. Noble, R.D ; Falconer, J.L ; Jia, M.D ; Chen, B (1993). J. Membr. Sci., 90, 1

6. Saracco, G ; Specchia, V (1994). Catal. Rev. - Sci. Eng., $\underline{36}, 305$

7. Mordkovich, V.Z ; Baichtock, Y.K ; Sosna, M.H (1992). Platinum. Metals. Rev., $\underline{36}, 90$

8. Philpott, J.E (1985). Platinum. Metals. Rev., $\underline{29}, 12$

9. Falconer, J.L ; Noble, R.D ; Sperry, D.P (1995). “Membrane Separations Technology.

Principles and Applications" (Ed. R.D. Noble, S.A. Stern) -Elsevier Science B.V., Chapter 14

10. Gryaznov, V.M ; Vedernikov, V.I ; Gul'yanova S.G (1986). Trans. Kinet. Katal., 27, 142

11. Cales, B ; Baumard, J.F (1982). J. High Temp.-High Press., 14, 681

12. Otsuka, K ; Morikawa, A (1985). Kagaku Kogaku., $\underline{49}, 61$

13. Kameyama, T ; Dokiya, M ; Yokokawa, H ; Fukuda, K (1983). Intern. J. Hydrogen Energy, $\underline{8}, \underline{5}$

14. Zaspalis, V.T ; Keizer, K ; Van Praag, W ; Van Ommen, J.G ; Ross, J.R.H ; Burggraaf, A.J (1989). Brit. Ceram. Soc. Proc., 43, 103

15. Kammermeyer, K ; Hwang, S (1975). "Techniques of Chemistry: Membranes in Separations" -Wiley Interscience, New York.

16. Suzuki, H (1987). U.S. Pat. 4699,892

17. Itoh, N ; Shindo, Y ; Haraya, K ; Obata, K ; Hakuta, T (1985). Intern. Chem. Eng., 225, 138 
18. Uhlhorn, R.J.R ; Keizer, K ; Burggraaf, A.J (1989). J. Membr. Sci., 46, 225

19. Uhlhorn, R.J.R ; Keizer, K ; Burggraaf, A.J (1990). Intern. Congr. Membr., 25, 448

20. Nagamoto, H ; Inoue, H (1981). J. Chem. Eng. Japan., 14, 377

21 Gryaznov, V.M (1986). Platinum Metals Rev., $\underline{30}, 68$

22 Omata, K ; Hashimoto, S ; Asami, K (1989). Abstracts, PACIFI-CHEM , Int. Chem. Cong. Pac. Basin. Soc., 139

23. Kiratzis, N ; Stoukides, M (1987). J. Electrochem. Soc., $\underline{8}, 134$

24. Itoh, N ; Xu, W.C (1993). Applied Catalysis A:General, 107, 83

25. Mohan, K ; Govind, R (1986). AIChE J., 32, 2083

26. Uhlhorn, R.J.R ; Burggraaf, A.J (1991). "Inorganic Membranes: Synthesis, Characteristics, and Applications" (Ed. R.R. Bhave), Publishers : Chapman and Hall, New York, Chapter 6

27. Liu, P.K.T ; Gallaher, G.R. (1994). J. Membr. Sci., $\underline{92}, 29$

28. Fain, D.E (1990). Proc. 1st Intern. Conf. Inorg. Membr. July'90., 199

29. Bart, J.C.J ; Sneeden, R.P.A (1987). Catalysis Today., 2 , 1

30. Klier, K ; Herman, R.G ; Nunan, J.G ; Smith K ; Bogdan C.E ; Young, C.W ; Santiesteban, J.G (1988). Methane Conversion, (Eds. D.M Bibby, C.D. Chang, R.F. Howe), 109

31. Santiesteban, J.G ; Bogdan, C.E ; Herman, R.G ; Klier, K (1988). Catalysis : Theory to Practice C1 Chemistry, Proc. 9th Intern. Congr. on Catal., $\underline{2}, 561$

32. Itoh, N ; Shindo, Y ; Haraya, K ; Hakuta, T (1988). J. Chem. Eng. Japan., 21, 399

33. Wu, J.C.S ; Flowers, D.F ; Liu, P.K.T (1993). J. Membr. Sci., 77, 85

34. Tsotsis, T.T ; Champagnie, A.M ; Vasileiadis, S.P ; Ziaka, Z.D ; Minet, R.G (1993). Sep. Sci. Technol., 2ㅇ, 397

35. Tronconi, E ; Ferlazzo, N ; Forzatti, P ; Pasquon, I (1987). Ind. Eng. Chem. Res., 26, 2122 
36. Mohan, K ; Govind, R (1988). AIChE J., 34, 1493

37. Hsieh, H.P (1991). Catal. Rev.- Sci. Eng., 33, 1-70

38. Moser, W.R ; Becker, Y ; Dixon, A.G ; Ma, Y.H (1992). Presented at 5th annual meeting of the N.A.M.S, Lexington, KE, paper 11E

39. Rao, M.B ; Sircar, S (1993). J. Membr. Sci., 모, 253

40. Veldsink, J.W ; Versteeg, G.F ; Van Swaaij, W.P.M (1995). Ind. Eng. Chem. Res., 34, 763

41. Jia, M.D ; Peinemann, K.V ; Behling, R.D (1993). J. Membr. Sci., 2ㅡ, 15

42. Liu, P.K.T ; Lin, C.L ; Flowers, D.L (1994). J. Membr. Sci., 92, 45

43. Bernstein, L.A ; Lund, C.R.F (1993). J. Membr. Sci., 77, 155

44. Agarwalla, S ; Lund, C.R.F (1992). J. Membr. Sci., 70, 129

45. Liu, P.K.T ; Gallaher, G.R., Jr. ; Gerdes, T.E (1993). Sep. Sci. Technol., 28, 309

46. Keizer, K ; Uhlhorn, R.J.R ; Burggraaf, A.J (1992). J. Mater. Sci., 27, 527

47. Laciak, D.V ; Quinn, R ; Appleby, J.B ; Puri, P.S (1990). Sep. Sci. Technol., 25, 1295

48. Hsieh, H.P (1989). AIChE. Symp. Ser., 포, 53

49. Khang, S.J ; Sun, Y.M (1988). Ind. Eng. Chem. Res., 27, 1136

50. Gokhale, Y.V ; Noble, R.D ; Falconer, J.L (1993). J. Membr. Sci., 77, 197 
APPENDIX A

Experimental Data for

Packed Bed Membrane Reactor 
Experimental Data for

Packed Bed Membrane Reactor

\section{APPENDIX A}

Page 1

\begin{tabular}{|c|c|c|c|c|c|c|c|c|}
\hline & & & Catalyst & Sample & A & & & \\
\hline & $\begin{array}{c}\text { MR1- } \\
250\end{array}$ & & & $\begin{array}{c}\text { MR1- } \\
225\end{array}$ & & & $\begin{array}{c}\text { MR1- } \\
200\end{array}$ & \\
\hline & $\begin{array}{c}\text { Area } \\
\mathrm{CO}\end{array}$ & Area M & $\mathrm{XCO} \%$ & $\begin{array}{c}\text { Area } \\
\mathrm{CO}\end{array}$ & Area M & $\mathrm{XCO} \%$ & $\begin{array}{c}\text { Area } \\
\mathrm{CO}\end{array}$ & Area M \\
\hline \multirow[t]{10}{*}{ Start } & 55489 & 10074 & 4.886 & 51375 & 3082 & 1.669 & 51626 & 655 \\
\hline & 52578 & 8679 & 4.462 & 49753 & 2447 & 1.372 & 53228 & 612 \\
\hline & 53627 & 8421 & 4.254 & 52872 & 2184 & 1.155 & 54261 & 678 \\
\hline & 54126 & 8037 & 4.032 & 53416 & 1880 & 1.024 & 54719 & 562 \\
\hline & 53637 & 7803 & 3.953 & 55772 & 1826 & .967 & 52265 & 533 \\
\hline & 53796 & 7462 & 3.776 & 52093 & 1686 & .8852 & 52079 & 510 \\
\hline & 55990 & 7638 & 3.716 & 50902 & 1931 & .971 & 52360 & 480 \\
\hline & 55171 & 7077 & 3.502 & & & & 53908 & 513 \\
\hline & 57560 & 7600 & 3.601 & & & & 52754 & 577 \\
\hline & 59104 & 7610 & 3.514 & & & & & \\
\hline End & & & & & & & & \\
\hline & & & & & & & & \\
\hline
\end{tabular}


Experimental Data for

\section{Packed Bed Membrane Reactor}

APPENDIX A (Contd..)

Page 2

\begin{tabular}{|l|c|l|l|l|l|l|l|l|}
\hline & & & Catalyst & Sample & A & & & \\
\hline & $\begin{array}{c}\text { MR2- } \\
250\end{array}$ & & & $\begin{array}{c}\text { MR3- } \\
250\end{array}$ & & & $\begin{array}{c}\text { MR3- } \\
225\end{array}$ & \\
\hline X CO \% & $\begin{array}{c}\text { Area } \\
\text { CO }\end{array}$ & Area M & X CO \% & $\begin{array}{c}\text { Area } \\
\text { CO }\end{array}$ & Area M & X CO \% & $\begin{array}{c}\text { Area } \\
\text { CO }\end{array}$ & Area M \\
\hline .357 & 43747 & 1524 & .9761 & 35960 & 1020 & .796 & 35604 & 311 \\
\hline .324 & 43366 & 1638 & 1.057 & 34902 & 881 & .709 & 35948 & 288 \\
\hline .352 & 44106 & 1637 & 1.039 & 33504 & 824 & .691 & 35847 & 462 \\
\hline .289 & 44752 & 1622 & 1.015 & 33762 & 841 & .700 & 35752 & 338 \\
\hline .287 & 45071 & 1653 & 1.027 & 33724 & 809 & .674 & 35650 & 276 \\
\hline .276 & 46576 & 1720 & 1.034 & 34388 & 804 & .657 & 35730 & 279 \\
\hline .278 & & & & 34450 & 800 & .652 & 35342 & 301 \\
\hline .258 & & & & 34016 & 831 & .686 & 35424 & 293 \\
\hline .268 & & & & 36890 & 989 & .753 & 35269 & 481 \\
\hline .308 & & & & & & & & \\
\hline & & & & & & & & \\
\hline & & & & & & & & \\
\hline
\end{tabular}


Experimental Data for

\section{Packed Bed Membrane Reactor}

\section{APPENDIX A (Contd..)}

Page 3

\begin{tabular}{|c|c|c|c|c|c|c|c|c|}
\hline & & & Catalyst & Sample & A & & & \\
\hline & $\begin{array}{c}\text { MR3- } \\
200\end{array}$ & & & $\begin{array}{c}\text { MR4- } \\
225\end{array}$ & & & $\begin{array}{c}\text { MR4- } \\
250\end{array}$ & \\
\hline $\mathrm{X} \mathrm{CO} \%$ & $\begin{array}{c}\text { Area } \\
\mathrm{CO}\end{array}$ & Area M & $\mathrm{XCO} \%$ & $\begin{array}{c}\text { Area } \\
\mathrm{CO}\end{array}$ & Area M & $\mathrm{XCO} \%$ & $\begin{array}{c}\text { Area } \\
\mathrm{CO}\end{array}$ & Area M \\
\hline .246 & 35370 & 147 & .117 & 51320 & 675 & .370 & 48543 & 1458 \\
\hline .226 & 34716 & 114 & .092 & 51272 & 729 & .400 & 49748 & 1695 \\
\hline .363 & 34745 & 99 & .080 & 50472 & 669 & .373 & 49139 & 1586 \\
\hline .266 & 34286 & 105 & .086 & 49085 & 711 & .408 & 49903 & 1625 \\
\hline .218 & 33645 & 108 & .090 & 48657 & 752 & .435 & 49780 & 1633 \\
\hline .220 & 34551 & 108 & .088 & 49698 & 811 & .459 & 48930 & 1566 \\
\hline .240 & & & & & & & 48542 & 1513 \\
\hline \multicolumn{9}{|l|}{.233} \\
\hline \multicolumn{9}{|l|}{.384} \\
\hline & & & & & & & & \\
\hline & & & & & & & & \\
\hline & & & & & & & & \\
\hline
\end{tabular}


Experimental Data for

\section{Packed Bed Membrane Reactor}

\section{APPENDIX A (Contd..)}

Page 4

\begin{tabular}{|c|c|c|c|c|c|c|c|c|}
\hline & & & Catalyst & Sample & $\mathrm{A}$ & & & \\
\hline & $\begin{array}{c}\text { MR4- } \\
200\end{array}$ & & & $\begin{array}{c}\text { MR5- } \\
225\end{array}$ & & & $\begin{array}{c}\text { MR5- } \\
250\end{array}$ & \\
\hline $\mathrm{X} \mathrm{CO} \%$ & $\begin{array}{c}\text { Area } \\
\text { CO }\end{array}$ & Area M & $\mathrm{XCO} \%$ & $\begin{array}{c}\text { Area } \\
\text { CO }\end{array}$ & Area M & $\mathrm{XCO} \%$ & $\begin{array}{c}\text { Area } \\
\text { CO }\end{array}$ & Area M \\
\hline .842 & 50096 & 446 & .251 & 48083 & 422 & .247 & 48644 & 970 \\
\hline .955 & 50766 & 366 & .203 & 49531 & 509 & .290 & 50618 & 1099 \\
\hline .905 & 50468 & 331 & .185 & 51157 & 553 & .304 & 52209 & 1090 \\
\hline .913 & 49706 & 284 & .161 & 51053 & 497 & .274 & 49967 & 976 \\
\hline .919 & 49363 & 272 & .155 & 50708 & 489 & .272 & 47902 & 913 \\
\hline .897 & 46115 & 213 & .130 & 51721 & 523 & .285 & 47067 & 861 \\
\hline .874 & & & & & & & 47007 & 829 \\
\hline & & & & & & & & \\
\hline & & & & & & & & \\
\hline & & & & & & & & \\
\hline & & & & & & & & \\
\hline & & & & & & & & \\
\hline
\end{tabular}


Experimental Data for

\section{Packed Bed Membrane Reactor}

\section{APPENDIX A (Contd..)}

Page 5

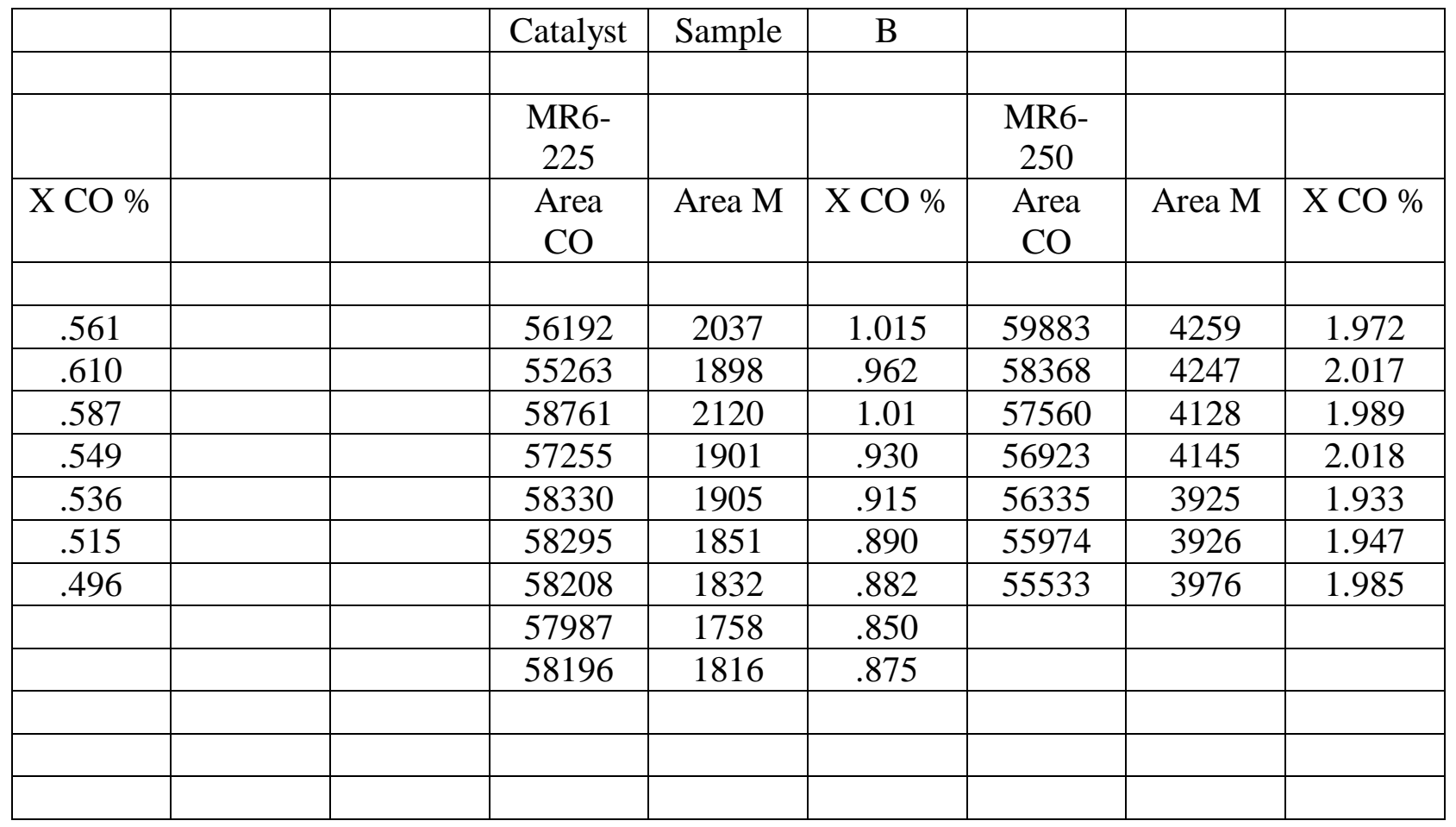


Experimental Data for

\section{Packed Bed Membrane Reactor}

APPENDIX A (Contd..)

Page 6

\begin{tabular}{|c|c|c|c|c|c|c|c|c|}
\hline & & & Catalyst & Sample & B & & & \\
\hline & & & & & & & & \\
\hline $\begin{array}{c}\text { MR7- } \\
250\end{array}$ & & & $\begin{array}{c}\text { MR7- } \\
225\end{array}$ & & & $\begin{array}{c}\text { MR8- } \\
250\end{array}$ & & \\
\hline $\begin{array}{c}\text { Area } \\
\text { CO }\end{array}$ & Area M & X CO \% & $\begin{array}{c}\text { Area } \\
\text { CO }\end{array}$ & Area M & X CO \% & $\begin{array}{c}\text { Area } \\
\text { CO }\end{array}$ & Area M & X CO \% \\
\hline & & & & & & & & \\
\hline 50604 & 4139 & 2.262 & 49876 & 2032 & 1.139 & 66191 & 2821 & 1.191 \\
\hline 48974 & 4032 & 2.276 & 48778 & 1723 & .989 & 66496 & 2818 & 1.185 \\
\hline 46933 & 3926 & 2.312 & 47234 & 1669 & .989 & 66623 & 2733 & 1.147 \\
\hline 48062 & 4010 & 2.306 & 47122 & 1580 & .939 & 66958 & 2733 & 1.141 \\
\hline 49338 & 4170 & 2.335 & 46590 & 1361 & .819 & 67144 & 2583 & 1.076 \\
\hline 49702 & 4203 & 2.337 & 45238 & 1208 & .750 & 67125 & 2508 & 1.046 \\
\hline 49455 & 4161 & 2.325 & 44375 & 1216 & .769 & 67160 & 2573 & 1.072 \\
\hline 47159 & 3928 & 2.302 & 43567 & 1179 & .760 & 67344 & 2459 & 1.022 \\
\hline 47293 & 3658 & 2.141 & 43134 & 1120 & .729 & 67391 & 2482 & 1.031 \\
\hline 47602 & 3598 & 2.094 & & & & 67687 & 2356 & .975 \\
\hline 46555 & 3543 & 2.108 & & & & & & \\
\hline 47026 & 3528 & 2.078 & & & & & & \\
\hline
\end{tabular}


Experimental Data for

\section{Packed Bed Membrane Reactor}

APPENDIX A (Contd..)

\section{Page 7}

\begin{tabular}{|c|c|c|}
\hline Catalyst & Sample & B \\
\hline $\begin{array}{c}\text { MR9- } \\
225\end{array}$ & & \\
\hline $\begin{array}{c}\text { Area } \\
\text { CO }\end{array}$ & Area M & X CO \% \\
\hline & & \\
\hline 67254 & 1728 & .721 \\
\hline 67226 & 1794 & .749 \\
\hline 67404 & 1672 & .697 \\
\hline 66848 & 1563 & .657 \\
\hline 66739 & 1617 & .680 \\
\hline 66569 & 1552 & .655 \\
\hline 66487 & 1548 & .654 \\
\hline 66290 & 1513 & .641 \\
\hline 66227 & 1453 & .617 \\
\hline & & \\
\hline & & \\
\hline & & \\
\hline
\end{tabular}




\section{APPENDIX B}

Program for developing a Model for

Packed Bed Membrane Reactor 


\begin{tabular}{|c|c|}
\hline $\mathrm{C}$ & Setup Minimization Function \\
\hline $\mathrm{C}$ & ( Main Program ) \\
\hline
\end{tabular}

parameter $(\mathrm{mp}=5, \mathrm{np}=4)$

real k(np),p(mp,np),ftol,y(mp)

common $\mathrm{k}$

external amoeba,amotry,umach,funk

open (unit=11,file='mode2try.out',status='new')

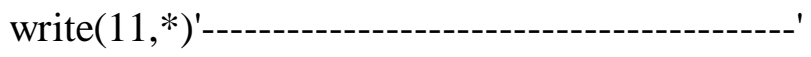

write $(*, *)$ 'input guess values of $\mathrm{K}$ for five trial points'

Do $1 \mathrm{i}=1,5$

write $(*, *)$ 'enter a guess point'

Do $2 \mathrm{j}=1,4$

$\operatorname{read}(*, *) p(i, j)$

2 continue

write $(*, *)^{\prime} \quad \mathrm{OK}^{\prime}$

1 continue

Do $3 \mathrm{i}=1,5$

Do $4 \mathrm{j}=1,4$

$k(j)=p(i, j)$

4 continue 


$$
\mathrm{y}(\mathrm{i})=\text { funk }(\mathrm{k})
$$

C write(*,*) 'Vector $\mathrm{Y}=$ ',y(i)

3 continue

C pause

write $(*, *)^{\prime}$ '

write $(*, *)$ 'The simplex driver has begun.'

C Driver for simplex

ftol $=1.0 \mathrm{e}-4$

ndim $=4$

call amoeba(p,y,mp,np,ndim,ftol,funk,iter)

write $(*, *) ' V e r t i c e, ~ k 1, k 2, k 3, \mathrm{k} 4$, error'

write $\left(11,{ }^{*}\right)$ 'Vertice,k1, k2, k3, k4, error'

Do $7 \mathrm{i}=1, \mathrm{mp}$

write(*,*)i,p(i,1),p(i,2),p(i,3),p(i,4),y(i)

write(11,*)i,p(i,1),p(i,2),p(i,3),p(i,4),y(i)

\section{7 continue}

C write $(*, 50) \mathrm{k}, \mathrm{f}$

C 50 format('the parameters are :',5x,5f8.2)

end 


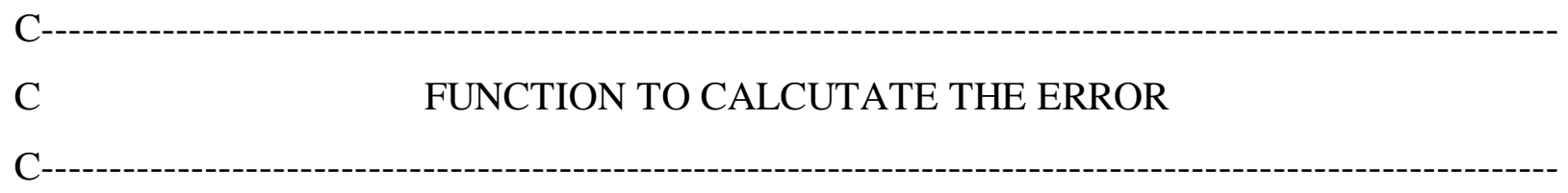

real function funk $(\mathrm{k})$

integer neq,mxparm,n,i,j

parameter $(\mathrm{mxparm}=50, \mathrm{neq}=8, \mathrm{n}=4)$

integer ido,istep,nout

real a(9),b(9),c(9),d(9),e(9),r(9),param(mxparm),fcn,y(neq),

\& float,x,xend,tol,err,k(n)

intrinsic float

external fen,ivprk,sset,umach

err $=0.0$

funk $=0.0$

write $(*, *) \mathrm{k}(1), \mathrm{k}(2), \mathrm{k}(3), \mathrm{k}(4)$

Do $5 \mathrm{j}=1,4$

if((k(j).1t.0.5) .or. $(k(j) \cdot g t \cdot 30))$ then

funk $=10000000$

write $(*, *)$ funk

return

endif

5 continue

data a/50.0,50.0,50.0,40.0,40.0,40.0,40.0,50.0,50.0/

data $b / 50.0,50.0,50.0,40.0,40.0,40.0,40.0,50.0,50.0 /$

data $c / 0.0,0.0,0.0,0.0,10.0,0.0,10.0,20.0,50.0 /$

data $\mathrm{d} / 0.0,0.0,0.0,0.0,10.0,10.0,0.0,20.0,50.0 /$

data e/40.0,60.0,100.0,40.0,40.0,40.0,40.0,0.0,0.0/ 
data $\mathrm{r} / 4.7,2.75,1.75,2.6,1.7,2.4,3.0,1.9,1.3 /$

C $\quad$ write $(*, *) \mathrm{k}(1), \mathrm{k}(2), \mathrm{k}(3), \mathrm{k}(4)$

C

\section{INITIALIZATION}

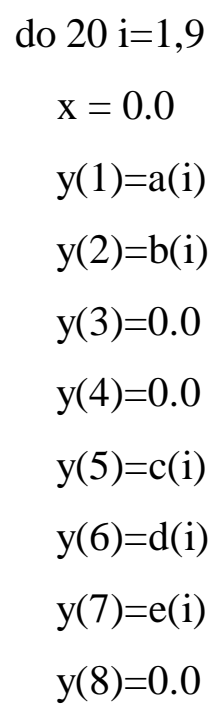

C

set error tolerance

tol $=0.0000001$

C

set parameter to default

call sset(mxparm, 0.0, param, 1)

$\mathrm{C}$ select absolute error control

$\operatorname{param}(10)=1.0$

C Do actual calculations

ido $=1$

do 10 istep $=1,10$

xend $=$ float $($ istep $)$

call ivprk(ido, neq, fcn, $x$, xend, tol, param, y)

C $\operatorname{write}(*, *) \mathrm{x}, \mathrm{y}(4), \mathrm{y}(8)$

10 continue 
err $=\operatorname{err}+((y(4)+y(8)) * 100 /(b(i)+d(i))-r(i)) * * 2$

C $\quad$ write $(*, *) i$, ' error=',err

C

Releasing the work space

ido $=3$

call ivprk(ido, neq, fcn, $\mathrm{x}$, xend, tol, param, y)

20 continue

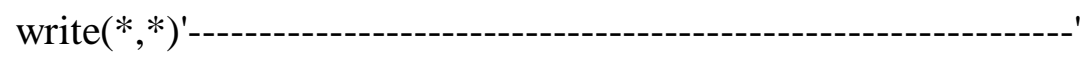

funk=err

write $(*, 300)$ funk

300 format(1f8.3)

write(11,300) k(1),k(2),k(3),k(4),funk

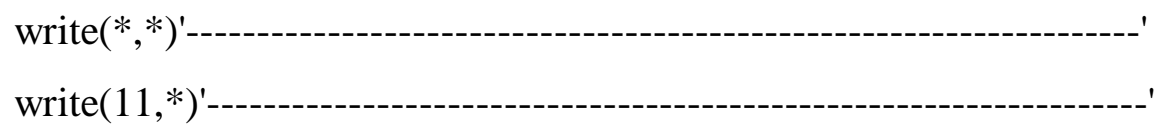

return

end 
C-

C

Subroutine to evaluate the differential equations

C-

subroutine fcn(neq, $x, y$, yprime)

integer neq, $\mathrm{n}$

parameter $(\mathrm{n}=4)$

real $\mathrm{k}(\mathrm{n}), \mathrm{x}, \mathrm{y}($ neq), yprime(neq)

common $\mathrm{k}$

yprime $(1)=-1.42 *(\mathrm{y}(1) * * 1.2716) *(\mathrm{y}(2) * * 0.7461) /((\mathrm{y}(1)+\mathrm{y}(2)+\mathrm{y}(3)+$

$1 \quad \mathrm{y}(4)) * * 2.0117)-2.638 * \mathrm{k}(1) *(\mathrm{y}(1) /(\mathrm{y}(1)+\mathrm{y}(2)+\mathrm{y}(3)+\mathrm{y}(4))-$

$1 \quad \mathrm{y}(5) /(\mathrm{y}(5)+\mathrm{y}(6)+\mathrm{y}(7)+\mathrm{y}(8)))$

yprime $(2)=-0.71 *(\mathrm{y}(1) * * 1.2716) *(\mathrm{y}(2) * * 0.7461) /((\mathrm{y}(1)+\mathrm{y}(2)+\mathrm{y}(3)+$

$1 \quad \mathrm{y}(4)) * * 2.0117)-2.638 * \mathrm{k}(2) *(\mathrm{y}(2) /(\mathrm{y}(1)+\mathrm{y}(2)+\mathrm{y}(3)+\mathrm{y}(4))-$

$1 \quad \mathrm{y}(6) /(\mathrm{y}(5)+\mathrm{y}(6)+\mathrm{y}(7)+\mathrm{y}(8)))$

yprime $(3)=-2.638 * \mathrm{k}(3) *(\mathrm{y}(3) /(\mathrm{y}(1)+\mathrm{y}(2)+\mathrm{y}(3)+\mathrm{y}(4))-\mathrm{y}(7) /(\mathrm{y}(5)+\mathrm{y}(6)+$

$1 \quad \mathrm{y}(7)+\mathrm{y}(8)))$

yprime $(4)=0.71 *(\mathrm{y}(1) * * 1.2716) *(\mathrm{y}(2) * * 0.7461) /((\mathrm{y}(1)+\mathrm{y}(2)+\mathrm{y}(3)+$

$1 \quad \mathrm{y}(4)) * * 2.0117)-2.638 * \mathrm{k}(4) *(\mathrm{y}(4) /(\mathrm{y}(1)+\mathrm{y}(2)+\mathrm{y}(3)+\mathrm{y}(4))-$

$1 \quad \mathrm{y}(8) /(\mathrm{y}(5)+\mathrm{y}(6)+\mathrm{y}(7)+\mathrm{y}(8)))$

yprime $(5)=2.638 * \mathrm{k}(1) *(\mathrm{y}(1) /(\mathrm{y}(1)+\mathrm{y}(2)+\mathrm{y}(3)+\mathrm{y}(4))-\mathrm{y}(5) /(\mathrm{y}(5)+\mathrm{y}(6)+$

$1 \quad \mathrm{y}(7)+\mathrm{y}(8)))$

yprime $(6)=2.638 * \mathrm{k}(2) *(\mathrm{y}(2) /(\mathrm{y}(1)+\mathrm{y}(2)+\mathrm{y}(3)+\mathrm{y}(4))-\mathrm{y}(6) /(\mathrm{y}(5)+\mathrm{y}(6)+$

$1 \quad \mathrm{y}(7)+\mathrm{y}(8)))$

yprime $(7)=2.638 * k(3) *(y(3) /(y(1)+y(2)+y(3)+y(4))-y(7) /(y(5)+y(6)+$

$1 \quad \mathrm{y}(7)+\mathrm{y}(8)))$

yprime $(8)=2.638 * \mathrm{k}(4) *(\mathrm{y}(4) /(\mathrm{y}(1)+\mathrm{y}(2)+\mathrm{y}(3)+\mathrm{y}(4))-\mathrm{y}(8) /(\mathrm{y}(5)+\mathrm{y}(6)+$

$1 \quad \mathrm{y}(7)+\mathrm{y}(8)))$

return

end 
C-

C

Subroutine Amoeba for Minimization

C-

SUBROUTINE amoeba(p,y,mp,np,ndim,ftol,funk,iter)

INTEGER iter,mp,ndim,np,NMAX,ITMAX

REAL ftol,p(mp,np),y(mp),funk

PARAMETER $($ NMAX=20,ITMAX=5000)

EXTERNAL funk

C USES amotry,funk

INTEGER i,ihi,ilo,inhi,j,m,n

REAL rtol,sum,swap,ysave,ytry,psum(NMAX), amotry iter $=0$

1 do $12 \mathrm{n}=1$,ndim

sum $=0$.

do $11 \mathrm{~m}=1, \mathrm{ndim}+1$

$\operatorname{sum}=\operatorname{sum}+p(m, n)$

11 continue

$\operatorname{psum}(n)=\operatorname{sum}$

12 continue

2 ilo $=1$

if (y(1).gt.y(2)) then

ihi $=1$

inhi $=2$

else

ihi $=2$

inhi $=1$

endif

do $13 \mathrm{i}=1, \mathrm{ndim}+1$

if(y(i).le.y(ilo)) ilo=i 
if(y(i).gt.y(ihi)) then

inhi=ihi

ihi $=\mathrm{i}$

else if(y(i).gt.y(inhi)) then

if(i.ne.ihi) inhi=i

endif

13 continue

rtol=2.*abs (y(ihi)-y(ilo))/(abs(y(ihi))+abs(y(ilo)))

if (rtol.lt.ftol) then

$$
\begin{aligned}
& \text { swap=y(1) } \\
& y(1)=y(\text { ilo }) \\
& y(\text { ilo })=\text { swap } \\
& \text { do } 14 \text { n=1,ndim } \\
& \text { swap=p(1,n) } \\
& \text { p(1,n)=p(ilo,n }) \\
& \text { p(ilo,n)=swap }
\end{aligned}
$$

14 continue

return

endif

if (iter.ge.ITMAX) pause 'ITMAX exceeded in amoeba'

iter $=$ iter +2

ytry=amotry(p,y,psum,mp,np,ndim,funk,ihi,-1.0)

if (ytry.le.y(ilo)) then

ytry=amotry(p,y,psum,mp,np,ndim,funk,ihi,2.0)

else if (ytry.ge.y(inhi)) then

$$
\text { ysave }=y(\text { ihi) }
$$

ytry=amotry(p,y,psum,mp,np,ndim,funk,ihi,0.5)

if (ytry.ge.ysave) then

do $16 \mathrm{i}=1$,ndim+1

if(i.ne.ilo)then 
do $15 \mathrm{j}=1$,ndim

$$
\begin{aligned}
& \operatorname{psum}(j)=0.5^{*}(p(i, j)+p(i l o, j)) \\
& p(i, j)=\operatorname{psum}(j)
\end{aligned}
$$

15 continue

$$
y(i)=\text { funk }(\text { psum })
$$

endif

16 continue

iter=iter+ndim

goto 1

endif

else

iter=iter-1

endif

goto 2

END 
C-

$\mathrm{C}$

Function Amotry required by amoeba for iterating

C

FUNCTION amotry(p,y,psum,mp,np,ndim,funk,ihi,fac)

INTEGER ihi,mp,ndim,np,NMAX

REAL amotry,fac,p(mp,np),psum(np),y(mp),funk

PARAMETER $($ NMAX $=20)$

EXTERNAL funk

C USES funk

INTEGER $\mathrm{j}$

REAL fac1,fac2,ytry,ptry(NMAX)

common ptry

fac $1=(1 .-\mathrm{fac}) / \mathrm{ndim}$

fac $2=$ fac $1-f a c$

do $11 \mathrm{j}=1$,ndim

$$
\operatorname{ptry}(j)=\operatorname{psum}(j) * f a c 1-p(i h i, j) * f a c 2
$$

11 continue

ytry=funk(ptry)

if (ytry.lt.y(ihi)) then

$y($ ihi $)=y t r y$

do $12 \mathrm{j}=1$,ndim

$\operatorname{psum}(j)=p s u m(j)-p(i h i, j)+p t r y(j)$

$p(i h i, j)=p t r y(j)$

12 continue

endif

amotry=ytry

return

End 


\section{ACKOWLEDGEMENTS}

I wish to express my sincerest gratitude to my advisor Dr. Edwin Kugler for his guidance and encouragement during the course of this work. It has been a pleasure and honor to work for such a gifted researcher.

I am very grateful to the members of my advisory committee, Dr. Ray Yang, and Dr. Dady Dadyburjor for their guidance and help in obtaining and analyzing the data for the reactor systems. My sincere thanks to Dr.Li for all his help in setting up the reactors. I wish to thank James Hall and Joel Bowlby for their help during this project.

I am thankful to all the graduate students and faculty in the Chemical Engineering Department for their friendliness and warmth that made my stay in Morgantown pleasant and productive. I also wish to thank DOE for their financial support.

Last, but not the least, I wish to thank my family in India for their love and support throughout the course of my education in the United States. 
Experimental and Modeling Studies on

A Catalytic Packed Bed Membrane Reactor

By

Ashutosh G Deshpande

\author{
A Thesis \\ Submitted to \\ West Virginia University \\ in partial fulfillment of the requirements \\ for the degree of \\ Master of Science
}

APPROVAL OF EXAMINING COMMITTEE

Dady B. Dadyburjor, Ph.D

Ray Y. K. Yang, Ph.D

Date

Edwin Kugler, Ph.D, Chair 


\title{
RESUME
}

\author{
ASHUTOSH DESHPANDE \\ 454 Doyle Road, Apt.4 \\ San Jose, CA 95129 \\ (408) 996-7084 \\ ashutoshd@hotmail.com
}

\section{SUMMARY}

* M.S.Chemical Engg with experience of more than 1 year.

* Good knowledge of System Modeling Techniques and tools

* Worked on a variety of applications

\section{TECHNICAL SKILLS}

* Operating Systems

* Database Systems

* GUI

* Networking

* Plotting/Graphics

\author{
$\mathrm{C}++, \mathrm{C}$, Java, SQL, PL/SQL, PRO*C, Visual Basic, Visual C++, Pascal \\ Unix, Windows NT 4.0, Windows 95, Windows 3.1, DOS \\ Oracle 7.x on Unix, Personal Oracle 7, Access \\ Oracle Forms 3.0 and 4.5, Crystal Reports 4.0 and 5.0 \\ Windows NT 4.0, Novell 3.x, Sockets, TCP/IP \\ Sigma Plot, WordPerfect, Harvard Graphics
}

\section{EMPLOYMENT}

* Software Engineer, Finnovative Solutions Inc., CA, Sep '97 - Present

- Working on an application for attribution of stock investments. The application categorizes the market factors responsible for the outcome of stock investments by an individual, using different market- suggested algorithms. The application is being developed with Visual C++ using MFC classes, TCP/IP sockets on Windows NT 4.0 platform.

* Graduate Assistant, West Virginia University, WV, Sep '94 - Aug '96

- Performed research on packed bed membrane reactor for producing higher alcohols

- Computed a mathematical model for the experimental data for the reactor

- Compared the data with data for similar experiments carried out in packed-bed tubular reactor

\section{EDUCATION}

M. S. Chemical Engineering, 1998

B. S. Engineering, 1994
West Virginia University

G.P.A : 3.75 / 4.0

Bombay University, India

G.P.A : $3.8 / 4.0$ 